\title{
INTERAÇÃO DE ESPÉCIES E PROGÊNIES DE EUCALIPTO COM TRES NIVEIS DE TECNOLOGIA DE IMPLANTAÇÃO FLORESTAL
}

\author{
ADOLFO DINIS BILA \\ Engenheiro Florestal
}

Orientador: Prof. Dr. PAULO YOSHIO KAGEYAMA

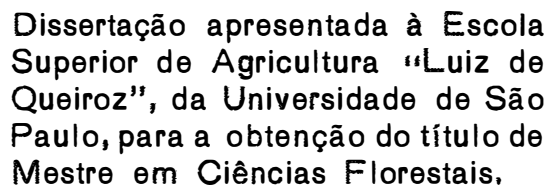

$P|R A C| C A B A$

Estado de São Paulo - Brasil Junho - 1988 


\section{A Ciarilia, Kuare co bugo}


$i i i$

A mintic mäe e as mintras irmãs

OFERECO 


\section{AGRADECIMENTOS}

Os meus sinceros agradecimentos as pessoas e instituições que contribuîram na realizaçä deste trabalho, com especial referência: ao Prof.Dr. Paulo Yoshio Kageyama pela orientaçäo na rea1ização deste trabalho, pelos valiosos ensinamentos transmitidos durante - curso de pös-graduaçäo, pela sua amizade e atenção dispersada durante a permanêricia no Brasil;

à Universidade Eduardo Mondlane, pela oportunidade de realização do curso de pōs-graduação;

à FAO pela bolsa de estudos oferecida;

aos Professores Rodrigues Pereira e Fernendo Sarävia pelo apoio e contactos realizajos que viabilizaram a participação no curso;

aos Ergenheiros Agrônomos João Luiz de Morais e Euripedes Morais, pesquisadores do Insticuto Florestal do Estado de São Paulo, Estação Experimental de Bento Quirino, pela instalação, condução dos ensaios e apoio no levantamento de dados;

aos docentes do Departamento de Ciências Florestais da Escola Superior de Agricultura "Luiz de Queiroz", da Universidade de São Paulo, pelos ensinamentos recebidos;

aos funcionärios do Departamento de Ciências Florestais pela atenção e boa convivência; 
aos pesquisadores e funcionārios do IPEF, em particular ao Engenheiro Florestal Carlos Hentique Garcia pelo auxilio no processamento dos dados;

à Engenheira Florestal Selma Ohashi pela colaboração na compilação da bibliografia;

aos colegas do curso de pös-graduação pelo auxílio e amizade. 


\section{SUMARTO}

Pägina

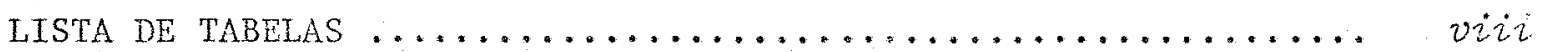

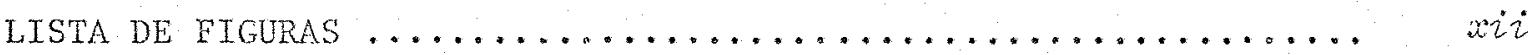

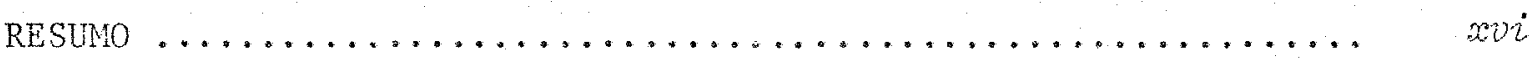

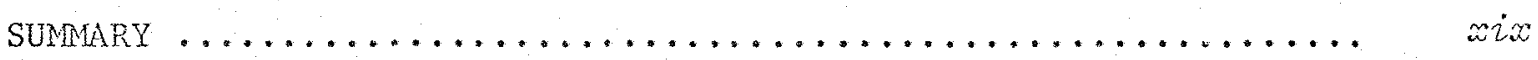

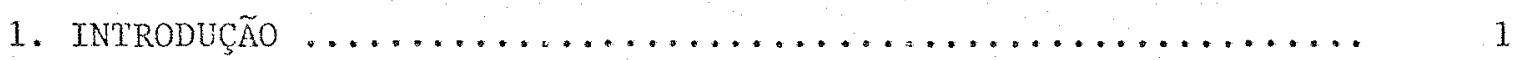

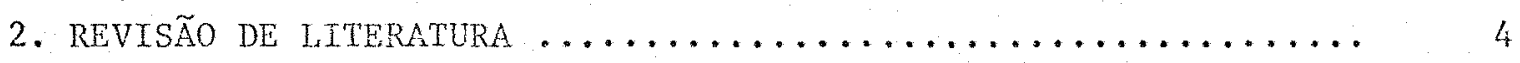

2.1. Resposta das espëcies às tëcrijicas de implantação

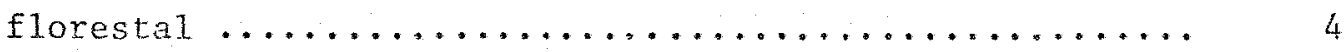

2.1.1. Preparo do solo $\ldots \ldots \ldots \ldots \ldots \ldots \ldots \ldots \ldots \ldots$

2.1.2. Fertilizaçăo mineral $\ldots \ldots \ldots \ldots \ldots \ldots \ldots$

2.2. Interação de Genötipos $x$ Técnicas Silviculturais ...... It

3. MATERTAL E METODOS ........................ 21

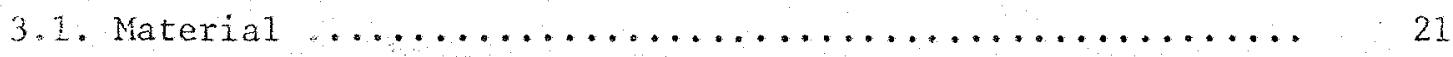

3.1.1. Material genético em estudo ............. 21

3.1.2. Local do ensaio .................... 22

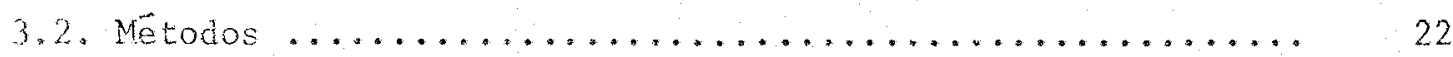

3.2 .1 . Instalação dos ensaios ............... 22

3.2.2. Avaliac̃a dos ensaios ............... 25

3.2.3. Analise estatistica ................ 26

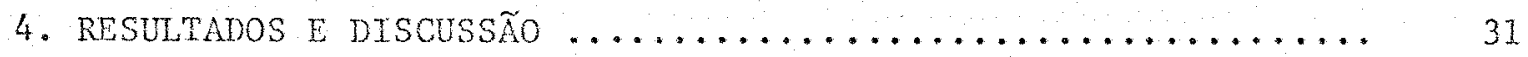

4.1. Comportamento das Especies nos Diferentes Níveis de Tecnologia Silvicultural $\ldots \ldots \ldots \ldots \ldots \ldots \ldots \ldots \ldots \ldots$

4.1.1. Avaliaģa das espëcies aos 7 meses de idade .... 31

4.1.2. Avaliaño das especies aos 12 meses de idade ... 38 
Pägịna

4.1.3. Avaliação das espēcies aos 18 meses de idade ..... 44

4.1.4. Avaliação das espēcies aos 24 meses de idade .... 51

4.2. Comportamento de Progênies Dentro de Espécies nos

Diferentes Niveis de Tecnologia .................. 62

4.2.1. Comportamento de progênies de Erandis ....... 62

4.2.2. Comportamento de progênies de E. camazdulensis .... 83

4.2.3. Comportamento de progênies de $E$. citriodor ...... 103

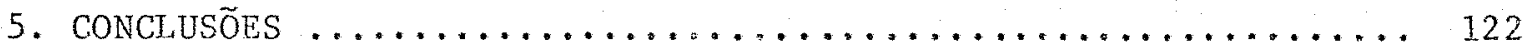

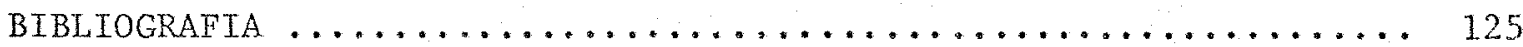

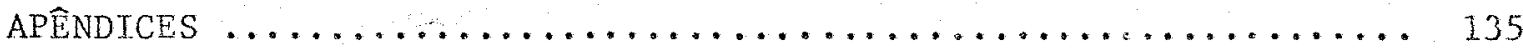


LISTA DE TABELAS

Tabela no

Pägina

1 Crescimento em altura de plantas e porcentagen de falhas de Eucalyptus nos três riveis de tecnologia de implantação florestal, aos 7 meses de idace ....

2 Resultados das anälises de variancia individuais e conjuntas para altura de plantas e porcentagen de falhas de Eucalyptus nos três níveis de tecnologia (NT), aos 7 meses de idade.

3 Crescimento em altura de plantas e porcentagen de falhas de Éucalyptus nos três níveis de tecnologia (NT) de implantação florestal, aos 12 meses de ida de

4 Resultados das anäises de variancia individuais e conjuntas para altura de plantas e porcentagen de falhas de Eucalyptus nos três niveis de tecnologia (NT) de implantação florestal, aos 12 meses de

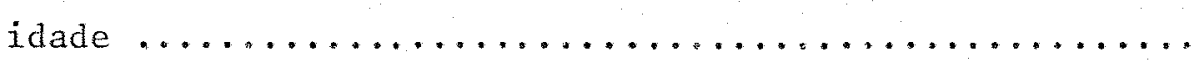

5 Crescimento em altura de plantas, DAP, volume cilindrico (VC) e porcentagen de falbas de Eucalyptus nos três níveis de tecnologia (NT) de implantação

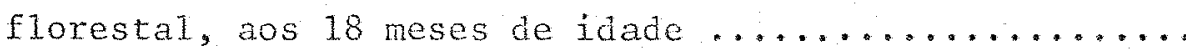

6 Resultados das anailises de varäncia individuais e conjuntas para altura de plantas, DAP, volume ciIndrico (VC) e porcentagem de falhas de Fucalyptus em três niveis de tecnologia (NT) de implantacão

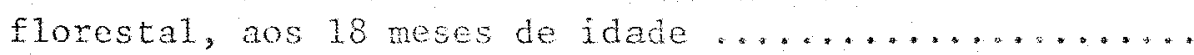


7 Crescimento em altura, DAP, volume cilindrico (VC) e porcentagem de falhas de Eucalyptus nos três niveis de tecnologia (NT) de implantação florestal,

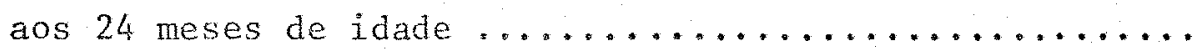

8 Resultados das anälises de variancia indivicuais e conjuntas para altura de plantas, DAP, volume cilindrico (VC) e porcentagem de falhas de Eucalyptus em três niveis de tecnologia (NT) de implantação

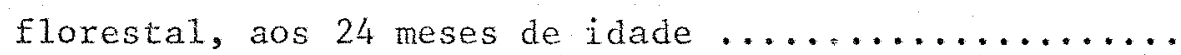

9 Resultados das anälises de variancia individuais e conjuntas para altura de plantas e porcentagem de falhas de progênies $(P)$ de $z$. grandis en três niveis de tecnologia (NT) de implantaçăo florestal,

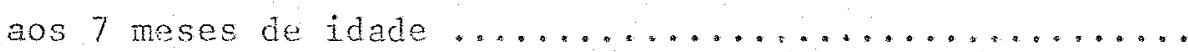

10 Resultados das anälises de variancia individuaís e conjuntas para altura de plantas e porcentagem de falhas de progênies (P) de E. grandis em três niveis de tecnologia (NT) de implantação florestal,

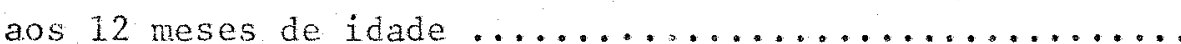

1) Resultados das anäises de variancia indiviauats e conjuntas para altura de plantas, DAP, volume ciIIndrico (VC) e porcentagem de fallias de progenies (P) de . grontis em tres niveis de tecnologia (NT) de implantação florestal, aos 18 meses de idade ...... 
Tabela no

12. Resultados das amalises de variancia individuais e conjuntas para altura de plantas, DAP, volume cilindrico (VC) e porcentagem de falhas de progeñes (P) de $E$. grandis en três niveis de tecnologia (NT) de implantação florestal, aos 24 meses de idade ......

13 Resultados das anälises de variância individuais e conjuntas para altura de plantas e porcentagem de falhas de progênies $(P)$ de $E$. canatautensis em três niveis de tecnologia (NT) de implantação florestal, aos 7 meses de idade $\ldots \ldots \ldots \ldots \ldots \ldots \ldots$

14 Resuitados das anäiises de variância individuais e conjuntas para altura de plantas e porcentagem de Falhas de progênies (P) de $E$. camatdulensis em três niveis de tecnologia (NT) de implantação Elorestal, aos 12 meses de idade $\ldots \ldots \ldots \ldots \ldots \ldots \ldots \ldots$

15 Resultados das anälises de variancia individuais e conjuntas para altura de plantas, DAP, volume cilíndrico (VC) e porcentagem de falhas de progenies $(P)$ de $E$. camaldulensis em tres niveis de tecnologia (NT) de implantação florestal, aos 18 meses de idade $\ldots \ldots \ldots \ldots \ldots \ldots \ldots \ldots \ldots \ldots \ldots \ldots \ldots \ldots \ldots \ldots$

16 Resultados das anälises de variancia individuais a conjuntas pata altra de plantas, nap, volume ciIindrico (VC) e porcentagen de falhas de progenies (P) de $E$. comoldulensis en três níveis de tecrom logia (NT) de jmplantação florestal, aos 24 meses

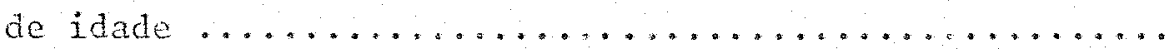


17 Resultados das anâlises de variancia individuais e conjuntas para altura de plantas e porcentagem de falhas de progênies (P) de E. citriodora em três niveis de tecnologia (NT) de implantação florestal, aos 7 meses de idade.

18. Resultados das anälises de variancia individuais e conjuntas para altura de plantas e porcentagem de falhas de progênies (P) de $E$. citriodora em três niveis de tecnologia (NT) de implantação florestal, aos 12 meses de idade $\ldots \ldots \ldots \ldots \ldots \ldots \ldots \ldots \ldots \ldots \ldots$

19 Resultados das anälises de variancia individuais e conjuntas para altura de plantas, DAF, volume ciIndrico (VC) e porcentagen de falhas de progênies (P) de E. citriodora em três niveis de tecrologia (NT) de implantação florestal, aos 18 meses de ida de

20 Resultados das anälises de variância individuais e conjuntas para altura de plantas, DAP, volume cilindrico (VC) e porcentagem de falhas de progenies (P) de E. citriodora em três niveis de tecnologia (NT) de implantação florestal, aos 24 meses de idade 
LISTA DE EIGURAS

Figura n?

pägina

1 Altura mëdia de plantas de Eucalyptus em três niveis de tecnologia (NT) de implantação florestal, aos 7 meses de idade

2 Altura média de plantas de Eucalyptus em três niveis de tecnologia de implantação florestal, aos 12 meses de idade $\ldots \ldots \ldots \ldots \ldots \ldots \ldots \ldots \ldots \ldots \ldots \ldots \ldots \ldots \ldots \ldots \ldots$

3. Altura média de plantas de Eucalyptus em três niveis de tecnologia (NT) de implantação florestal, aos 18 meses de idade $\ldots \ldots \ldots \ldots \ldots \ldots \ldots \ldots \ldots \ldots \ldots \ldots \ldots \ldots \ldots$

4. Diâmetro à altura de peito (DAP) de plantas de whoa lyptus, en tres niveis de tecnologia (NT) de implan tação florestal, aos 18 meses de idade ............

5 Volume cilíndrico (VC) de plantas de Eucalyptus, em três níveis de tecnologia (NT) de implantação flores tal, aos 18 meses de idade $\ldots \ldots \ldots \ldots \ldots \ldots \ldots \ldots \ldots$

6 Altura mëia de plantas de Tucatuptus em três nüveis de tecnologia (NT) de implantação florestal, aos 24

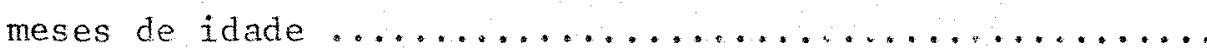

7 DAP de plantas de bucatuptas, en tres nives de teenologia (NT) de implantação Elorestal, aos 24 meses de idade .............................. 
8 Volume cilindrico (VC) de plantas de Rucalyptus, en três níveis de tecnologia (NT) de implantação flo restal., aos 24 meses de idade ................... 5

9 Crescimento en altura de progenies de E. grandis nos três níveis de tecnologia (NT) de implantaçäo florestal, aos 7 meses de idade $\ldots \ldots \ldots \ldots \ldots \ldots \ldots \ldots$

10 Crescimento em altura de progênies de $E$. grandis nos três nîveis de tecnologia (NT) de implantação floresta1, aos 12 meses de idade .................. 68

11 Crescimento en altura de progênies de $E$. grandis nos três niveis de tecnologia (NT) de implantação florestal, aos 18 meses de idade $\ldots \ldots \ldots \ldots \ldots \ldots \ldots \ldots$

12. Crescimento en DAP de progênies de E. grandie nos três niveis de temologia (NT) de implantação flo-

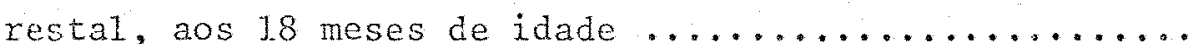

13 Crescimento em volume cilindrico (VC) de progênies

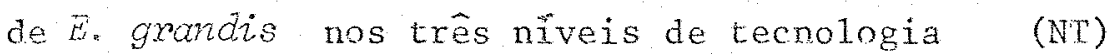
de implantação florestal, aos 1.8 meses de idade ........ 74

14 Creschmento em altura de progênies de $E$, grandis nos três niveis de tecnologia (NT) de implantação flom

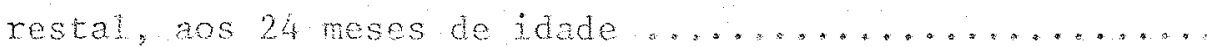

15 Crescimento em DAP de progenies de $E$. grandis nos três niveis de tecnologia (NT) de implantação flo-

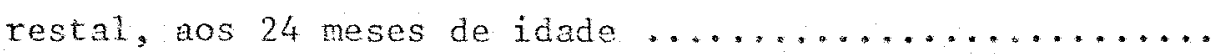


16 Crescimento em volume cilindrico (VC) de progênies de E. grandis nos três níveis de tecrologia (NT) de implantação florestal, aos 24 meses de idade ...........

17 Crescimento em altura de progênies de $\mathbb{E}$. camalduLensis nos três niveis de tecnologia (NT) de implantação florestal, aos 7 meses de idade .............. 86

18 Crescimento em altura de progênies de E. camazduIensis nos três niveis de tecnologia (NT) de implantação florestal, aos 12 meses de idade ..............

19 Crescimento em altura de progênies de E. camalduZensis nos três niveis de tecnologia (NT) de implantação florestal, aos 18 meses de idade...

20 Crescimento em DAP de progênies de E. comaldulenisis nos três niveis de tecnologia (NT) de implantação flo restal, aos 18 meses de idade ................... 94

21 Crescimento em volume cilindrico (VC) de progênies de $t$. camaldutensis nos três niveis de tecnologia (NT) de implantação florestal, aos 18 meses de idade....

22 Altura media de progênies de $E$. canaldulensis, nos três niveis de tecnologia (NT) de implantação flo-

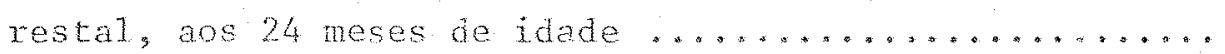

23 Crescimento em DAP de progenies de $E$. comalduzensis nos três niveis de tecnologia (NT) de implantação flo restal, aos 24 meses de idare $\ldots \ldots \ldots \ldots \ldots \ldots \ldots \ldots$ 
24 Crescimento en volume cilindrico (vC) de progênies de $E$, camatduzensis nos três nüveis de tecnologia (NT) de implantação florestal, aos 24 meses de idade

25 Crescimento en altura de progenies de E. citriodora nos três niveis de tecnologia (NT) de implantaçăo

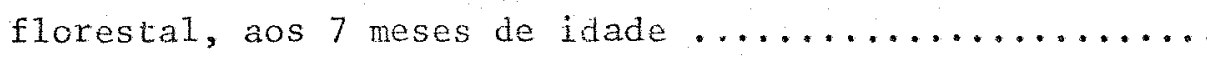

26 Crescimento em altura de progênies de $E$. citmiodona nos três níveis de tecnologia (NT) de implantação florestal, aos 12 meses de idade .................

27 Crescimento em altura de progenies de E. aitriodora nos três níveis de tecnologia (NT) de implantaçáo florestal, aos 18 meses de idade

28 Crescimento em DAP e volume cilindrico (VC) de progênies de Ei.citriodora nos trës nivveis de tecnologia (NT) de implantação florestal, aos 18 meses de idade.

29 Crescimento em altura de progênies de E.citmodona nos três niveis de tecnologia (NT) de implantação florestal, aos 24 meses de idade

30 Crescimento em DAP e volume cilindrico (VC) de progenies de E.citrodor nos tres niveis de tecnologia (NT) de implantaçăo floresta1,aos 24 meses de idade 


\section{INTERAÇÃO DE ESPECIES E PROGENIS DE EUCALIPTO COM}

TRES NIVEIS DE TEGNOLOGIA DE IMPLANTACAOO FLORESTAL

Autor: Adolfo Dinis Bila

Orientador: Prof.Dr. Paulo Yoshio Kageyara

RESUMO

Com o objetivo de avaliar a interação de espécies e progênies dentro de espécies de Eucalyptus com níveis de tecnologia silvicultural, foram instalados ensaios com niveis crescentes de tecnologia de implantação florestal, na Estação Experimental de Bento Quirino, do Instituto Florestal do Fstado de São Paulo, localizada no municipio de são Simão, São Paulo.

Três ensaios foram estabelecidos, um ao lado do outro, em solo areia quartzosa, originalmente sob vegetaçäo de cerrado, utilizandose, para cada ensaio um nivel de tecnologia de implantação florestai; nivel de tecnologia 1 - sen preparo do solo e sem acubacão mineral; nivei de tecnologia II - preparo do solo (aração e gradagem) sem acubação nineral; nivel de temologia II - preparo do solo e adriço nineral (100g de NPK 10:28:6 por planta).

Para cada ensajo foram utilizadas as seguintes espécies: Eucalyptza grardis Hill Ex Maiden, sementes obtidas de un Pomar de Sementes clonal instalado en Botucatu-sp; Eucctyptus camidubenale 
DEHN, sementes obtidas de uma populaçäo natural de Gibb River, Western Australia; e Eucalyptile citmiodora Hook, sementes coletadas de ärvores selecionadas (1:10000) em um povoariento estabelecido em Pederneiras-sP (exRio Claro-SP). Foram utilizadas progênies de polinização livre em nümero variável para as diferentes espécies, sendo: 13 para o E. grandis, 22 para OE. conaldulensis e 14 para o E. citriodora.

o delineamento experimental utilizado para os três ensaios foi em blocos de famîlias compactas, com três repetições, onde as espëcies constituiram as parcelas e as progenies formaram as sub-parcelas. 0 espaçamento utilizado foi de $2 \times 2$ metros.

Os ensaios foram instalados em maio de 1986 e as avaliações foram realizadas aos 7 e 12 meses de idade, coletando-se os dados de altura total e mortalidade de plantas, e aos 18 e 24 meses de idade, acrescentando-se às características mencionadas o DAP (diânetro à altura do peito) e o volume cilindrico.

As principais conclusões ao nĩvel de espécies foram? a) - E. grandis foi a especie nats apta, o. E. comaluulensis intermediario e o F. citriodora a menos apta à resposta a tecnologia silvicultural; b) a diferenciaça entre as espëcies foi major com a melhoria do nivel de tecnologia silvicultural; c) houve um aunento da variação genética relativa entre especies con a melhoria do nivel de tecnologia silvicultural; d) no nivel mais baixo de tecnologia silvicultural o E. camaldulensis e o E. citriodora apresentaram alta sobrevivência e maior produtividade, en termos de matëria seca por unidade de ärea, do que o E. grandis; e) houve aumento de eficiencia estatistica dos ensios con a melhoria do nivei 
de tecnologia de implantação florestal.

As principais conclusões ao nivel de progênies dentro de espécies foram: f) a melhoria do nivel de tecnologia silvicultural acarre tou a diminuição da variação genética entre progênies relativamente à variação ambiental, para as três espécies; g) no nîvel mais baixo de tecnologia de implantação florestal, somente as progênies de E. granais mostraram a variação genëtica para a sobrevivência de plantas e interação significativa com preparo do solo e fertilização mineral; h) as progênies das três espécies responderam diferentemente ern termos de variação genéti ca e de níveis de tecnologia silvicultural; i) houve, com o decorrer da idade, um decréscimo do efeito dos nîveis de tecnologia silvicultural; j) observou-se una clara tendência de comportamento dif́erencial das progênies nos diferentes níveis de tecnologia de implantação floresta1; 1) a adequação do material genético à tecnologia silvicultural permite o uso racional dos recursos genéticos, ambientais e tecnolögicos. 
INTERACTION OF SPECIES AND PROGENY OF EUCALYPT WITH

THREE LEVELS OF FOREST IMPLANTATION TECHNOLOGY

Author: Adolfo Dinis Bila

Advisex: Prof.Dr. Paulo Yoshio Kageyama

\section{SUMMARY}

With objective to evaluate interaction of species and progenies within species with silviculture technological levels, various trials at increase levels of forest implantation technology were established, at Bento Quirino Experimental Station, which belongs to Forestry Institute of São Paulo State, situated at São simão-gP munjeipal district.

Three trials were established next to each other, in sandy soil which previously had been under woodland vegetation, using, for each trial, one level of forest implantation technology level: technology level one-unprepared soil without fertilization; technology level twom prepared soil (ploughed and graded) without fertilization; technology level three-prepared and fertilized soil (100g of NPK 10: 28:6 per plant).

For each trial the following species was used: Eucalypptus coterge

grandis Hill ex Maiden, seeds gathered from a clonal seed orchard in Botu-

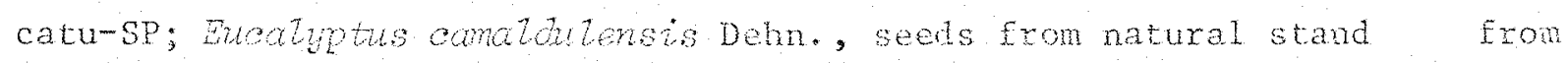
Gibb River, Western Australia; Eloolyotue atriodora Hook, seeds gathered 
from selected trees (1:10000) from a plantation in Pederneiras-SP (ExRio Claro-SP). Different number of open pollinated progenies were used, being: 13 for E. grondis, 22 for $E$ comaldutensis, and 14 for E. citrio dora.

For three trials, the experimental design was used in compact family blocks, replicated three times, with species forming plots and progenies forming sub-plots. The spacing used was $2 \times 2$ neters.Trials were established in may, 1986. Evaluations were made at the ages of 7 and 12 months, collecting data concerning height and mortality of plants. At age of 18 and 24 months, additional information of DBH (diameter breast height) and cylindrical volume was collected.

The main conclusions at species level were: a) E. grandis was the most apt, E. comalduteneis was average and E. citriodora the least apt to respond to silviculture technology; b) differentiation between species was greater at the highest silviculture technological level; c) there was an increase of relative genetic variation between species with improvements of technological level; d) at lowest level of technology, $E$, comatdutensis and $E$. citriodora had a higin survival rate and greater productivity, in terms of dry material per unit of area, than that of E. granais; e) there was an increased statistic efficiency of the trials with improvements made at forest implantation technology levels.

The main conclusions at progenies within species level were; f) improvement of implantation technology level caused a decrease in relative genetic variation between progenies for the three species; $g$ ) at 
lowest technological level of forest implantation, only E. grandis showed a genetic variation for the survival of plants and significant interaction with soil preparation and mineral fertilization; h) progenies of the three species reacted differently in terms of genetic variation and levels of silviculture technology; i) there was a noted decrease of implantation technology effects with plant age; j) a clear trend for different behaviour was observed in the progenies at different forest implantation technologies; 1) genetic material adjustment to silviculture technologies permits rational use of genetic, environmental and technological resources. 
1. INTRODUÇ̃̃O

o plantio de espécies exóticas de rápido crescimento, com vista à produção de matéria prina industria1, combustível lenhoso e de outros produtos para o consumo doméstico, constitui uma atividade importante em muitos paises. As espécies dos gêneros Pinus e Eucazyptus têm sido as mais utilizadas nesses plantios.

Dada a competição com a agricultura, em solos e demais insumos, os povoamentos florestais são estabelecidos em äreas marginais, onde a eliminação da vegetação natural e a melhoria das condições edáficas, através do preparo do solo, fertilização mineral e de outras práticas silviculturais säo fatores indispensäveis para o sucesso das plantações.

Entre os eucaliptos mais utilizados nos reflorestamentos no Brasil destacamme o $\ddot{E}$. grondis e o E. saligna, pela sua boa adaptação, räpido crescimento e, principalmente, pela resposta à tecnologia silvicultural. Estas espécies, as mais plantadas na maioria dos países tropicais (TURNBULL \& PRYOR, 1978), são consideradas muito exigentes quanto às condicões climäticas, edáficas e adequadas para a silvicultura intensiva, 
caracterizada por elevados investimentos em capital e a utilização de alta tecnologia silvicultural.

Estudos sobre as exigências das espécies florestais são recentes e pouco explorados (SIMÕES et alii, 1981). Informações disponiveis revelam comportamento diferenciado das espécies em relação às tēcnicas de implantação, manejo e proteção florestal, indicando a necessidade de escoTha criteriosa destas para cada nivel de tecnologia e vice-versa.

Por outro lado, estudos de interação envolvendo progênies e clones com fatores ambientais tên revelado resultados expressivos, mostrando que dentro das populações existe variação genētica para a resposta a diferentes pressões de seleção do ambiente (KAGEYAMA, 1980; PATIÑo-VALERA, 1986, MORI et alii, 1986).

Desta forma, na seleção déespécies, procedências e progênies para a utilização em programas de reflorestamento deve-se considerar, alēm das condições edâficas e climäticas, o nível de tecnologia silvicultural que será utilizado nas plantações. Em geral, as espécies mais exigentes quanto ao clima e solo, têm-se revelado, também, mais exigentes em relação ao preparo do solo, fertilização mineral e tratos culturais (KAGEYAMA, 1984).

Värias espëcies, dentre elas o E. camaldulensis, E. citriodora e E. tereticomis, são citadas na literatura cono sendo menos exigentes do que o. E. grandis e E. satigna e, aparentemente, seriam indicadas para condições de baixa tecnologia silvicultural. 
O presente trabalho tem por objetivo:

a) estudar o comportamento de espécies e progênies de Eucalyptus (E. grandis, E. camalaulensis e E. citriodora) em três niveis de tecnologia de implantação florestal;

b) quantificar as possíveis interações de genótipo $x$ nivel de tecnologia para as diferentes espëcies e progênies. 
2. REVISÃO DE ITTERATURA

2.1. Resposta das espécies às técnicas de implantação Elorestal

A implantaçäo florestal envolve um conjunto de atividades que vão desde a escolha de ärea a plantar até o pleno estabelecimento do povoamento. Inclui a escolha do terreno e de espëcies a plantar, a produção de mudas, o preparo do solo, a fertilização mineral, o plantio. e os tratos culturais (MAGALHÃES \& RESENDE, 1983; KELLISON, 1983).

Neste tópico serão abordados somente aspectos do preparo do solo e fertilização mineral, as tëcnicas de implantação florestal consideradas no presente trabalho.

\subsubsection{Preparo do Solo}

o comportamento das espécies florestais é funçäo do seu potencial genëtico, do clima, do solo e das tëcnicas silviculturais. Para qualquer espécie, è possível aumentar, dentro de certos limites, a produtividade melhorando o ambiente en que crescem as plantas, principalmente 
na época do plantio (HERBERT, 1985). Com essa finalidade, o preparo do solo tem sido prätica comum em plantações de eucaliptos (WATTLE RESEARCH INSTITUTE (WRI), 1972; KELLISON, 1983; CRONER, 1984).

Em florestas, o preparo do solo visa criar condições propícias para a plantação e futuro desenvolvimento de mudas (SIMÕes et alii, 1981). Segundo estes autores, o terreno destinado ao plantio de essências florestais deve ser devidamente preparado, uma vez que desta operação depende, em grande medida, o resultado econômico da plantação.

FONSECA (1978) define o preparo do solo como todas as operações realizadas no campo antes do plantio. Salienta existirem düvidas quanto à intensidade a que o solo deve ser preparado, e sugere que as operações a considerar, bem como a intensidade a que serão realizadas, sejam definidas para cada espēcie con base na experimentação em diferentes condi ções de solo.

Segundo CROMER (1984), na maioria dos países que plantam eu caliptos, o preparo do solo tem sido muito intensivo, e envolve a utilização de equipamento pesado. Menciona que o preparo manual é comum nos pã̃ses que praticam o sistema "taungya".

BALLONI \& SIMÕES (1979) citam que o preparo do solo é função de espécie, clima, topografia, e da vegetaçäo presente na ärea a reflorestar. Indicam, por exemplo, que em áreas de cerrado a gradagen pesada tem constituído a unica operação de revolvimento do solo, e em locais declivosos o preparo manual tem sido a ünica altemativa. Entretanto, em algumas regiões, o preparo do solo tom sido täo intensivo cono para qualquer cultura agrícola. 
De acordo com WAKELEY (1954), o melhor método de implantação florestal depende do sucesso na escolha da espécie, fonte de sementes e da qualidade de mudas. Relata que nos Estados Unidos da América tem-se conseguido resultados satisfatōrios em äreas sem nenhum preparo do solo. Acrescenta que a operação tem sido fundamental para a sobrevivência das plantas em äreas adversas.

A mesma idéia é compartilhađa por BROWN \& HALL (1968). Re-latam que em solos arenosos ou franco-arenosos de regióes com elevada precipitação, o plantio de espëcies florestais pode ser feita sem nenhum preparo do solo. Contudo, acrescentam que em regiões com deficit hídrico o preparo do solo é necessārio.

Wahlenberg, citado por MELLO \& RODRIGUES (1966), referindo-se ao preparo do solo como uma tëcnica importante na implantação florestal, considerou a negligência na sua realização como um fator que pode levar à ruína do povoamento; o preparo exagerado como desperdício de esforço; e o preparo adequado como um investimento economicamente rentável.

Segundo SCHÖNAU (1977) as principais espēcies de eucalipto utilizadas nos reflorestamentos na África do Sul não são adequadas ao plan tio direto. o sistema radicular é superficial e muito sensível à competição com vegetação natural.

KREJCI et aliz (1986) verificaran que os encaliptos possuem sistemas radiculares diferenciados. Aos oito meses de idade, em diferentes tipos e mëtodos de preparo do solo, o E. grandis apresentou raiz superficial com maior desenvolvimento no sentido horizontal, tendo sido 
considerado sensível às condições adversas, e adequado à silvicultura intensiva. O sistema radicular do E. citriodora mostrou-se predominantemente pivotante; esta espécie foi considerada adaptada à regiões secas e, apa rentemente, a condições de baixa tecnologia. $O E$. camatdutensis foi considerado uma das espécies com maior plasticidade para o reflorestamento; seu sistema radicular mostrou-se bem desenvolvido tanto no sentido horizontal quanto no sentido vertical.

Värias pesquisas, visando definir sistemas de preparo. de solo para as espécies florestais, têm sido realizadas em diferentes condições de clima e solo.

A maioria dos estudos envolve aração, gradagem, subsolagem e feitura de camalhões $\epsilon$, em geral, apenas uma espécie é considerada por ensaio. Pesquisas com värias espëcies ou progênies, simultaneamento são reduzidas. Os resultados que vêm sendo obtidos para os eucaliptos revelam efeito positivo do preparo do solo no desenvolvimento do povoamento, principalmente durante os primeiros três anos (WRI, 1972; DONAID \& SCHUTZ, 1977, SCHÖNAU, 1985).

Conforme COSTA \& CARMO (1983), o preparo do solo através da aração e gradagem mistura a manta de resíduos orgânicos com a camada super ficial, rica em nutrientes e matëria orgânica, e a sub-superficial do so1o, criando un novo ambiente, mais umido, axejado, con melhor equilibrio tērmico e favorävel a processos de decomposição e liberação de nutrientes.

Esse ambiente favorece a penetração e desenvolvimento das raízes, e a absorção de nutrientes, resultando em maior crescimento en al tura e diâmetro, maior porcentagem de sobrevivencia, maior uniformidade do 
povoamento $e_{s}$ consequentemente, maior produção final (SCHÖNAU et alii, 1981; HERBERT, 1985). Estas observações são corroboradas por trabalhos rea lizados com eucaliptos e com espëcies de outros gêneros (LADRACH, 1983b; INSTITUTE FOR CORERCIAL FOREST RESEARCH (ICFR), 1985).

FONSECA (1978), por exemplo, observou em resultados preliminares aos 4 anos, haver tendência para a redução da porcentagem de faThas e aumento da produção volumêtrica com a intensificação do preparo do solo em E. grandis e P. taeda.

DELWAULLE (1979), analisando o crescimento de E. camaZduZensis sob condições de preparo do solo mecânico e manual, aos 42 meses de idade, não encontrou diferenças entre os dois métodos quanto à sobrevivência; porém o ganho em altura devido ao preparo mecânico foi de $11 \%$.

Apesar do incremento registrado, esse autor considerou satisfatórios os resultados obtidos com o mëtodo manual, em vista das características do terreno e as razões söcio-econômicas associadas a este tipo de preparo do solo.

SUITER FILHO et alii (1980) notaran que, en solos com camada de impedimento, a subsolagem favorecia o crescimento do E. grandis. o melhor tratamento envolveu a subsolagem, gradagem com a grade "bedding" e plantação mecânica, o qual proporcionou incrementos de $112 \%$ em volume ci Iindrico, em relação à testemunha, aos 14 meses de idade.

$$
\text { Em outro ensaio com a mesma espëcie, RocHA et alii }
$$
constataram aos 24 meses de idade, aumento na sobrevivencia de plantas, al tura, diâmetro e volume cilindrico, à medida que preparo do solo abrangia 
toda a superfície da plantação. Atribuíram o fato à melhoria da fertilidade do solo, resultante da incorporação da matëria orgânica.

Em conformidade com CoSTA \& CARMO (1983) a maior parte dos nutrientes está mobilizada na vegetação natural e na camada superficial do solo e, assim, o preparo do solo deve considerar a economia destes nutrien tes para a sua utilização pela plantação.

LADRACH (1983b) estudou o comportamento de E. grandis, Cupressus lusitanica e P. oocarpa em diferentes métodos de preparo do so1o e tratos culturais. Aos 24 meses de idade, as duas primeiras espécies responderam à intensificação do preparo do solo e tratos culturais; 0 P. oocarpa foi indiferente. Os valores mëdios para altura obtidos na testemunha e no preparo completo de solo foram, respectivamente, 6.4 e 7.8 metros para E. grandis, 3.9 e 4.3 metros para o C. Zueitanica e 3.0 metros para o P. oocarpa.

Idênticos resultados foram observados por ICFR (1985), em E. grandis, Acacia meamsii e $P$. taeda. o maior crescimento, sobrevivência e uniformidade do povoamento foram obtidos nas parcelas que receberam o preparo completo do solo.

\subsubsection{Fertilização Mineral}

Acubação mineral é una das técmicas de uso generalizado, fejta para aumentar a produtividade de plantações florestais (DONALD \& SCHUTZ, 1977; CROMER, 198:) 
A maioria dos povoamentos de eucaliptos são estabelecidos em solos pobres, que precisam de ser adubados para garantir rendimentos sa tisfatörios (HAAG et alii, 1977). Como enfatizam SIMÕES \& BRANDI (1983) a produção de eucaliptos, cultivados em ciclos curtos, depende bastante da fertilização mineral.

Extensa revisão bibliogräfica sobre a fertilização mineral em florestas implantadas foi realizada por HAAG (1983). Segundo este autor, os eucaliptos são, dentre as exöticas de rápido crescinento, as espécies que melhor respondem à adubação; salienta que ainda não se ten resultados conclusivos e realça a necessidade de continuação de estudos sobre o tema.

Os resultados da adubação miñeral em plantações de eucaliptos são às vezes contraditórios. Em alguns casos a resposta inicial prevalece até o corte final, en outros casos ela desaparece com a maturação da plantação (SCHUTZ, 1976). Iđênticas observações foran feitas por SIMÕES \& SPINA-FRANÇA (1983). Os autores destacam que a espécie, o material genético e o tipo de solo são fatores determinantes na resposta à adu bação.

Segundo BARROS (1982), a eficiência da adubação depende da espécie, do tipo de fertilização, do método de aplicação e das condições edafo-cimáticas. Nenciona, anda, que a fertilização en florestas poderia ser dispensada através da escolha de genötipos mais apropriados a cada ambiente e pela adoção de técnicas silviculturais adequadas. 
SIMÕES et $a$ lii (1981) relatam que as espëcies florestais apresentan exigências nutricionais diferentes e que esse aspecto pode ser utilizado no zoneamento para o reflorestamento. Citam que os pinheiros são menos exigentes que os eucaliptos. Em solo pobre, por exemplo, os pinheiros tropicais, sem receberem nenhuma fertilizaçäo mineral, apresentam rendimentos similares ou até superiores a eucaliptos adubados com $100 \mathrm{~g}$ de NPK $(10: 34: 6)$ por planta. Citam, ainda, que o $E$. saligna tem se revelado mais exigente do que o E. grandis nessas condições.

De acordo com as colocações de KAGEYAMA et alii (1987), as espëcies do gênero Pinus são mais estäveis, reagem pouco as mudanças ambientais e são adequadas a sítios ruins e a condições de baixa tecnologia silvicultural. Os Eucalyptus, ao conträrio, são mais variáveis, reagem bastante às mudanças ambientais e de técnicas silviculturais, e apresentan espēcies adaptadas a cada ambiente ou nível de tecnologia silvicultural.

Realçando, Copener, citado por RAGEYAMA et alii (1987), ayaliando espécies de Eucalyptus em dois niveis de fertilização mineral, obteve para volume cilindrico aos 24 meses, no nivel mais baixo e no nivel mais alto de fertilização, respectivamente $6.1 \mathrm{~m}^{3} / \mathrm{ha}$ e $18.5 \mathrm{~m}^{3} / \mathrm{ha}$ para o E. grandis e $10.7 \mathrm{~m}^{3}$ /ha e $14.5 \mathrm{~m}^{3} /$ ha para o E. citriodora.

Esses resultados estão de acordo com as observações de KREJCI et atit (1986), segundo os quais, espécies cono o grondie, que possuem sistema radicular superficial, respondem mais à adubação do que as espécies que apresentam sistema radicular profundo. 
Conforme ICFR (1985), a relação $N: P$ e K:P nos fertilizantes não deve exceder a unidade. Em casos do preparo do solo, a proporção de $P$ deverā ser bem maior do que a proporção de $\mathrm{N}$; o inverso deve ser observado no caso de plantio direto ou de preparo de solo deficiente.

Ainda ICFR (1985), avaliando o desempenho de E.grandis, sob diferentes niveis de preparo de solo e fertilização mineral, obteve para. altura de plantas, aos 19 meses, os seguintes resultados: testemunha, 1,60 metros; preparo do solo sem adubação, 5,62 metros; preparo do solo e aduba ção de $100 \mathrm{~g}$ por planta de superfosfato de amônio, fertilizante considerado rico em $\mathrm{P}$ e pobre em $\mathrm{N}, 6,81$ metros; e preparo do solo e adubação de $100 \mathrm{~g}$ por planta de NPK $(3: 2: 1), 6,11$ metros.

Observe-se que a resposta ao preparo do solo foi de $251 \%$ e a resposta à adubação, nas parcelas que receberam o preparo do solo, foi de apenas 15\%, em mëdia. A discriminação do fertilizante proporcionou acréscimo adicional de 5\%. De acordo com HERBERT (1985), o aumento da relação N:P devido a incorporação e decomposição de matéria orgânica, diminui a disponibilidade do $\mathrm{P}$, e afeta, dessa forma, o crescimento das plantas.

As pesquisas de adubação en eucaliptos mostram que a respos ta é expressiva durante os primeiros anos, e vai diminuindo com a idade do povoamento, podendo ser ou näo significativa no corte final (DoNALD \& SCHUTZ, 1979; SCHÖNAU, 1983).

A resposta inicial varia de 1 a 3 metros para altura, 2 a 5 centímetros para o diâmetro, podendo atingir entre 30 a 40 toneladas de 
matēria seca no corte final (HERBERT, 1.985). Em geral, segundo SCHÖNAU (1985), a resposta à adubação prevalece até cerca do décimo ano, e pode proporcionar rendimentos que, em média, chegam a $25 \%$ da produtividade por hectare por ano.

MAGALHÃES \& RESENDE (1983) afirmam que, independentemente da adequação do fertilizante quanto a formulação e quantidade a aplicar, a resposta à adubação em florestas energëticas tem sido positiva, chegando a superar em 70\% a produção de locais não adubados. Acréscimos expreśsivos na produção f́inal são relatados também por WRI (1972). O aumento na produção total resulta do maior crescimento em altura e diâmetro, maior porcentagem de sobrevivência e da maior uniformidade do povoamento (ICFR, 1985).

Pelos resultados apresentados na literatura, a resposta dos eucaliptos ao preparo do solo parece ser maior do que a resposta à aplicação de fertilizantes minerais. Os melhores resultados, tanto em crescimento inicial como na produção final, são obtidos quando o preparo completo do solo é combinado com adubação mineral eficiente, em termos de formulação, quantidade e mëtodo de aplicação (MALvos, 1983; ICFR, 1985).

De acordo com HERBERT (1985), adubação mineral durante o plantio tem efeito positivo no desenvolvimento do sistema radicular, permitindo a planta o melhor aproveitamento das condiçoes favoräveis ao crescimento, criadas atraves do preparo do solo. 


\subsection{Interação de Genótipos x Técnicas Silviculturais}

A interação de genötipo $x$ ambiente em florestas vem merecendo muita atenção nos ü1timos anos (BARNES et alii, 1984). Ela constitui una das mais importantes manifestações biológicas que, dependendo do seu controle ou não, pode proporcionar ganhos ou prejuizos no reflorestamento e no melhoramento florestal (ZOBEL \& TALBERT, 1984).

Os resultados que vêm sendo obtidos no estudo da interação de genótipo $\mathrm{x}$ ambiente revelam que ela è muito mais importante do que se imaginava, realçando a necessidade de estudos mais aprofundados sobre o assunto, bem como a definição de estratégias com vistas à sua correta utilização na silvicultura (KAGEYAMA, 1986).

BARNES et alį (1984) definem a interação de genótipo $x$ ambiente como a falta de uniformidade das diferenças entre os genótipos em värios ambientes; a sua presença indica que um genötipo pode ser melhor num ambiente $e$ mediocre noutro.

o termo genótipo é usado para designar os diferentes niveis de organização genética como a espécie, a procedência, progênie ou clone. Por ambiente se refere a determinada combinação de fatores climáticos, edá ficos e bióticos em que se desenvolvem os genótipos (BARNES, 1984). O termo ambiente inclui, tambëm, as condições artificialmente criadas, atravês do preparo do solo, fertilização mineral, espaçanento, tratos culturais e de outras técnicas silviculturais (KAGEYAMA, 1986).

Segundo BURLEY \& KEMP (1972), a interaçäo de genótipo x ambiente é comum quando dois ou nais genótipos são avaliados em värios 
ambientes devido: às diferenças genéticas entre os materiais em testè; às diferenças entre os ambientes; e às diferenças entre os tratamentos aplicados aos genótipos antes do teste, principalnente a seleção e as präticas silviculturais.

NAMKOONG et alii (1980) relatam que as espëcies florestais exibem, em suas áreas de ocorrência natural, padrões de variação que mostram a existência de ampla variação genética entre os diferentes componentes da espécie.

AYALA (1978) cita que as espécies que ocorrem em ambiente heterogêneo estão sujeitas à seleção natural diversificada, que culmina com a formação de populações geneticamente distintas, adaptadas a cada sub-ambiente. Assim, fortes interações de genótipo x ambiente são esperadas quando amostras dessas populações são avaliadas em värios ambientes (FERREIRA, 1986).

As variações entre e dentro de espëcies fiorestais são bem conhecidas e têm sido exploradas em programas de reflorestamento e melhoramento genético (FERRETRA \& ARAUJo, 1981; ZOBEL \& TALBERT, 1984; KAGEYAMA, 1984). Essas variações aparecem em ensaios de competição de espécies, tes tes de procedências e testes de progênies, realizados em diferentes condições de clima, solo e técnicas silviculturais. Dentre os inüneros trabaIhos apresentados na literatura, citam-se, a titulo de exemplos, as pesqui sas desenvolvidas por KAGEYAMA (1980), LADRACH (1983a), MALVOS PATIÑN-VALERA (1986) e MORT et alii (1986).

A variação ambiental é mujto evidente na silvicultura, o 
seu controle constitui o fundamento das präticas silviculturais (ZOBEL \& TALBERT, 1984). Alguns fatores ambientais, como a competição, excesso ou deficiência de água, compactação do solo, podem ser alterados, dentro de certos limites, através de tēcnicas silviculturais. Outras variáveis, tais como a precipitação, temperaturas e velocidade de vento, são pouco influen ciados pela atividade humana.

Por outro lado, dado as grandes äreas envolvidas nos reflorestamentos e ao longo ciclo de vida das essencias florestais, o controle ambiental torna-se bastante limitado. Nessas condições, e principalmente quando se utilizam espécies exóticas, a interação de genótipos $x$ ambiente assume particular importância. De acordo com KAGEYAMA (1986), quanto mais controlado o ambiente menor a importância da interação e vice-versa.

De acordo com QUIJADA (1980) a interação de genótipo $x$ ambiente pode manifestar-se através de mudanças das posições relativas dos genótipos em cada ambiente ou pela diferença na magnitude de superioridade nos diferentes ambientes. A estes tipos de interação são denominadas, res pectivamente, de interação complexa e interação simples (FONSECA, 1979).

Shelbourne e Goddard, citados por ZOBEL \& TALBERT (1984), relatam que a maior parte das causas de interação de genótipo $x$ anbiente estão, aparentemente, mais relacionadas com fatores edăficos do que com fatores climäticos.

Por sua vez, BARNES (1984) cita que os resultados que vêm sendo obtidos de ensaios de espécies e procedencias e nos testes de materiais selecionados em programas de melhoramento indicam que a interação 
ao nível de espécie e procedências parece estar associada a fatores climáticos, enquanto que ao nível de progênies e clones estaria ligada a fatores edäficos.

Considerando que os fatores edáficos são influenciados pelo preparo de solo, fertilização mineral e tratos culturais (CROMER, 1984; FRANCIS, 1984), a interação de genōtipo x tecrologia pode se manifestar quando genótipos selecionados en determinado nível de tecnologia são utilizados em condições diferentes daquelas em que se procedeu a seleção.

Segundo KAGEYAMA (1984), as espécies florestais respondem diferentemente as técnicas silviculturais; algumas espécies respondem muito mais a tecnologia silvicultural do que outras. Este aspecto pode ser de grande utilidade na escolha de espécies a utilizar nos diferentes níveis de tecnologia. Relata, ainda, que em geral espécies como o E. saligna e E. grandis, muito exigentes em nutrientes, têm se mostrado, tambèm, mais exigentes em umidade, preparo do solo, tratos culturais, e demais präticas silviculturais. Esta tendência, segundo o mesmo autor, pode ser observada ainda dentro da espécie, ou seja, ao nível de procedência, progênie ou clo ne.

TURNBULL (1978) relata ser possível identificar dentre as 450 espēcies de Eucalyptus que ocorrem na Austrälia, genötipos adequados à maioria das condições de reflorestamento de miitos países tropicais. ELDRIDGE (1975) comenta que as procedências de E. camaldulensis do norte e sul da Austrälia têm sido as mais utilizadas em plantações. Salienta que - sucesso destas procedencias não significa que foram esgotadas as possibilidades de escolha de novas Eontes de sementes e que, provavelmente, 
existem outras procedencias melhores, esperando sex testadas.

Estudos específicos para avaliar a interação de genōtipos $\mathrm{x}$ tēcnicas silviculturais säo limitados (ZOBEL \& TALBERT, 1984; MORA, 1986). A maioria das pesquisas de preparo de solo e adubação mineral envolve uma ünica espëcie, e nos casos de ensaios de competição de espécies as tēcnicas silviculturais, geralmente, não são consideradas.

KAGEYAMA et alii (1987) avaliaram a resposta de eucaliptos à tecnologia silvicultural a partir de estudos de preparo do solo, fertilização mineral e ensaios de competição de espécies, estabelecidos em locais com diferentes potenciais florestais. Os autores observaram que o gênero Eucalyptus apresenta una grande variação e que existem espëcies adaptadas a plantações comerciais, com o uso de alta tecnologia silvicu1tura1, e outras espécies adequadas a condições de baixa tecnologia. Citan como exemplos do primeiro caso o $E$. grandis e $O E$. urophyz $Z$, e do segundo - E. citriodora e o E. camaldutensis.

Num ensaio de competição de espécies e procedências de Euca lyptus em seis locais na Colômbia, aos dois anos de idade, o E. grandis e - E. saligna se evidenciaram nos locais com maior potencial florestal, no meadamente solo fértil, maior precipitação e altitude; o $E$. camalaulensis e. E. tereticomis foram as melhores espécies em condições de baixo potencial florestal (LADRACH, 1983a).

Idêntica tendência foi verificada por RIBEIRO (1971) quando avaliou o desempenho de eucaliptos em dois locais do Estado da Bahia. Aos 12 meses de idade, o $E$, grandis foi superior ao E. citriodora e 
E. camaldulensis en Santa Terezinha e foi inferior às duas espécies em Valença, locais com maior e menor potencial florestal, respectivamente.

Copener, citados por KAGEYAMA et alii (1987), notaram, aos 24 meses, que em condiçōes de solo pobre e baixa dose de fertilização mineral, o E. citriodoxa era bem superior ao E. grandis e que a situação se invertia com o aumento da dose do fertilizante. O incremento de volume, devido a elevação da dosagem, foi de $203 \%$ e $35 \%$, para o E. grandis e $E$. citriodora, respectivamente.

A resposta expressiva à tecnologia silvicultural do $E$. grandis em relação a outras espécies é relatada tambémpor LADRACH (1983b), WRI (1983) e ICFR (1985).

A interação de genótípos x tecnologia silvicultural pode se manifestar tambēm ao nível de progênie (KAGEYAMA, 1984).

A interação de progênies de E. saligna por espaçamento, obtida por PATIÑN-VALERA (1986), aos 32 meses, não foi estatisticamente expressiva. Entretanto, os valores de volume cilindrico revelaram, naquela idade, comportamento diferenciado das progênies nos dois espaçamentos.

KAGEYAMA (1980), avaliando progenies de F. grandis, em cinco locais aos 24 meses de idade, constatou existir variação genética entre as progênies em cada local e entre locais, para a maioria das caracteristicas estudadas. O efeito de locais na variação total foi, segundo o autor, preponderante, revelando a sensibilidade diferencial das progênies às condições edäficas. Resultados similares foram obtidos por MORI et aliz (1986), em progênies de $\mathbb{E}$. Saligna, avaliadas aos 36 meses de idade, em três locais com diferentes potenciais silviculturais. 
As técnicas silviculturajs crian ambientes especiais, alteram o comportamento dos genötipos e poden provocar a interação de genötipo $x$ ambiente (ALLARD \& BRADSHAW, 1964). Nos casos de interação significativa seria desejâvel utilizar genötipos adequados a cada tecnologia e estabelecer programa de melhoramento genético especifico a essa condição.

o ganho do melhoramento genético pode ser facilmente perdido quando genótipos selecionados em determinado ambiente são utilizados em condições diferentes daquelas ern que se procedeu a seleção (KAGEYAMA, 1986). Idêntico comportamento pode ser observado quando genótipos melhorados em condições de alta tecnologia silvicultural são utilizados em condições de baixa tecnologia, o que requer cuidados especiais na transferência de materiais selecionados de unia situação para outra. 
3. MATERIAI E METTODOS

\subsection{Material}

3.1.1. Material genético em estudo

No presente trabalho foran utilizadas progenies de polinizaçäo livre de E. grandis, Er. conatdulensis e E. citriodora, espécies escolhidas por indicações preliminares de respostas diferenciais à tecrologia silvicultural.

As sementes de E. grandis foram obtidas de un Pomar de Sementes Clonal instalado em Botuactu-SP; as de Lr. citriodora foran coletadas em ärvores selecionadas fenotipicamente, com uma intensidade aproximada de 1:10.000, en um povoamento de 550 hectares, estabelecido em 1964-65 em Pederneira-SP com sementes procedentes, provavelmente, de Rio Claro-SP. As sementes de E. comatdutensis foram obtidas de uma população natural de Gibb River, Western Australia, na latitude $16^{\circ} 06^{\prime}$ Sul, longitude $126^{\circ} 31^{\prime}$ Este de Greenwich, a 240 netros de altitude. 
3.1.2. Local do ensaio

o experimento foi instalado na Estação Experimental de Ben to Quirino (EEBQ), do Instituto Florestal. do Estado de São Paulo, que fica situada no Municipio de São Sinão-SP, na latitude $21^{\circ} 29^{\prime}$ Sul, longitum de $47^{\circ} 33^{\prime}$ Este, a uma altitude de 640 metros (VENTURA et alii, 1965-66).

o clima da região é tropical de inverno seco, con precipitação mêdia anual de 1360 milimetros; as temperaturas mëdias do mês mais quente e do mês mais frio são de $24^{\circ} \mathrm{C}$ e $18^{\circ} \mathrm{C}$, respectivamente.

A ārea experimental è bastante honogênea em suas caracteristicas físicas e quimicas. Apresenta um solo classificado como areia quarizosa (OLIVEIRA \& PARDO, 1983), relevo suavenence ondulado, originalmente sob vegetaçäo de cerrado. Os resultados da anälise füsica e quimica do solo da área experimental säo apresentados no Apênáice l. Esses dados são similares aos obtidos por RODRIGUES et aliz (1986) na região de São Simão e por BERTOLOTI (1986) em solo areia quartzosa älica pobre,em Lençöis Paulista-SP.

\subsection{Métodos}

3.2.1. Instalação dos ensaios

Os ensaios foram estabelecidos em maio de 1986, con mudas produzidas no viveiro da EEBQ, seguindo o sistena tradicional de semeadura em alfobres e posterior repicagen de plantulas em recipientes individuais. 
Três ensaios forarn instalados um ao lado do outro, no taThão nümero 57 da EEBQ, utilizandomse, para cada ensaio, um nivel de tecnologia de implantação floresta1. A descriçäo dos níveis de tecnologia considerados nos diferentes ensaios $\vec{e}$ apresentada a seguir:

Ensaio A - nive1 de tecnologia I (NTI)

Designação: sem preparo do solo e sem adubação mineral. Limpeza do terceno: roçada con roçadeira hidräulica tracionada por trator marca VALMET 85 ID.

Tratos culturais: 1impeza manual na linha de plantio com enxada e roçada, tambên mamal, nas entrelinhas com foice.

Ensaio B - nível de tecnologia II (NTIT)

Designação: preparo do solo sem adubação mineral.

Preparo do solo: aração com grade aradora de arrasto, de 12 discos de 20 polegadas, atingindo uma profundidade de 30 centimetros e gradagem cruzada, com grade hidraulica, de 20 discos de 20 polegadas. Os dois implementos foram tracionados por trator marca VALMET $85 \mathrm{ID}$.

Tratos culturais: idênticos ao nível de tecnologia $I$. 
Ensaio C - nivel de tecnologia III (NTIII)

Designação: preparo de solo e adubação mineral. Preparo do solo: idêntico ao nível de tecnologia i.

Adubação mineral: $100 \mathrm{~g}$ de NPK $10: 28: 6$ por planta, aplicadas na cova no momento do plantio.

Tratos culturais: idênticos aos niveis de tecnologia I e II.

Os tratos culturais, num total de cinco, foram uniformes nos três niveis de tecnologia de implantação florestal e suficientes para a não ocorrência de competíção com as ervas daninhas.

Os três ensaios foram instalados segundo o delineamento em blocos de familias compactas (compact family blocks), uma variante do deIineamento em parcela sub-dividida (PINTO JR., 1984), onde as três espécies constituíram as parcelas e as progênies dentro de espécies, em nümero variävel por espécie, formaram as sub-parcelas. Este delineamento foi utilizado pelo citado autor, assim como por BRASII (1983) em pesquisac en volvendo procedências e progênies dentro de procedências de E. urophy 2 za.

Os ensaios foran considerados em dois niveis: ao nível de espēcies e ao nĩvel de progênies dentro de espécies. No primeiro caso, considerou-se o conjunto de progênies de cada espécie como sendo um binico tratamento. No segundo caso, cada especie constituiu un ensaio à parte tendo como tratamento as progênies.

As très especties, bem como as respectivas progenies, foram comuns aos três ensatos ou niveis de tecnología. Foram utilizadas 
progênies, sendo 13 de $E$. grandis, 22 de $E$. comaldutensis e 14 de $E$. citriodora. A relação das espécies com as respectivas progênies é apresentada no apêndice 2 .

As parcelas foram retangulares ao nivel de espécies, e lineares com 6 plantas mensuräveis ao nível de progênies o nümero de repetições foi de 3 e o espaçamento nos três ensaios foi de $2 \times 2$ metros. Os ensaios foram circundados por bordadura simples formada de plantas da mesma espëcie e idade.

\subsubsection{Avaliação dos ensaios}

Os ensaios foram avaliados no campo nas idades de 7 e 12 meses, coletando-se os dados de altura total e mortalidade de plantas, e aos 18 e 24 meses de idade, acrescentando-se às caracteristicas mencionadas o DAP (ciâmetro à altura do peito) e volume cilindrico.

A avaliação de altura e DAP foi efetuada ao nível de plantas individuais, de onde foram obtidas as médias de espécies e progênies dentro de espécies, para efeito de anälise estatística. Para a mortalida de de plantas os dados foram obtidos ao nivel de totais de parcelas.

o volume cilindrico foi calculado ao nivel de plantas individuais, a partix dos dados combinados de DAP e altura de cada una das ärvores, sendo que posteriormente foram geradas tambëm as mëdias de espëcies e progênies.

A mediçäo de altura e DAP foi feita segundo os esquenas usuais, ntilizando-se o hipsômetro "blume Leiss" e a rëgua graduada, 
respectivamente. A caracteristica mortalidade de plantas foi obtida pela contagem de plantas mortas em cada parcela e expressa em termos percentuais em relação ao numero total de plantas que deveria conter a parcela.

\subsubsection{Anälise estatística}

A anälise estatistica foi feita, de acordo com PINTO JR., (1984), ao nivel de espëcies e ao nível de progênits separadamente. As më dias dos tratamentos, ou seja, as mëdias de espëcies e de progênies, foram geradas a partir de dados do conjunto das progênies e de cada progênie, respectivamente. Ao nível de espécies, como o tamanho de parcela foi variado, devido ao desiguaí número de progênies, a anälise estatistica foi aproximada.

3.2.3.1. Anälise de variância Individual para cada nïvel de tecnologia

A anälise de variância individual para os dados de altura de plantas, DAP, volume cilindrico e porcentagen de falhas, nas diferentes idades e para cada nivel de tecnologia, ao nivel de espécies e progénies dentro de espêcies, foi realizada segundo o esquema para delineamento em blocos ao acaso, conforme FONSECA (1979) e PINTO JR., (1984).

o modelo matemático para a anälise individual ao nível de espēcies foi o seguinte:

$$
Y_{i j}=m+b_{j}+t_{i}+e_{i j}
$$

com os tratamentos considerados como efeitos fixos, onde $Y_{\hat{i} j} \vec{e}$ a media 
da parcela do tratamento i, no bloco j; m è a média geral; bje e ofeito do bloco; $t_{i}$ e o efejto do tratamento $e e_{i j} \vec{e}$ o efeito do erro experimental.

Ả estrutura da análise de variäncia individual, com os dados de médias de parcelas ficou:

\begin{tabular}{lcccc}
\hline FV & GL & QM & $E(Q M)$ & $F$ \\
\hline Blocos & $r-1$ & $Q_{1}$ & $\sigma^{2}+n \sigma_{b}^{2}$ & $Q_{1} / Q_{3}$ \\
Especies & $n-1$ & $Q_{2}$ & $\sigma^{2}+r v_{t}$ & $Q_{2} / Q_{3}$ \\
Erro & $(r-1)(n-1)$ & $Q_{3}$ & $\sigma^{2}$ & \\
\hline
\end{tabular}

$\mathrm{QM}=$ quadrado médio; $\mathrm{E}(\mathrm{QM})=$ esperança do quadrado mëdio; $\mathrm{r}=$ nümero de blocos; $n=$ nümero de espécies; $\sigma_{b}^{2}=$ variancia entre blocos; $v_{t}=$ variân cia entre especies; $\sigma^{2}=$ variancia do erro entre parcelas.

Ao nivel de progênies dentro de espécje, o modelo matemätico ficou da seguinte forma:

$$
\mathrm{Y}_{i j k}=m+b_{j}+p_{i}+e_{i j}+d_{i j k}
$$

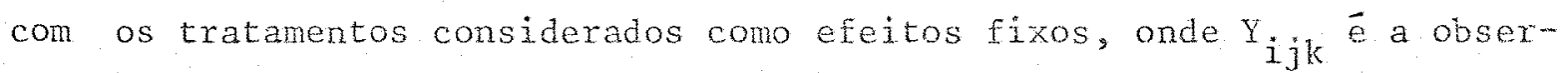
vação no individuo $k$, do tratamento is no bloco $c o ; p_{j} \vec{e}$ o efeito de txatamenco; $e_{i j} \bar{e}$ o efeito do erro experimental; $e$ $d_{i j k}$ é o efeito dentro de parcelas. 
o esquena dà anälise de variância, con dados de médias de parcelas, foi o seguinte:

\begin{tabular}{|c|c|c|c|c|}
\hline FV & GL & $Q M$ & $E(Q M)$ & $\mathrm{F}$ \\
\hline Blocos & $x-1$ & $\mathrm{Q}_{1}$ & $\frac{\sigma_{d}^{2}}{s}+\sigma_{e}^{2}+p \sigma_{b}^{2}$ & $Q_{1} / Q_{3}$ \\
\hline Progênies & $\mathrm{p}-1$ & $Q_{2}$ & $\frac{\sigma_{\mathrm{d}}^{2}}{\mathrm{~s}}+\sigma_{\mathrm{e}}^{2}+r v_{\mathrm{p}}$ & $Q_{2} / Q_{3}$ \\
\hline Erro & $(r-1)(p-1)$ & $\mathrm{Q}_{3}$ & $\frac{\sigma_{d}^{2}}{s}+\sigma_{e}^{2}$ & \\
\hline
\end{tabular}

$\mathrm{p}=$ nümero de progênies; $\mathrm{s}=$ nümero de plantas por parcela; $\sigma_{\mathrm{d}}^{2}=$ variância entre plantas dentro de parcelas; $\sigma_{b}^{2}=$ variancia entre blocos; $\quad v_{p}=$ variância entre progênies; $\sigma_{e}^{2}=$ variância do erro entre parcelas.

3.2.3.2. Anälise de variância conjunta para os três niveis de tecnologia

A anälise conjunta para os txês níveis de tecnologia, envolvendo cada una das caracteristicas estudadas, nas diferentes idades ao nivel de espêcies e ao nivel de progênies dentro de espécies, foi efetuada seguindo também o esquema para delineamento em blocos ao acaso, de acordo com PONSECA (1979), PTNTO JR. (1984) e IPEX (1986).

o modelo matenático para a anälise conjunca ao nível de espécies foi o seguinte: 


$$
\mathrm{Y}_{i j \ell}=\mathrm{m}+\mathrm{b}_{j(\ell)}+t_{i}+\mathrm{f}_{\ell}+(t f)_{i \ell}+\mathrm{e}_{i j \ell}
$$

com os tratamentos e niveis de tecnologia silvicultural considerados como efeitos fixos, onde $Y_{i j \ell}$ e a média do tratamento i no bloco j, no nivel de tecnologia $\ell ;$ m $\vec{E}$ a média geral; $b_{j(\ell)} \vec{e}$ o efeito do bloco dentro do nivel de tecnologia; $t_{i} \vec{e}$ o efeito de tratamento; $f_{\ell} \vec{e}$ ofeito do nivel de tecnologia; (tf) ${ }_{i \ell}$ e o efeito da interação de tratamentos $x$ nivel de tecnologia; e $e_{i j \ell} \vec{e}$ o efeito do erro experimental.

A estrutura de anälise de variancia conjunta ficou como segue:

\begin{tabular}{|c|c|c|c|c|}
\hline $\mathrm{FV}$ & $\mathrm{GI}_{2}$ & $\mathrm{QM}$ & $\mathrm{E}(\mathrm{QM})$ & $F$ \\
\hline Blocos/Niveis de tecnologia & $a(x-1)$ & $?_{1}$ & $\sigma^{2}+n \sigma_{b}^{2}$ & $\mathrm{O}_{1} / \mathrm{s}_{5}$ \\
\hline Niveis de tecnologia (NT) & $(a-1)$ & $\mathrm{Q}_{2}$ & $\sigma^{2}+n \sigma_{b}^{2}+m v_{f}$ & $Q_{2} / Q_{1}$ \\
\hline Espécies (E) & $(n-1)$ & $8_{3}$ & $\sigma^{2}+\operatorname{rav}_{t}$ & $Q_{3} / Q_{5}$ \\
\hline $\mathrm{E} \times \mathrm{NT}$ & $(a-1)(n-1)$ & $\Omega_{4}$ & $\sigma^{2}+r v_{t E}$ & $Q_{4} / Q_{5}$ \\
\hline Erro médio & $a(r-1)(n-1)$ & $Q_{5}$ & $\sigma^{2}$ & $Q_{5}$ \\
\hline
\end{tabular}

$a=$ numero de niveis de tecnologia; $\sigma_{b}^{2}=$ variancia entre blocos; $v_{t}=$ variância entre espécies; $V_{f}$ = variância entre niveis de tecnologia; $V_{t f}=$ = variância da interação de especies $x$ niveis de tecnologia; $\sigma^{2}=$ variancia do erco entre parcelas.

o modelo matemático assumido para a análise conjunta, ao nivel de progênies dencro de espëcies, foi o que se segue: 


$$
\mathrm{Y}_{i j \ell k}=\mathrm{m}+\mathrm{b}_{\mathrm{j} \ell} \ell+\mathrm{p}_{\mathrm{i}}+\mathrm{f}_{\ell}+(\underline{\mathrm{f}})_{i \ell}+\mathrm{e}_{i j \ell}+\mathrm{a}_{i j \ell k}
$$

com os tratamentos e niveis de tecnologia considerados como efeitos fixos, onde $Y_{i j \ell k} \vec{e}$ a observação no individuo $k$, no tratamento i, no bloco $j$, no nível de tecnologia $\ell ; m$ è a média geral; $b_{j}(\ell)$ é o efeito do bloco dentro do nível de tecnologia; $p_{i}$ e o efeito de tratamento; $f_{\ell}$ é o efeito do nîvel de tecnologia; (pf) il e o efeito da interação de tratamencos x ni veis de tecnologia; $e_{i j \ell}$ èo efeito do exro experimental; e $d_{i j l k}$ e o efeito dentro de parcelas.

o esquema de anālise de variância, neste caso, fica:

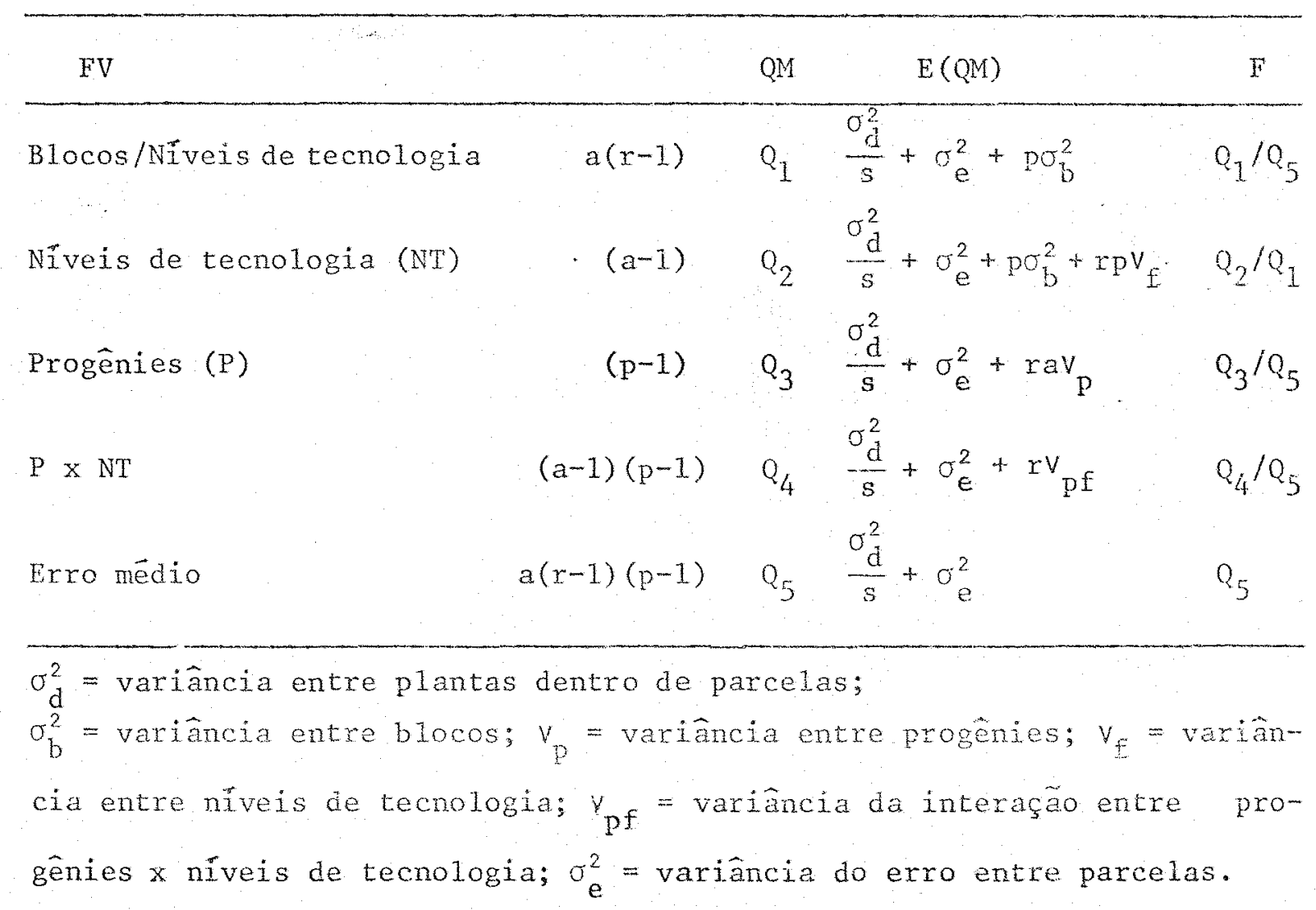


4. RESULTADOS E DISCUSSÃO

4.1. Comportamento das Espëcies nos Diferentes Niveis de Tecnologia Silvicu1tura1

4.1.1. Avaliação das espëcies aos 7 meses de idade

os resultados de crescimento inicial em altura e a porcen-tagem de falhas para as três espëcies nos diferentes niveis de tecnologia de implantação florestal são representados na Tabela 1.

Em geral, a altura mëdia de plantas aumentou do nĩvel de tecnologia I $(0,96 \mathrm{~m})$ para o nível de tecnologia II $(1,60 \mathrm{~m})$ e não se alte-rou deste para o nível de tecnologia III $(1,59 \mathrm{~m})$. Os ültimos dois níveis de tecnologia apresentaram valores semelhantes e foram, em média, $\quad 66,14 \%$ superiores ao nivel de tecnologia I. 
Tabela 1. Crescimento em altura de plantas e porcentagem de falhas de Eucalyptue nos três nưveis de tecnologia de implantação florestal, aos 7 meses de idade

\begin{tabular}{|c|c|c|c|c|c|c|}
\hline \multirow{3}{*}{ Espécies } & \multicolumn{3}{|c|}{ Altura (m) } & \multicolumn{3}{|c|}{ Falhas (\%) } \\
\hline & \multicolumn{6}{|c|}{ Niveis de tecnologia } \\
\hline & NTI & NIII & NSIII & NTT & NTII & NTIII \\
\hline E. grandis & 0,77 & 1,67 & 1,69 & 21,97 & 5,12 & 15,07 \\
\hline E. camalduzensis & 1,11 & 1,80 & 1,87 & 3,95 & 0,40 & 0,35 \\
\hline E. citriodora & 0,99 & 1,34 & 1,22 & 10,62 & 0,33 & 6,96 \\
\hline Mêdia & 0,96 & 1,60 & 1,59 & 12,18 & 1,25 & 7,46 \\
\hline
\end{tabular}

NTI: sem preparo do solo e sem adubação mineral;

NTII: preparo do solo sem adubação mineral;

NTIII: preparo do solo e adubação mineral. 
Como se pode perceber, o crescimento de plantas nas parcelas que receberam somente o preparo do solo (NTIX) ou preparo do solo e fertilização mineral (NTIII) foi expressivo en relação a testemunha (NTI), nesta idade inicial.

Ao nivel de espécies, o E. grandis e o E. canaldulensis tiveram a mesma tendência, de aumento de altura de plantas com a elevação do nivel de tecnologia. Esse aumento foi mais expressivo quando se passou do primeiro para o segundo nivel de tecnologia. Para o E. citriodora a altura de plantas aumentou somente do nível de tecnologia I $(0,99 \mathrm{~m})$ para 0 nüvel de tecnologia II $(1,34 \mathrm{~m})$ e sofreu un decxéscimo no nivel de tecnolo gia $\operatorname{III}(1,22 \mathrm{~m})$.

- E. comaldulensis apresentou o melhor crescinento em todos os niveis de tecnologia; o Ero grandis foi a seguna melhor especie nos niveis de tecnologia II e III e a pior especie no nivel de tecnologia I. O E. citriodora, por sua vez, foi intermediáxio no primeiro nivel de tecnologia e a pior espécie nos restantes dois niveis de tecnologia.

A porcentagem de falhas foi maior no nivel de tecnologia I do que nos niveis de tecnologia II e III. A reduçáo na mortalidade de plantas foi acentuada no nivel de tecnologia II. Idêntica tendêncía obser vou-se ao nível de espëcies, sendo que, no conjunto dos três nĩveis de tec nologia, of. grandis apresentou a mator porcentagem de falhas (14,05\%), vindo a seguir o E. citmiodora $(5,97 \%)$ e por ultimo o E. camatautensis $(1,56 \%)$

Os resultados das anelises de variancia individuais e conjunta para os três niveis de tecrologia são apresentados na Tabela 2. 
Tabela 2. Resultados das anälises de variância individuais e conjuntas pa ra altura de plantas e porcentagem de falhas de Eucalyptus nos três niveis de tecnologia (NT), aos 7 meses de idade

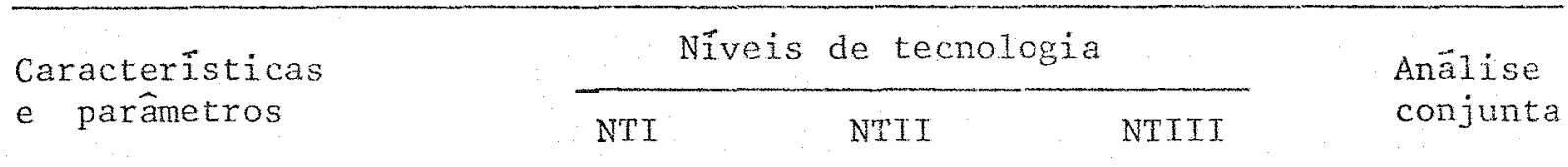

Altura $(\mathrm{m})$

Media geral

$\mathrm{F}(\mathrm{E})$

$\mathrm{F}(\mathrm{NT})$

$F(E \times N T)$

CV experimental (\%)

\begin{abstract}
0,96
\end{abstract}
(1) $2,27^{\mathrm{ns}}$

(2) -

(3) -

(4) 20,70

$$
1,60
$$

$5,30^{\text {ns }}$

$-$

-

11,09

1,59

1,38

$14,35 * \%$

$37,12 * *$

$3,99 \%$

11,72

\section{Falhas (\%)}

Media geral

$\mathrm{F}(\mathrm{E})$

$\mathrm{E}(\mathrm{NT})$

$\mathrm{E}(\mathrm{E} \times \mathrm{NT})$

CV experimenta1 (\%)

\begin{abstract}
12,18
\end{abstract}
$86,39 * *$

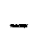

$-$

1,36
1,95

$0,98^{\mathrm{ns}}$

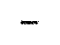

$-$

4,46
7,46

7,19

$14,47 * *$

$9,90 *$

$1,44 \mathrm{~ns}$

-

4,22

NXI: sem preparo do solo e sem adubação mineral;

NTII: preparo do solo sem adubação minexa1;

NTIII: preparo do solo e adubação mineral;

(1), (2) e (3): teste $F$ para as espëcies, niveis de tecnologia e interaçäo de especies $x$ niveis de tecnologia;

(4): coeficiente de variação experimental em porcentagem;

ns: não significativo;

$*$ : significativo ao nivel de $5 \%$;

** : significativo ao nivel de $1 \%$. 
Nas anālises de variância individuais, para os dados de altura de plantas, observa-se um increnento do valor de F para as espëcies com o aumento do nível de tecnologia, sendo o mesmo significativo somente no nível de tecnologia III. Por outro 1ado, o coeficiente de variação experimental apresentou una tendência inversa, diminuindo do nivel de tecnologia I para o nível de tecnologia IIT. A não detecçäo de variações genëticas entre as espécies, nos nivveis de tecnologia I e II, talvez se deva ao maior coeficiente de variação experimental. Isso pode ser constatado observando-se as diferenças entre as mëdias de espēcies, que são de magnitudes semelhantes nos três niveis de tecnologia.

Para a porcentagem de falhas, o vaíor de $\mathrm{F}$ para espécies - coeficiente de variação experimental, para cada nivel de tecnologia, tiveram um comportamento diferente. O valox de F foi alto e significativo a 1\% para o nivel de tecnologia I, diminuiu com o aumento do nível de tecnologia e não se revelou significativo nos niveis de tecnologia Il e. III. A alta significância do teste $F$ no nivel de tecnologia I pode ser atribuäda à elevada mortalidade de plantas verificada no E. grandis. Esta espécie se revelou mais sensivel às condiçöes adversas do que o. E. camaldulensis e o E. citriodora, o que ë confirmado por PIRES et alii (1980) e KAGEYAMA et $a$ li $(1987)$.

Os coeficientes de variaçäo experimentais para a poxcentagem de falhas foram, em geral, nais baixos do que os obtidos para altura de plantas e aumentaram com o nivel de tecnologia.

Na anáije conjunta para os três niveis de tecnologia, as espëcies apresentaram para altura de plantas e porcentagen de falhas 
variaçöes genëticas significativas, de acoxdo com os valores de $F$ obtidos. Os efeitos dos níveis de tecnologia foram tambèm significativos para as duas caracteristicas.

o valor de $F$ da interação de espécies $x$ nîveis de tecnologia mostrou-se significativo somente para altura de plantas, ao nível de $5 \%$, indicando que as espëcies reagiram diferentemente à mudança do nivel de tecnologia de implantação florestal. A ilustração da interação de espécies $x$ nîveis de tecnologia pode ser visualizada na Figura 1.

Enquanto que o E. grandis teve um acrēscimo em altura de $116,88 \%$, quando passou do nivel de tecnologia I para o nivel de tecnologia II, o E. citriodora teve somente un increnento de $35,35 \%$; $\circ$. comatarZensis foi intermediärio às duas espécies.

Os coeficientes de variação experimental para as anälises conjuntas foram intermediärios aos das anälises individuais, sendo maior - coeficiente de variação experimental para a altura de plantas e menor pa ra a porcentagem de falhas. 


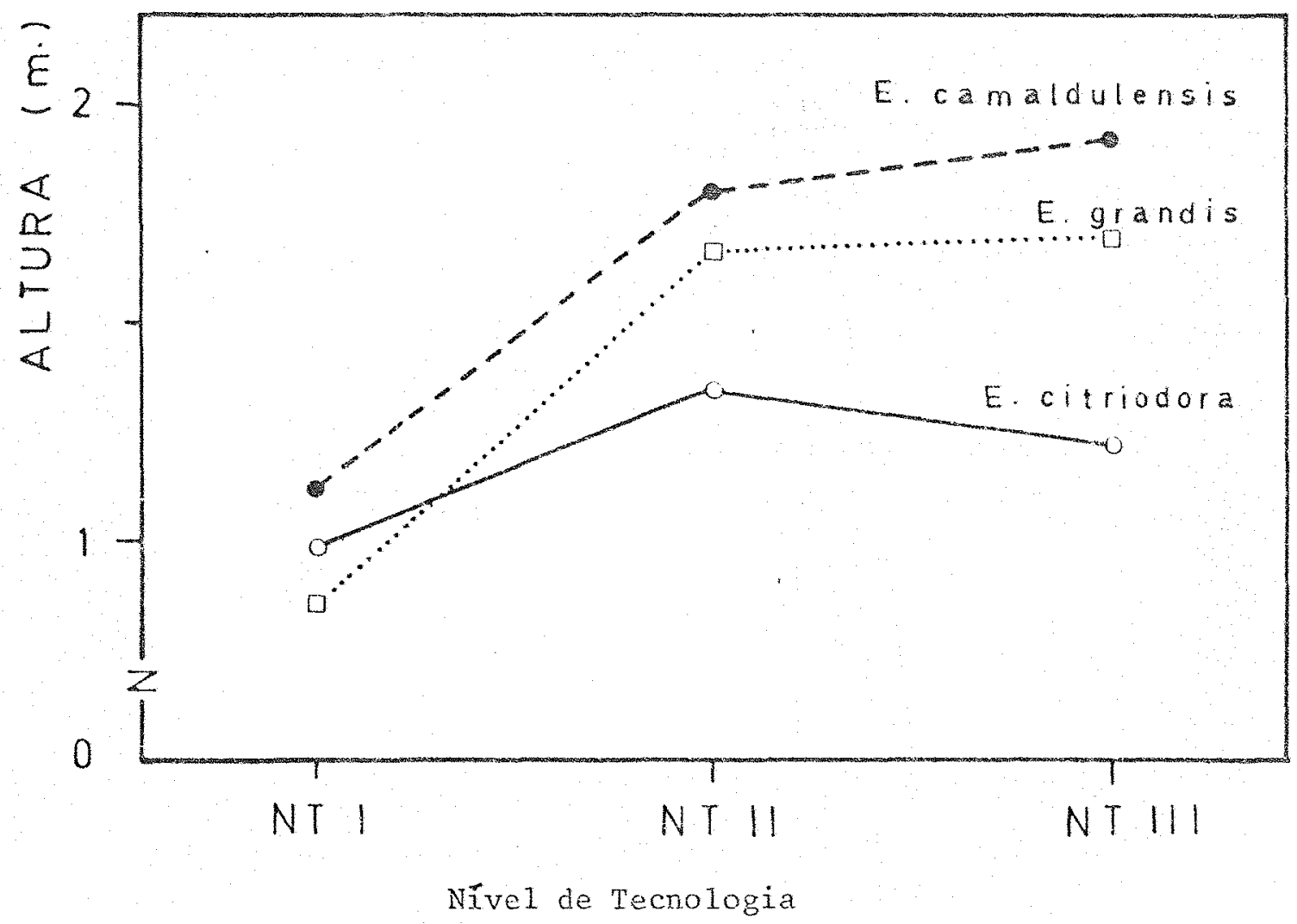

Figura 1. Altura média de plantas de Eucalyptus em três niveís de tecnologia (NT) de implantação florestal, aos 7 meses de idade 


\subsubsection{Ava1iação das espécies aos 12 meses de idade}

Os resultados de crescimento em altura e porcentagem de faThas para as três espécies nos diferentes níveis de tecnologia de implantação florestal são apresentados na Tabela 3.

Os dados de altura de plantas e porcentagem de falhas, para os diferentes niveis de tecnologia, seguiram a mesma tendência verificada aos 7 meses de idade, com o aumento das diferenças entre os niveis de tecnologia. Assim, para altura de plantas, o nivel de tecnologia III foi 4,82\% superior ao nível de tecnologia II, que por sua vez foi $92,26 \%$ superior ao nível de tecnologia $I$.

Esse comportamento geral observa-se tambër ao nivel de espécies. As três espécies tiveran o maior crescimento en altura no nĩvel de tecnologia III e o menor crescimento no njvel de tecnologia $I . \quad 0 \quad E$. grandis e o E. citriodora foran, respectivamente, a melhor e a pior espécie nos niveis de tecnologia II e III. O E. camalduzensis foi semelhante ao E. citriodora no nivel de tecnologia I e ambas superaram $o \quad E$. grandis no nivel de tecnologia I. Comparativamente à primeira avaliação, e pelos valores de $F$ obtidos das anälises de variancia individuais para cada nível de tecnologia, as variações entre as espécies aumentaram nos nîveis de tecnologia II e III e diminuíram no nível de tecnologia I.

A porcentagem de falhas aumentou em todos os níveis de tecnologia e espécies. O acréscimo na porcentagem de falhas foi na seguinte ordem decrescente: nível de tecnologia I $(3,66 \%)$, nível de tecnologia III $(1,22 \%)$, e nïvel de tecnologia II $(1,12 \%)$. Ao nîvel de espëcjes. o aumento 
Tabela 3. Crescimento em altura de plantas e porcentagem de falhas de Eucalyptus nos três niveis de tecnologia (NT) ảe implantação floresta1, aos 12 meses de idade

\begin{tabular}{|c|c|c|c|c|c|c|}
\hline \multirow{3}{*}{ Espëcies } & \multicolumn{3}{|c|}{ Altura $(m)$} & \multicolumn{3}{|c|}{ Falhas (\%) } \\
\hline & \multirow[b]{2}{*}{ NTI } & \multirow{2}{*}{\multicolumn{2}{|c|}{ Niveis de }} & \multicolumn{2}{|c|}{ Ecnologia } & \multirow{2}{*}{ NTIII } \\
\hline & & & & NTI & NTII & \\
\hline E. grandis & 1,65 & 4,60 & 4,77 & 28,65 & 8,44 & 17,84 \\
\hline E. camatdutensis & 2,08 & 3,71 & 4,06 & 5,57 & 0,45 & 0,58 \\
\hline E. citriodora & 2,09 & 2,88 & 2,91 & 13,30 & 0,33 & 7,62 \\
\hline Média & 1,94 & 3,73 & 3,91 & 15,84 & 3,07 & 8,68 \\
\hline
\end{tabular}

NTI: sem preparo do solo e sem adubação mineral;

NTII: preparo do solo sem adubação mineral;

NTIII: preparo do solo e adubação mineral. 
na mortalidade de plantas foi maior para o E. grondis $(4,26 \%)$, vindo a seguir o E. citriodora $(1,11 \%)$ e por ultimo o E. camalatzensis $(0,64 \%)$. Os resultados das anälises de variância individuais e conjuntas para os três nîveis de tecnologia são apresentados na Tabela 4 . Esses resultados são tambèm, em geral, similares aos obtidos aos 7 meses de idade.

Os valores de $\mathrm{F}$ e os coeficientes de variação experimental das anälises de variância individuais e conjunta para altura de plantas e porcentagem de falhas, apresentaram a mesma tendência observada aos 7 me-ses de idade.

Nos níveis de tecnologia I e II foram detectadas variações genéticas significativas entre as espëcies somente para a porcentagem de falhas e altura de plantas, respectivamente. No nivel de tecnoiogia III for am constatadas variações genéticas entre as espécies para as duas caracteristicas. Os coeficientes de variação experimentais para altura. foram maiores do que para a porcentagem de falhas em todas as anälises de variância e seguiram a mesma tendência observada aos 7 meses de idade ou de sua diminuição com a elevação do nível de tecnologia.

Aparentemente, para altura de plantas, os niveis de tecnologia determinaram coeficientes de variação experimentais diferentes, o que sugere a necessidade de se utilizar tamanhos de parcelas ou número de repetições diferentes, para se atingir a mesma precisão estatistica.

$\mathrm{Na}$ anälise conjunta para os três níveis de tecnologia, os valores de $\mathrm{F}$ para espēcies e niveis de tecnologia continuaram altamente 
Tabela 4. Resultados das anälises de variância individuais e conjuntas pa ra altuxa de plantas e porcentagem de falhas de Eucalyptus nos três niveis de tecnologia (NT) de implantação florestal, aos 12 meses de idade

\begin{tabular}{llll}
\hline $\begin{array}{l}\text { Características } \\
\text { e parâmetros }\end{array}$ & \multicolumn{2}{c}{ Níveis de tecnologia } & $\begin{array}{l}\text { Anälise } \\
\text { conjunta }\end{array}$ \\
\cline { 2 - 4 } & NTI NTI NTII & NII & NTI \\
\hline
\end{tabular}

Altura (m)

Média geral

$F(E)$

$\mathrm{F}(\mathrm{NT})$

$\mathrm{F}(\mathrm{F} \times \mathrm{NT})$

$\mathrm{CV}$ experimental
1,94

(1) $\quad 0,53^{\mathrm{ns}}$

(2)

(3)

(\%)

(4) 30,42

\section{3,73}

3,91

3,19

$7,81 * \quad 40,83 * *$

$10,87 * *$

$42,70 * \%$

$5,43 *$

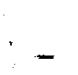

14,30
$-$

6,50

Falhas (\%)

Média geral

$\mathrm{F}(\mathrm{E})$

$F(N T)$

$\mathrm{F}(\mathrm{F} \times \mathrm{NT})$

CV experimental (\%)
15,84

$21,10 * *$

3,07

8,68

$7,75 \%$

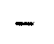

-

3,33 $2,45^{\text {ns }}$

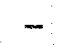

$-$

4,67
9,19

$23,39 \%$

$20,87 \% *$

$1,66^{\text {ns }}$

4,16

NTI: sem preparo do solo e sem adubação mineral;

NTII: preparo do solo sem adubação mineral;

NTIII: preparo do solo e adubação mineral;

(1), (2) e (3): teste $F$ para as espécies, nỉveis de tecnologia e interação de espëcies $x$ niveis de tecnologia;

(4): coeficiente de vaxiação experimental en porcentagem;

ns: não significativo;

* : significativo ao nivel de $5 \%$;

$* *$ : significativo ao nível de $1 \%$. 
significativos para altura de plantas, com diminuição do primeiro valor de F e aumento do segundo, relativamente aos valores obtidos aos 7 meses. Isso se deve, possivelmente, à diminuição das variações entre as espécies no nível de tecnologia $I$, e ao aumento das diferenças entre os níveis de tecnologia, conforme indicam os dados da tabela 3 .

0 efeito da interação de espêcies $x$ niveis de tecnologia foi altanente significativo para altura de plantas, reforçando as observações feitas aos 7 meses de idade. Como nostra a Figura 2, houve uma res posta diferencial das espëcies aos nïveis de tecnologia testados. Os incrementos em altura nos níveis de tecnologia II e III, em relação ao nível de tecnologia I, foram, respectivamente, de $178,78 \%$ e $189,09 \%$ para o E. grandis, $78,36 \%$ e $95,19 \%$ para o E. camatdulensis, e de somente $37,79 \%$ e $39,23 \%$ para o E. citriodora.

A maior resposta do $E$. grandis à melhoria da tecnologia si1 vicultural, em relação a outras espécies florestais, foi observada também por LADRACH (1983b) e ICFR (1985), dentre outros. Segundo KREJCI et alii (1986), essa maior resposta à tecnologia silvicultural se deve, aparentemente, ao grande volume de sistema radicular łateral, que permitiria à espécie o melhor aproveitamento do preparo do solo e da adubação mineral no plantio.

Para a porcentagem de falhas, os valores de $F$ para espëcies e nỉvel de tecnologia, na análise conjunta para os três niveis de tecnologia, continuaram altamente significativos. O valor de $\mathrm{F}$ para a interação, embora tenha aumentado em valor, ainda não foi significativo. 


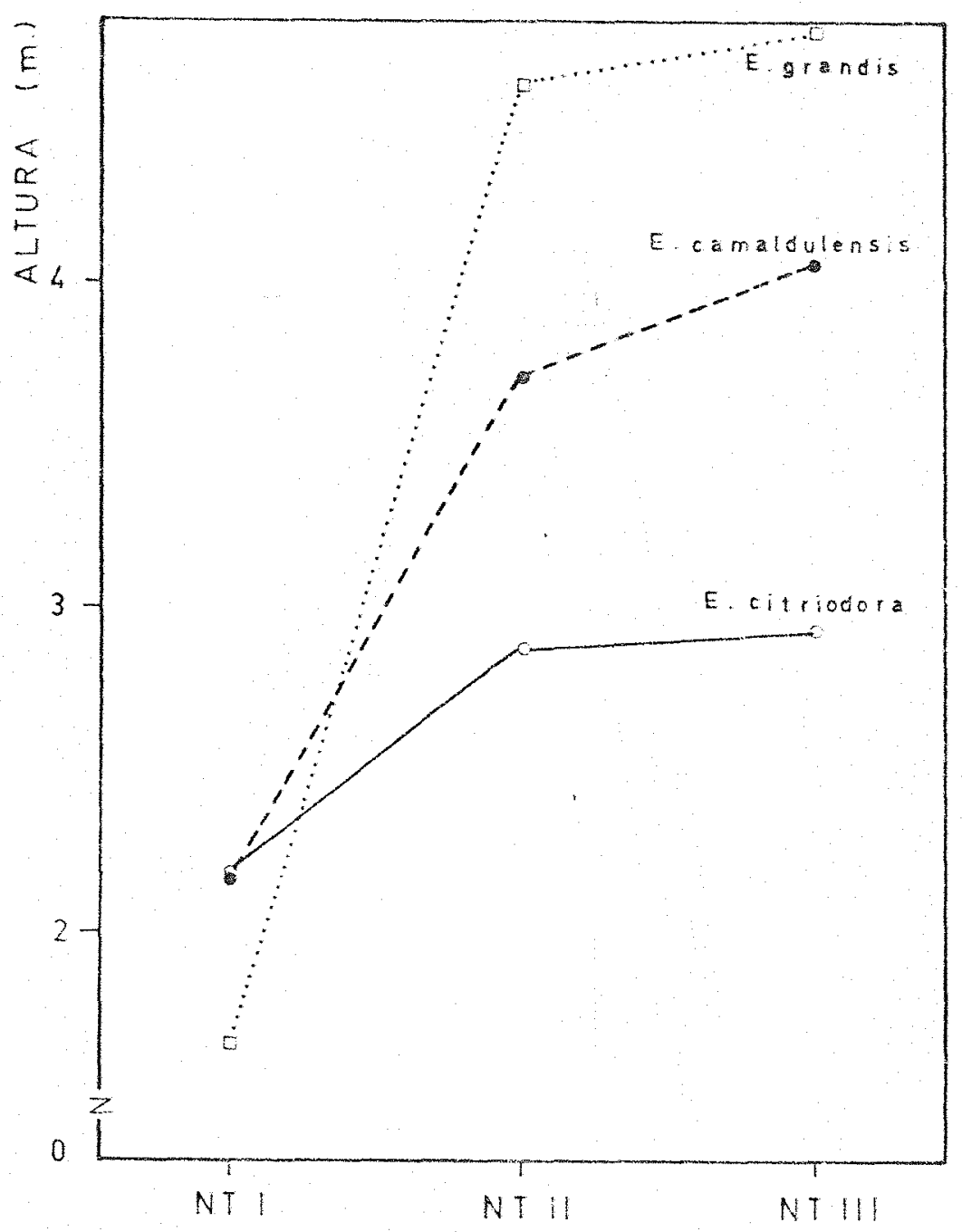

Níveis de Tecnologia

Figura 2. Altura mëdia de plantas de Eucalyptus en três níveis de tecnologia de implantação florestal, aos 12 meses de idade 


\subsubsection{Avaliação das espécies aos 18 meses de idade}

os resultados de crescimento em altura, DAP, volume cilindrico e porcentagem de falhas das três espécies, nos três níveis de tecnologia de implantação florestal, são apresentados ria Tabela 5.

Os dados de crescimento em altura de plantas aos 18 moses de idade confirmam as tendencias observadas durante o primeiro ano de cres cimento, para os diferentes níveis de tecnologia e espécies.

A esta idade, para altura de plantas, o nivel de tecnologia III foi 5,63\% superior ao nível de tecnologia II, que por sua vez foi $58,95 \%$ superior ao nivel de tecnologia $I$. Verificou-se, portanto, um 1igeiro aumento na diferença entre o nivel de tecnologia III e II, e a diminuição das diferenças entre o nivel de tecnologia $I$ e os outros dois niveis de tecnologia. As espëcies mantiveram as suas posições relativas em cada nîvel de tecnologia, sendo que as variaçöes entre elas aumentaram no nivel de tecnologia II, e diminuiram nos niveis de tecnologia I e III.

Os dados de DAP e volume cilindrico tiveram, em geral, o mesmo comportamento verificado para altura de plantas. Contudo, no nivel de tencologia I, o E. grandis foi superior ao E. citriodora em DAP. A porcentagem de falhas aumentou ligeiramente nos diferentes níveis de tecnologia e espécies.

Os resultados das anālises de variância individuais e conjuntas, para os três niveis de tecnologia, envolvendo altura de plantas, DAP, volume cilindrico e porcentagem de falhas, são apresentados na Tabe1 a 6. 


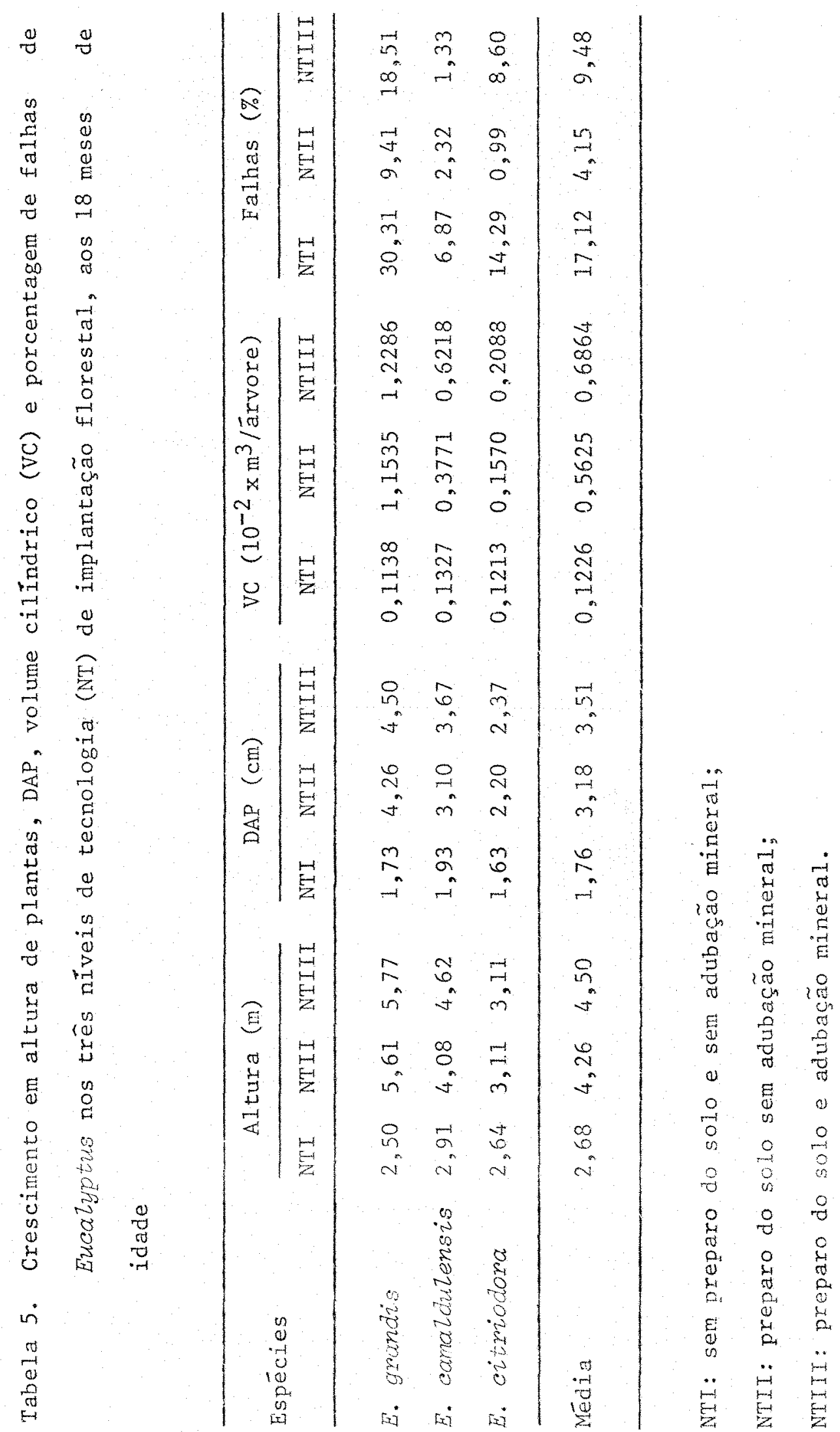


Tabela 6. Resultados das anälises de variância individuais e conjuntas pa ra altura de plantas, DAP, volume cilíndrico (VC) e porcentagen de falhas de Eucalyptus em três niveis de tecnologia (NT) de implantação florestal, aos 18 meses de idade

Características

e parâmetros
Niveis de tecnologia

NTI NTII NTIII

Anälise

conjunta

Altura (m)

Media geral

$F(E)$

$\mathrm{F}(\mathrm{NT})$

$F(E \times N T)$

CV experimental

(\%)

$\begin{array}{lcccc} & 2,68 & 4,26 & 4,50 & 3,81 \\ \text { (1) } & 0,27 \mathrm{~ns} & 8,70 * & 39,20 * * & 16,63 * * \\ \text { (2) } & - & - & - & 19,53 \% \\ \text { (3) } & - & - & - & 5,15 \% \\ \text { (4) } & 25,30 & 17,35 & 8,20 & 16,13\end{array}$

DAP (cm)

Média geral

$\mathrm{F}(\mathrm{E})$

$\mathrm{F}(\mathrm{NT})$

$F(E \times N T)$

$C V$ experimental

(\%)

1,76

$0,14 \mathrm{~ns}$

3,18

$7,39 *$

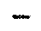

$-$

40,02

20,71

3,51

2,82

$12,72 \% *$

$18,37 \approx x$

$2,86 \mathrm{~ns}$

21,48

VC $\left(10^{-2} \mathrm{x} \mathrm{m}^{3} /\right.$ árvore $)$

Mêdia geral

$F(E)$

$\mathrm{F}(\mathrm{N} I)$

$\mathrm{F}(\mathrm{E} \times \mathrm{NT})$

CV experimental (\%)

0,12

$0,02^{\text {ns }}$

-

$-$

90,13

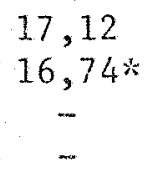

(\%)
0,56

$4,48 \mathrm{~ns}$

0,58

$18,67 * *$

0,65

$13,27 * *$

$8,89 \%$

$-$

76,08

-

29,95

$3,53 x$

61,58

Falhas (\%)

Média geral

$\mathrm{F}(\mathrm{E})$

$\mathrm{F}$ (NT)

$\mathrm{F}(\mathrm{E} \times \mathrm{NT})$

$\mathrm{CV}$ experimental

$\begin{array}{ccccc} & 17,12 & 4,15 & 9,48 & 10,25 \\ & 16,74 * & 2,55^{\text {ns }} & 7,43 * & 21,79 * * \\ & - & - & - & 17,07 * * \\ & - & - & - & 1,79 \text { ns } \\ & 3,74 & 4,33 & 4,60 & 4,22\end{array}$

NTI: sem preparo do solo e sen adubação mineral;

NTII: preparo do solo sem abbacho mineral;

NTIII: preparo do solo e ambecáo mineral;

(1), (2) e (3): teste $F$ para as espécies, niveis de tecnologia e interaçäo de espécies $x$ nuveis de tecnologia;

(4): coeficiente de variação experimental em porcentagem;

ns: não significativo;

* : significativo ao nivel de $5 \%$;

** : significativo ao nivel de $1 \%$ 
Os valores de $F$ e os coeficientes de variação para as caracteristicas de crescimento (altura, DAP e volume cilindrico) seguiram a mesma tendência observada para a altura de plantas nas duas avaliações ini ciais. No nível de tecnologia I, foram detectadas vaxiações genëticas significativas entre as espécies somente para a porcentagem de falhas, sem guindo a tendência verificada durante os primeiras 12 meses. Foram constatadas variações genéticas significativas para as quatro características e apenas para altura de plantas e DAP, respectivamente, nos nïveis de tecnologia III e II. A não deteç̧ão de variações genēticas entre as espécies, para o volume cilindrico no nivel de tecnologia II se deve, provavelmente, ao elevado coeficiente de variação experimental obtido nesse nivel de tecnologia. Comparando-se os coeficientes de variação experimental das características de crescimento, verifica-se que foram maiores para o volume cilíndrico, menores para altura de plantas e intermedias para o DAP. Esse comportamento geral e coerente com as observações de KAGEYAMA (1980) sobre as tendências dos erros experimentais para essas caracteristicas.

Na análise conjunta para os três niveis de tecnologia, os valores de $F$ para as espécies e niveis de tecnologia mostraram-se significativos para todas as caracteristicas. A interação de espëcies $x$ nĩveis de tecnologia foi significativa para duas características: altura de plantas e volume cilindrico.

As Figuras 3, 4 e 5 ilustram o crescimento em altura, DAP e volume cilïndrico das três espëcies, nos três niveis de tecnologia. Assim como nas idades iniciais, a maior resposta à elevação do nível de tecnologia foi observada em E. grandis a a menor resposta foi em $E$. citriodora. 


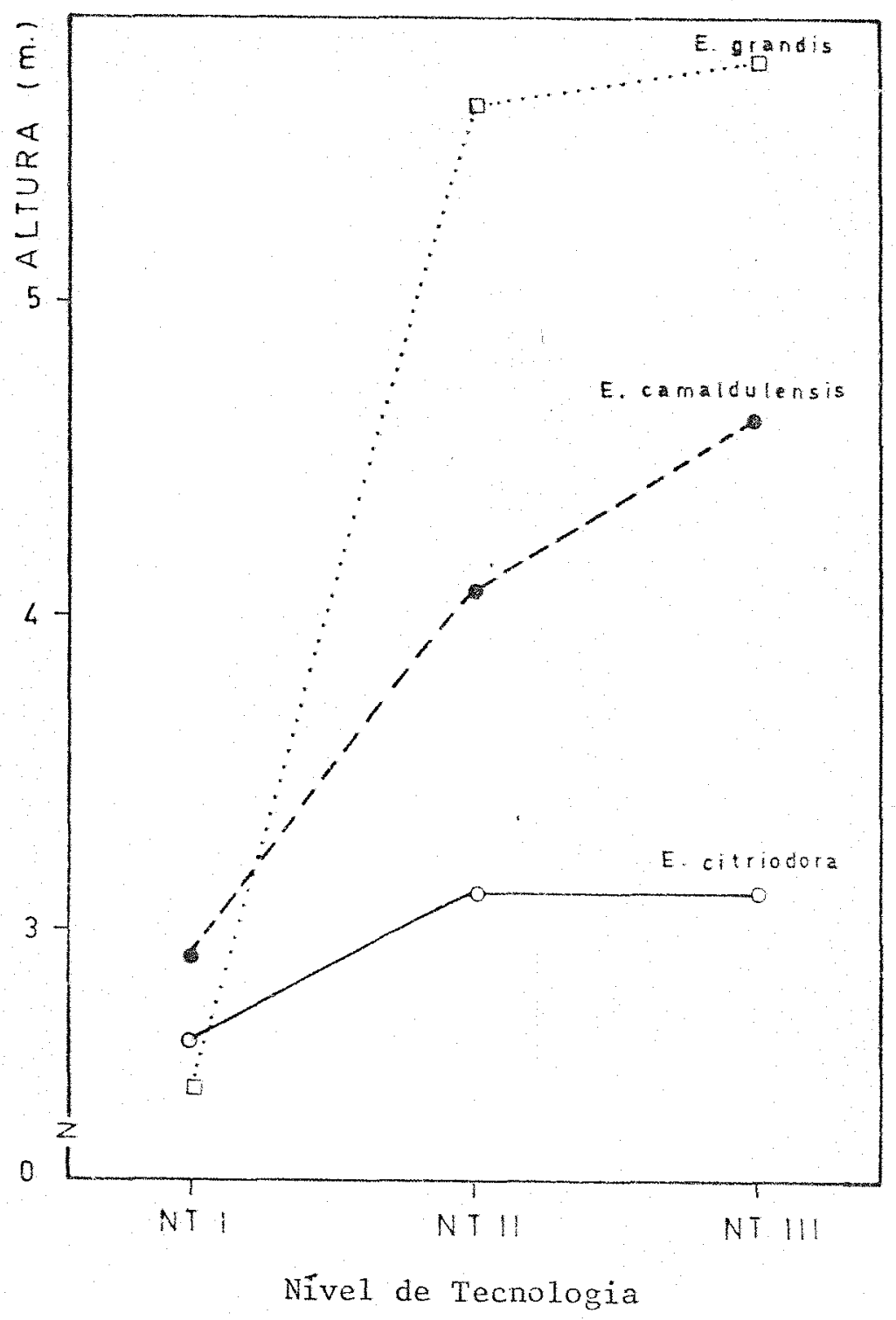

Figura 3. Altura média de plantas de Euoaluptus em três niveis de tecnom logia (NT) de implantação florestal, aos 18 meses de idade 


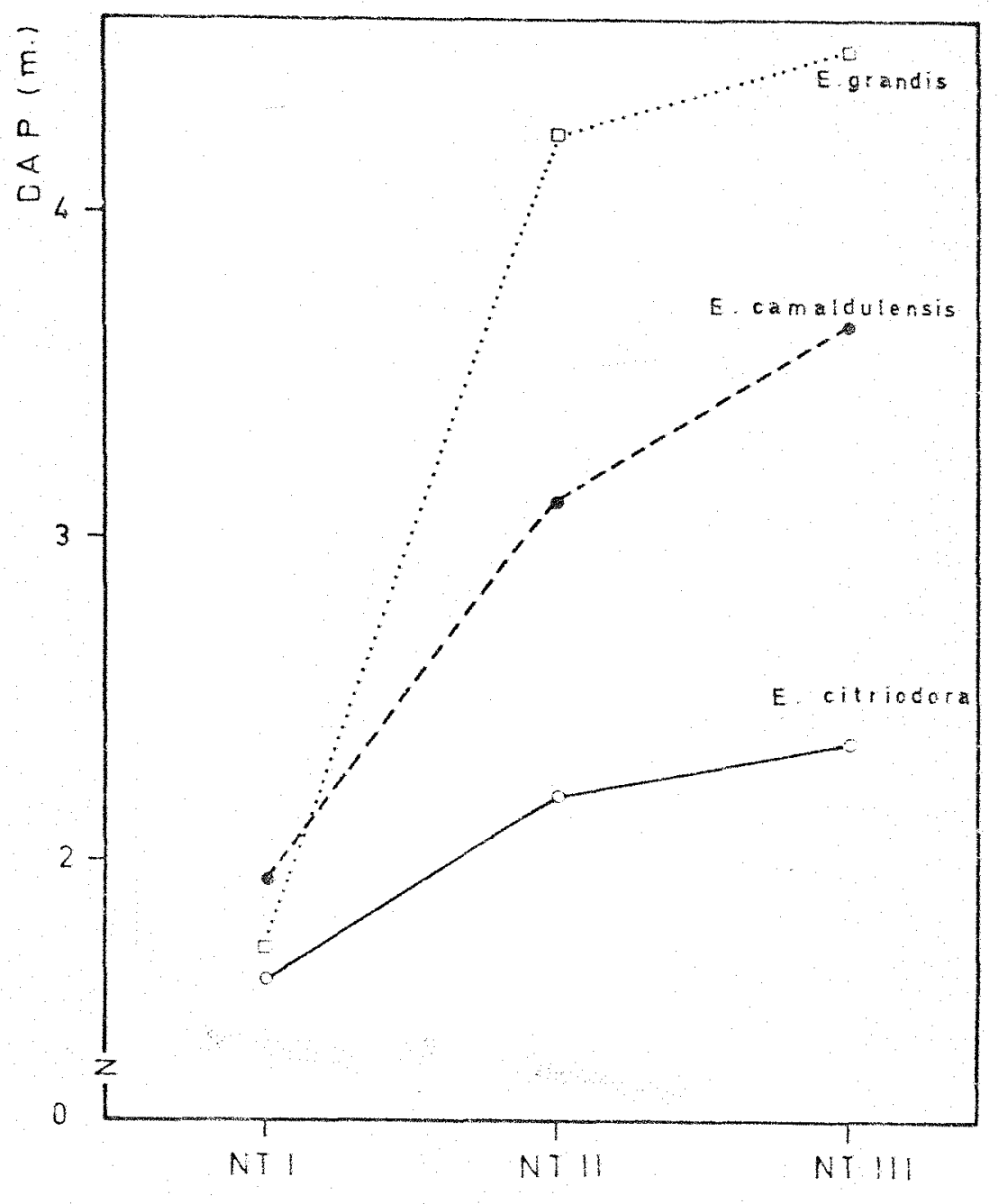

Nível de Tecnologia

Figura 4. Dianetro à altura de peito (DAP) de plantas de Eucalyptus, em três niveis de tecnologia (NT) de implantação florestal, aos 18 meses de idade 


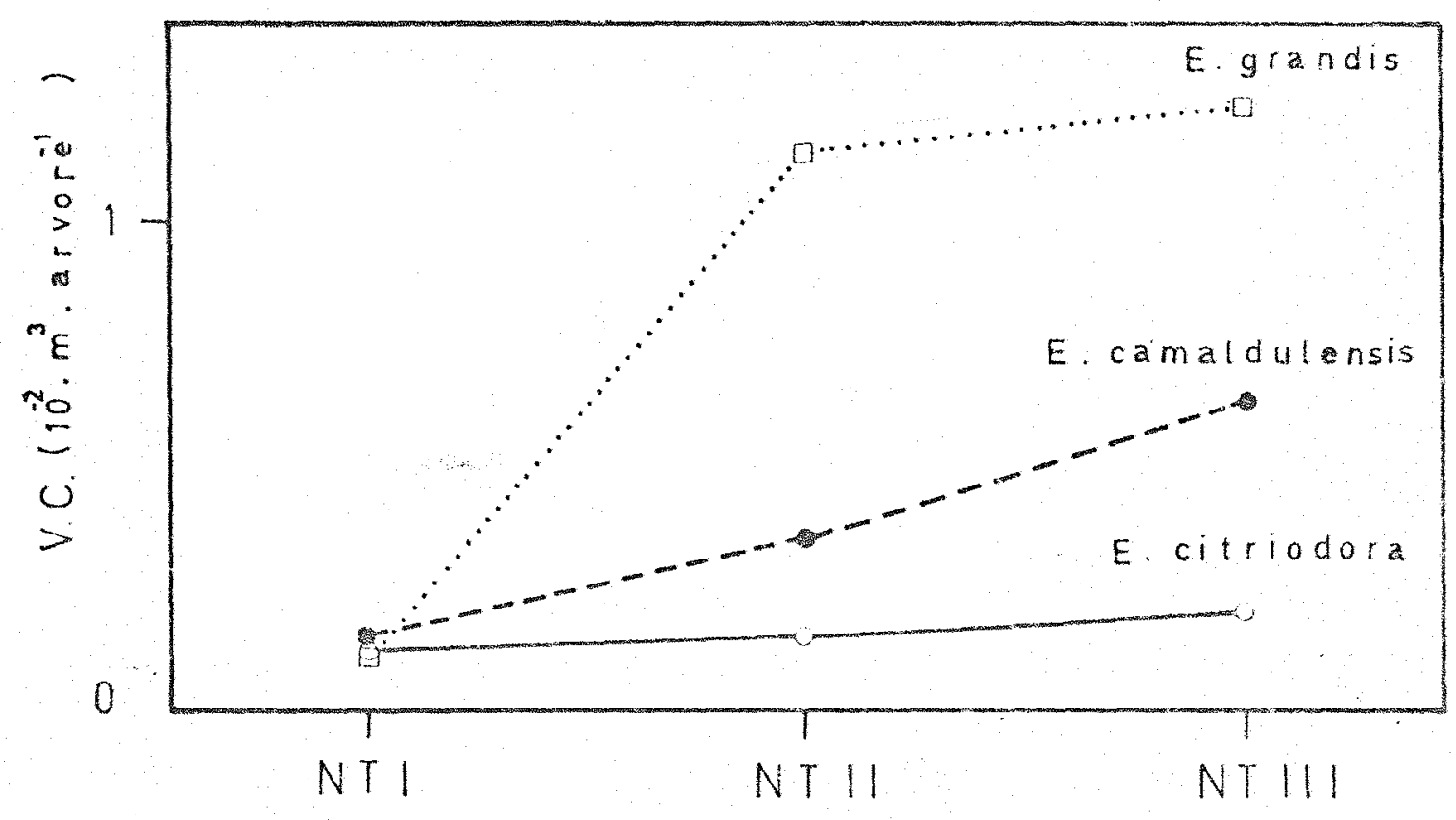

Nivel de Tecnologia

Figura 5. Volume cilindrico (vC) de plantas de Eucalyptus em três niveis de tecnologia (NT) de implantação florestal, aos 18 meses de idade 
4.1.4. Avaliação das espécies aos 24 meses de idade

Os resultados aos 24 meses de idade de crescimento em altura de plantas, DAP, volune cilindrico e porcentagem de falhas, das três espécies nos três nỉveis de tecnologia, säo apresentados na Tabela 7.

Os dados de crescimento em altura confirman as tendencias constatadas nas avaliações anteriores, mostrando que o efeito do nível de tecnologia ainda continua prevalecendo aos 24 meses de idade. O nivel de tecnologia III superou em $7,28 \%$ o nivel de tecnologia II que, por sua vez, superou em $37,85 \%$ o nivel de tecnologia $I$. Observa-se, ainda, a tendência para a diminuição das diferenças entre o mível de tecnologia $I$ e os demais, e o aumento da diferença entre o nível de tecnologia III e II, como foi constatado aos 18 meses de idade.

As posições relativas das espécies nos níveis de tecnologia III e II não sofreram nenhuma alteraçăo. No nivel de tecnologia I, o E. grandis foi intermediärio ao $E$. camaldulensis e o E. citriodora. Considerando-se os valores médios das duas ültimas avaliações, as variações entre as espécies diminuiram notavelmente nos níveis de tecnologia I e III, aos 24 meses.

0 incremento em altura de plantas durante o segundo ano de crescimento variou em função do nỉvel de tecnologia e espécie. O maior incremento foi obtido no nivel de tecnologia I $(120,61 \%$ ), vindo a seguir o nỉvel de tecnologia III $(61,89 \%)$ e por ültimo o nivel de tecnologia II $(58,17 \%)$. Ao nivel de espécies o maior incremento em altura verificou-se para o $E$. grandis $(165,45 \%)$ no nive1 de tecnologia $I$; o menor incremento 


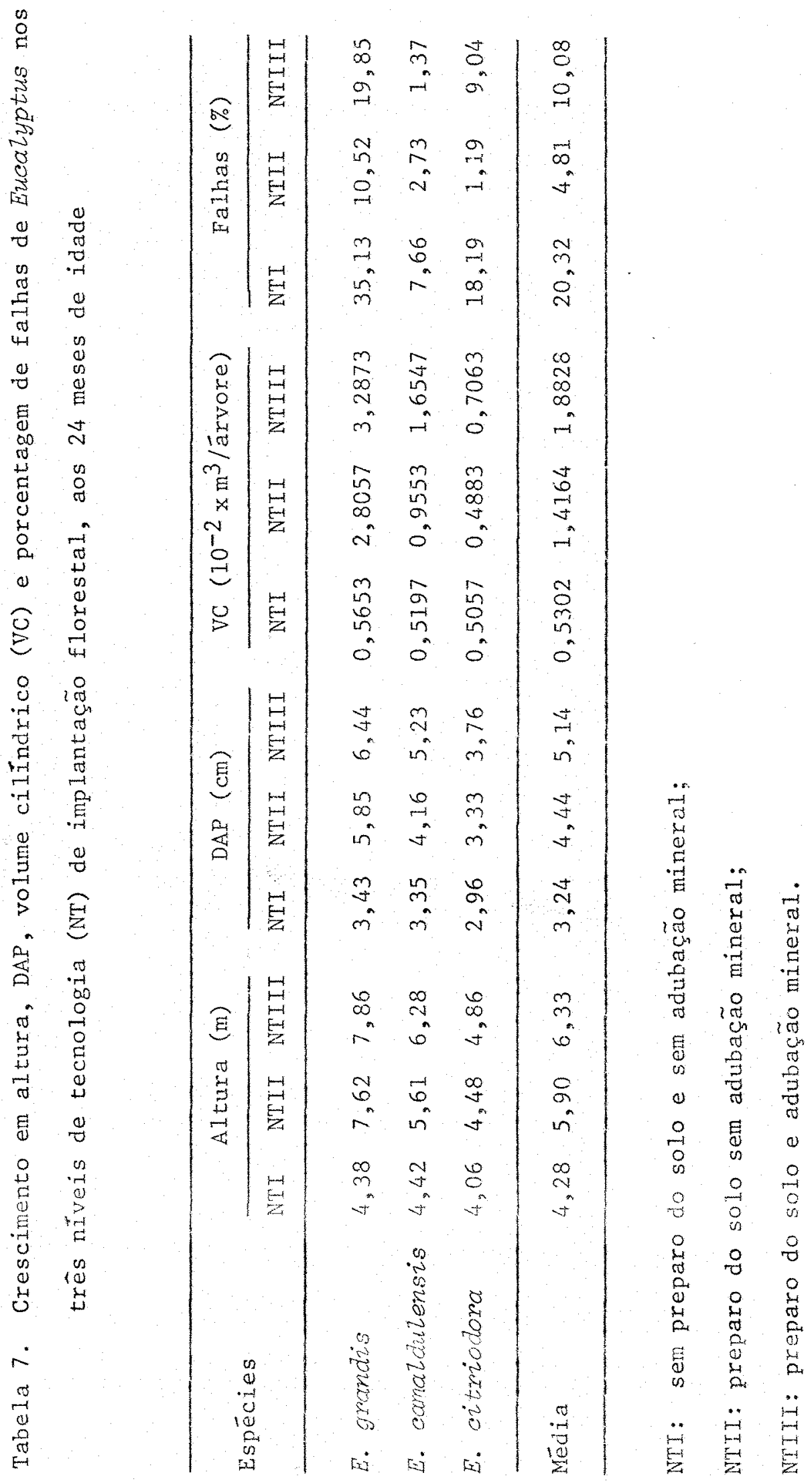


foi em $E$. camatautensis $(51,21 \%)$ no nivei de tecnologia $I I$. De acordo com KAGEYAMA (1980), estes resultados indicam a necessidade de precauções na extrapolação de dados de crescimento juvenil para as idades adultas, para os diferentes niveis de tecnologia e espëcies.

Os dados de DAP e volume cilindrico seguiram as mesmas tendências que as observadas para altura de plantas. Entretanto, para o DAP no primeiro nível de tecnologia, o E. grandis revelou-se a melhor espécie, oE. camaldulensis foi a segunda melhor espécie e o E. citriodora a pior espëcie.

A porcentagem de falhas aumentou muito pouco em relação aos 18 meses de idade. Assim como em avaliações anteriores, o maior acréscimo na mortalidade de plantas foi registrada en $E$. grandis, no nível de tecnologia I, comprovando a sensibilidade desta éppecie à condições de baixa tecnologia silvicultural em termos de sobrevivência.

Os resultados das anälises de variância individuais e conjuntas para os três níveis de tecnologia, envolvendo altura de plantas, DAP, volume cilindrico e porcentagem de falhas, são apresentadas na Tabela 8.

Nas anälises de variância para o nivel de tecnologia III, foram constatadas variações genéticas significativas entre as espécies, pa ra altura de plantas, DAP e volume cilindrico; as mesmas não se revelaram significativas para a poxcentagem de falhas, embora tenham sido expressivas. Nos niveis de tecnologia II e I, foram detectadas variações genëticas significativas entre as espécies para altura a porcentagen de falhas, respectivamente. 
Tabela 8. Resultados das anälises de variància individuais e conjuntas pa ra altura de plantas, DAP, volume cilindrico (VC) e porcentagem de falhas de Eucalyptus en três niveis de tecnologia (NT) de im plantação florestal, aos 24 meses de idade

Caracteristicas

e parâmetros
Niveis de tecnologia

NTI NTII NTIIT

Anälise conjunta

Altura (m)

Média geral

$\mathrm{F}(\mathrm{E})$

$\mathrm{F}(\mathrm{NT})$

$F(E \times N T)$

$\mathrm{CV}$ experimental (\%)
(1)

(2)

(3)

(4)

$\begin{array}{ccc}4,28 & 5,90 & 6,33 \\ 0,10 \text { ns } & 7,41 * & 19,50 * * \\ - & - & - \\ - & - & - \\ 24,43 & 17,14 & 9,29\end{array}$

5,50

$12,71 * *$

$10,67 \%$

2,42 ns

16,47

DAP (cm)

Média geral

$F(E)$

$F(N T)$

$\mathrm{F}(\mathrm{E} \times \mathrm{NT})$

CV experimental (\%)

VC $\left(10^{-2} \mathrm{x} \mathrm{m}^{3} /\right.$ ärvore $)$

Média geral

$\mathrm{F}(\mathrm{E})$

F (NT)

$\mathrm{F}(\mathrm{E} \times \mathrm{NT})$

$\mathrm{CV}$ experimental (\%)

$\begin{array}{cccc}3,24 & 4,44 & 5,14 & 4,27 \\ 0,18^{\mathrm{ns}} & 5,25^{\mathrm{ns}} & 11,22 * & 9,72 * * \\ - & - & - & 10,75 * \\ - & - & - & 1,50 \mathrm{~ns} \\ 31,38 & 22,01 & 13,47 & 21,25\end{array}$

$\begin{array}{lccc}0,53 & 1,41 & 1,88 & 1,27 \\ 0,01^{\mathrm{ns}} & 2,60 \mathrm{~ns} & 8,19 * & 7,94 * \% \\ - & - & - & 5,02^{\mathrm{ns}} \\ - & - & - & 1,88 \mathrm{~ns} \\ 77,97 & 92,79 & 41,95 & 72,64\end{array}$

Falhas (\%)

\begin{tabular}{|c|c|c|c|c|}
\hline Mëdia geral & 20,32 & 4,81 & 10,08 & 11,73 \\
\hline$F(E)$ & $21,65 \%$ & $2,98 \mathrm{~ns}$ & $6,17^{\mathrm{ms}}$ & $22,84 * *$ \\
\hline $\mathrm{F}(\mathrm{NT})$ & - & - & - & $21,88 * x$ \\
\hline$F(E \times N T)$ & - & - & - & $2,02^{\mathrm{ns}}$ \\
\hline CV experimental (\%) & 3,65 & 4,52 & 5,58 & 4,61 \\
\hline
\end{tabular}

NTI: sem preparo do solo e sem adubaça mineral;

NTII: preparo do solo sem adubação mineral;

NTIII: preparo do solo e adubação mineral;

(1), (2) e (3): teste $F$ para as espëcies, niveis de tecnologia e interação de especies $x$ niveis de tecnologia;

(4): coeficiente de variaçăo experimental em porcentagem;

ns: não signjuficativo;

* : significativo ao nivel de $5 \%$

$* *$ : significativo ao nivel de $1 \%$. 
Comparando-se os valores de $F$ obtidos para as quatro características, verifica-se que no nîvel de tecnologia I, as variações entre as espêcies foram mais expressivas para a porcentagen de falhas do que paxa as caracteristicas de crescimento. Nos niveis de tecnologia II e III, as variaçöes entre as espëcies foram, em ordem decrescente, maiores para altura de plantas, DAP, volume cilindxico e porcentagem de faThas, se bem que no nível de tecnologia II o valor de $F$ para a ültima caracteristica tenha sido ligeiramente superior ao do volume cilíndrico.

Os coeficientes de variaçäo experimental para as características de crescimento seguiram a tendência relatada aos 18 meses de idade: foram altos para o volume cilindrico, intermediário para o DAP e meno res para altura de plantas. Os coeficientes de variação experimentais para a porcentagem de falhas foram sempre os mais baixos e mantiveram a tendência de aumento com a elevação do nîvel de tecnologia.

Na anälise conjunta para os níveis de tecnologia, as espēcies apresentaram, para todas as caracteristicas estudadas, variaçoes genëticas significativas, basendo-se nos valores de F obtidos. Essas variaçöes foram mais expressivas para a porcentagem de falhas, vindo a seguir altura de plantas, o DAP e por ültimo o volume cilindrico. o efeito dos niveis de tecnologia foi significativo para altura de plantas, DAp e porcentagem de falhas, não o sendo para o volume cilindrico, provavelmente de vido ao erro experimental, expresso pelo alto coeficiente de variação experimental verificado. o efeito dos níveis de tecnologia foi mais expressivo para a porcentagem de falhas, altura de plantas, DAP e volume 
cilindrico, conforme os valores do teste $F$.

o comportamento dos coeficientes de variação experimentais na anälise conjunta foi similar ao observado nas anälises individuais. Para as características de crescimento, o coeficiente de variação experimental foi alto para o volume cilindrico $(72,64 \%)$, intermediário para o DAP $(21,25 \%)$ e menor para altura de plantas $(16,47 \%)$. o referente a porcentagem de falhas $(4,61 \%)$ foi baixo.

Como pode-se constatar, o volume cilindrico foi a característica que mostrou maior erro experimental, provavelmente sendo a causa da não deteç̧ão de variações entre os diferentes efeitos testados. o volume cilindrico, sendo uma caracteristica composta e sofrendo os efeitos de falhas, deve ter um maior nümero de repetições para a comparação da efi ciência estatística nesse tipo de ensaio.

o efeito da interação de espécies $x$ niveis de tecnologia, contrastando com os resultados obtidos até aos 18 meses, não se revelou significativo para nenhuma das caracteristicas estudadas. Entretanto, cs valores de $F$ obtidos para altura de plantas, porcentagem de falhas e volume cilindrico foram expressivos. No entanto, observando-se as Figuras 6, 7 e 8, verifica-se, como nas idades anteriores, que as espécies reagiram diferencialmente à elevação do nivel de tecnologia. Para as três caracteristicas de crescinento, a resposta à tecnologia silvicultural foi maior para o E. grandis, vindo a seguir o E. camazduzensis e por ültimo o $E$. citriodora. 


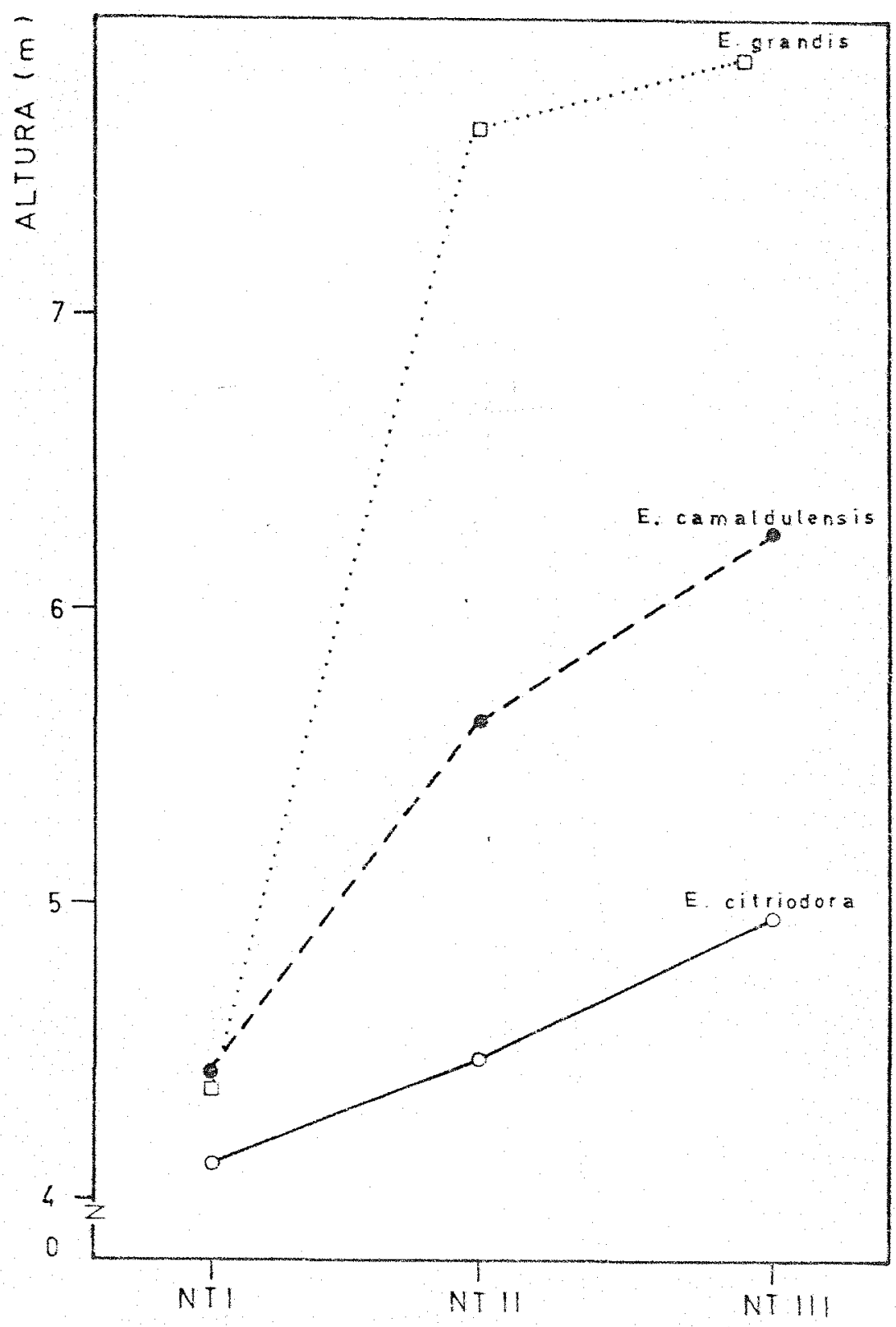

Nível de Tecnologia

Figura 6. Altura média de plantas de Eucalyptus em três níveis de tecnologia (NT) de implantação florestal, aos 24 meses de idade 


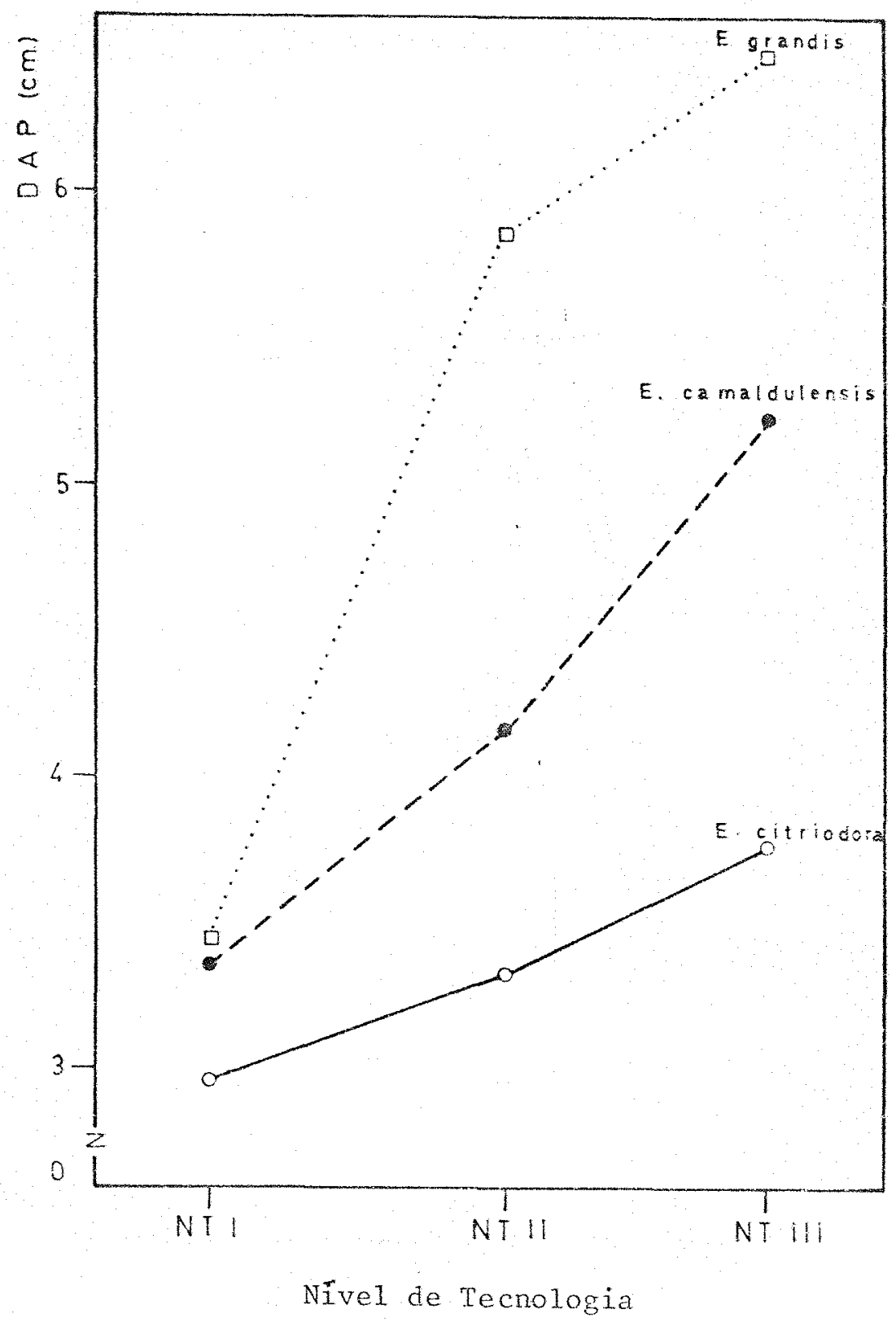

Figura 7. Diânetro à altura de peito (DAP) de plantas de Eucaiyptus, em três niveis de tecnologia. (NT) de implantação florestal, aos 24 meses de idade 


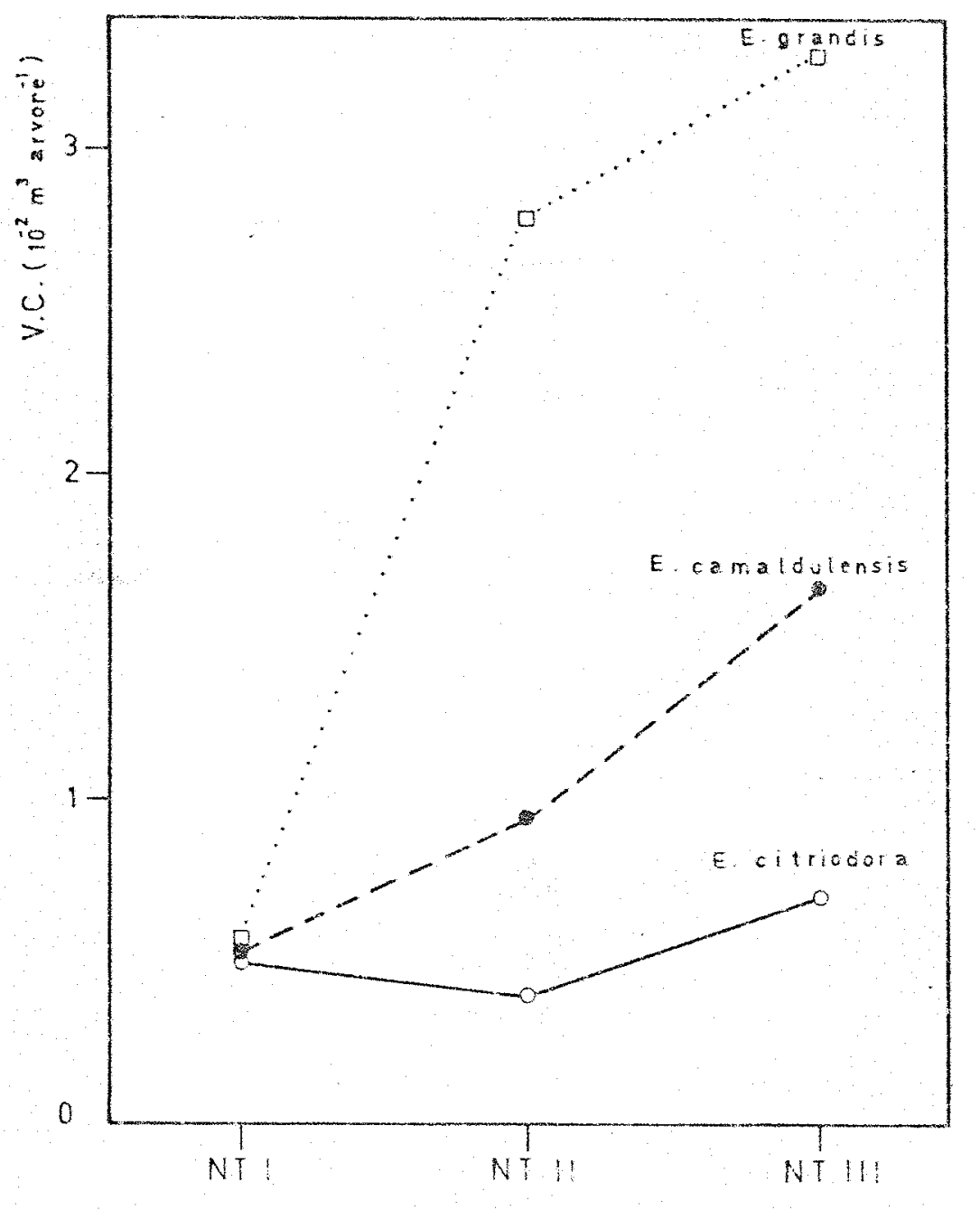

Nível de Tecnologia

Figura 8. Volume cilindrico (VC) de plantas de Eucalyptus, em três níveis de tecnologia (NT) de implantação florestal, aos 24 mew ses de idade 
Os resultados obtidos aos 24 meses de idade indicam que as variações entre as espēcies são mais expressjuas em condiçöes de alta tec nologia (NTII) do que em condições de baixa tecnologia (NII), e sugerem a ocorrência de interação simples de espécies $x$ níveis de tecnologia (FoN SECA, 1979). As diferenças entre as especies foram menores no nivel de tecnologia I e maiores no nivei de tecnologia TIT.

As variações constatadas são importantes na escolha de espëcies a utilizar em diferentes condições de reflorestamento e usos finais (KAGEYAMA et alii, 1987). Para o abastecinento industrial, por exem plo, alëm de características físicas e quinicas adequadas, a espécie deve apresentar rápido crescimento e responder ao aprimoramento de técnicas silviculturais (ZOBEL, 1972). Na produção de madeira em pequena escala, para fins energëticos ou consuno donëstico, seria desejävel utilizer espécies de uso múltiplo, adaptados a vários ambiontes e pouco exigentes quanto as tëcnicas silviculturais (FAO, 1978; NATTONAL ACADEMY OF SCTENCE, 1980).

Nesse sentido, o E. grandis mostrou, como se esperava, a sua alta potencialidade para a utilização em condições de alta tecnologia silvicultural, ou seja en reflorestamentos industriais. Entretanto, no nivel de tecnologia I Ẽi a espëcie nais sensivel, apresentando a maior porcentagem de rahas e a menor produção total, embora tivesse o major volume cilindrico médio por planta. No nivel de tecnologia I a maior pro dução foi obtida em E. camazdulensis $\left(11,99 \mathrm{~m}^{3} / \mathrm{ha}\right)$, vindo a seguir o $E$. citriodora $\left(10,34 \mathrm{~m}^{3} / \mathrm{ha}\right)$ e por vitimo o $E$. grandis $\left(9,16 \mathrm{~m}^{3} / \mathrm{ha}\right)$. 
A superioridade das duas primeiras espécies ë ainda maior quando se considera a produção de matéria seca, conforne mostrou ALBINO (1983). A densidade basica do $E$. camaldulensis e do $E$, citriodora $\vec{e}$ maior que a do E. grandis. O citado autor obteve, para três locais do Estado de Minas Gerais, os seguintes valores de densidade básica: $0,691 \mathrm{~g} / \mathrm{cm}^{3}$ para o E. citriodora, $0,617 \mathrm{~g} / \mathrm{cm}^{3}$ para o E. comaldulensis e $0,499 \mathrm{~g} / \mathrm{cm}^{3}$ para o E. grandis.

Desta forma, o E. camalduitensis e o E. citriodora säo, aparentemente, mais adequados para condições de baixa tecnologia do que - E. grandis, principalmente quando se pretende produzir madeira de a1ta densidade, como é o caso de madeira para fins energéticos ou para serraria. A utilização do $E$. grandis nessas condiçôes deve ser considerada com muitas precauções, rão sendo välida a extrapolaçäo do comportanento desta espëcie em condições de alta tecnologia para condiçōes de baixa tecnologia. 
4.2. Comportamento de Progênies Dentro de Espëcies nos Diferentes Niveis de Tecnologia

4.2.1. Comportamento de progènies de E. grondis

4.2,1.1. Avaliação de progênies de $E$. grandis aos 7 meses de idade

Os resultados de crescimento em altura de plantas, porcentagem de falhas, das anālises de variâncias individuais e conjuntas para os três nîveis de tecnologia de implantação florestal, nesta idade bem inicial, são apresentados na Tabela 9.

A julgar pelos valores de $F$, a variação genética entre pro gênies para altura de plantas foi significativa do nîvel de tecnologia I; nos niveis de tecnologia II e III tal variação não se revelou significativa. No entanto, ao se observar os valores dos coeficientes de variação experimentais percebe-se que os mesmos têm uma tendência contrária aos valores de $\mathrm{F}$. Essa tendência de aumento do coeficiente de variação experimental com a elevação do nível de tecnologia, $\vec{e}$ inversa à verificada na anälise estatística ao nîvel de espécies.

Para a porcentagem de falhas, os valores de $F$ não foram significativos para todos os niveis de tecnologia e os coeficientes de variação experimentais foran relativamente baixos e semelhantes. 
Tabela 9. Resultados das anälises de variancia individuais e conjuntas pa ra altura de plantas e porcentagen de falhas de progenies (P) de E. grandis em três niveis de tecnologia (NT) de implantação flo restal, aos 7 meses de idade

Características

e parâmetros

\section{Niveis de tecnologia}

NTI

NTII

Anälise conjunta

\section{Altura (m)}

Mẻdia geral

$$
0,77
$$

1,67

1,68

1,37

Amplitude de variação

$F(P)$

(1)

$0,58-1,00$

$$
1,36-2,09
$$$$
1,28-2,02
$$

NTIII

$1,46^{\mathrm{ns}}$

$1,07^{\mathrm{ns}}$

$-$

$\mathrm{F}(\mathrm{NT})$

$\mathrm{F}(\mathrm{P} \times \mathrm{NT})$

(2)

CV experimental

(3)

$7,50 * \%$

$-$

$1,57^{\mathrm{ns}}$

- $\quad-$

(\%) (4)

8,50

$-$

18,86

$-$

$29,17 * * 6$

$1,26^{\mathrm{ns}}$

21,25

20,21

Falhas (\%)

Média geral

Amplitude de variação

$\begin{array}{cccc}21,65 & 5,17 & 14,81 & 13,87 \\ 11,00-32,78 & 0,00-14,76 & 5,39-27,47 & - \\ 0,55^{\mathrm{ns}} & 0,75^{\mathrm{ns}} & 1,01^{\mathrm{ns}} & 1,08^{\mathrm{ns}} \\ - & - & - & 3,75^{\mathrm{ns}} \\ - & - & - & 0,58^{\mathrm{ns}} \\ 11,97 & 8,14 & 10,48 & 10,05\end{array}$

NTI: sem preparo do solo e sem adubação mineral;

NTII: preparo do solo sem adubação mineral;

NTIII: preparo do sclo e adubação mineral;

(1), (2) e (3): teste $F$ para as progênies, niveis de tecnologia e interação de progennies $x$ niveis de tecnologia;

(4): coeficiente de variaçăo experimental em porcentagem;

ns: não significativo;

* : significativo ao nivel de $5 \%$;

$* \%$ : significativo ao nivel de $1 \%$. 
$\mathrm{Na}$ anälise conjunta para os três níveis de tecnologia não se detectou a variação genética entre progênies, o efeito do nível de tecnologia foi altamente significativo e a interação de progênies $x$ níveis de tecnologia näo se mostrou significativa. Para a porcentagem de falhas não houve significância para nenhum dos efeitos.

$$
\text { Apesar de não ter havido interação entre progênies e ni- }
$$
veis de tecnologia, percebe-se una clara tendência de interação complexa entre as progênies e os níveis de tecnologia II e III, conforme ilustra a Figura 9 . 


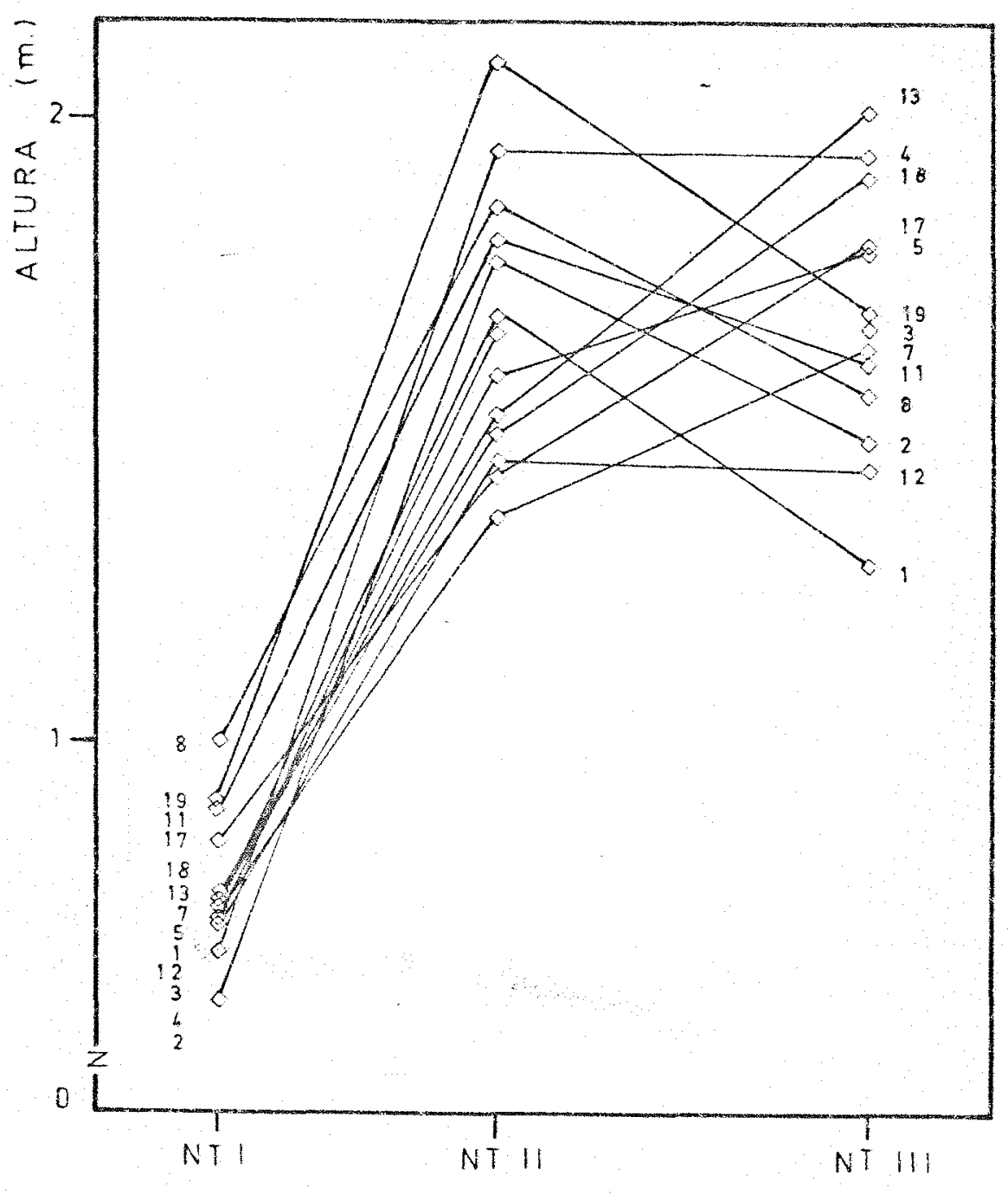

Nïvel de Tecnologia

Figura 9. Crescimento en altura de progênies de $E$. grandis nos trés niveis de tecnologia (NT) de implantação florestal, aos 7 meses de idade 
4.2.1.2. Avaliação de progenies de E. grandis aos 12 meses de idade

Os resultados de crescimento em altura de plantas, porcentagem de falhas, das anālises de variancia individuais e conjuntas para os três níveis de tecnologia, obtidos para progênies de E. grandic aos 12 meses de idade, são apresentados na Tabela 10.

A essa idade, nas anâlises de variância individuais para altura de plantas, detectou-se variações genëticas significativas somente para o nível de tecnologia I, porëm com uma tendência menos nítida em relação à idade de 7 meses. Os coeficientes de variação experimentais se tornaram mais semelhantes, modjficando-se portanto, em relação à avaliação anterior.

Para a porcentagem de falhas näo houve nenhuma alteraçäo, comparativamente aos 7 meses, e não se detectou variações genéticas entre progênies.

Na anālise conjunta para altura de plantas houve alta significância apenas para o efeito do nível de tecnologia, sendo o resultado muito semelhante ao da primeira avaliação. Para a porcentagem de falhas, os efeitos de progênies e niveis de tecnologia $j \vec{a}$ se revelaram significativos, alterando a tendência verificada aos 7 meses de idade.

A interaçäo de progênies z niveis de tecnologia continuou não significativa, mostrando, porêm, a tendencia para a interação complexa entre progênies e os níveis de tecnologia II e III, conforme ilustra a Figura 10 . 
Tabela 10. Resultados das anälises de variância indjviduais e conjuntas pa ra altura de plantas e porcentagem de falhas de progênies ( $(P)$ de $E$. grandis en três nîveis de tecnologia (NI) de implantaçäo florestal, aus 12 meses de jdade

\begin{tabular}{lcccc}
\hline $\begin{array}{l}\text { Caracteristicas } \\
\text { e parâmetros }\end{array}$ & \multicolumn{2}{c}{ Niveis de tecnologia } & Anälise \\
\cline { 3 - 6 } conjunta
\end{tabular}

Falhas (\%)

Média geral

27,73

8,13

17,26

17,70

Amplitude de variação

$15,97-58,50$

$0,00-32,12$

$5,39-32,12$

$\mathrm{F}(\mathrm{P})$

$0,95^{\mathrm{ns}}$

$2,30 *$

$0,84^{\mathrm{nis}}$

$1,96 \%$

$\mathrm{F}(\mathrm{NT})$

-

$-$

$5,92 \%$

$\mathrm{F}(\mathrm{P} \times \mathrm{NT})$

$-$

$-$

$-$

$0,72^{\text {ns }}$

CV experimental (\%)

13,87

8,78

12,00

12,21

NTI: sem preparo do solo e sem adubação mineral;

NTII: preparo do solo sem adubação mineral;

NiIII: preparo do solo e adubaçäo mineral;

(1), (2) e (3): teste F paxa as progênies, niveis de tecuologia e interação de progenties $x$ niveis de tecnologia;

(4): coeficiente de variação experimental em porcentagem;

ns: não significativo;

* : significativo ao nivel de $5 \%$;

** : significativo ao nivel de $1 \%$. 


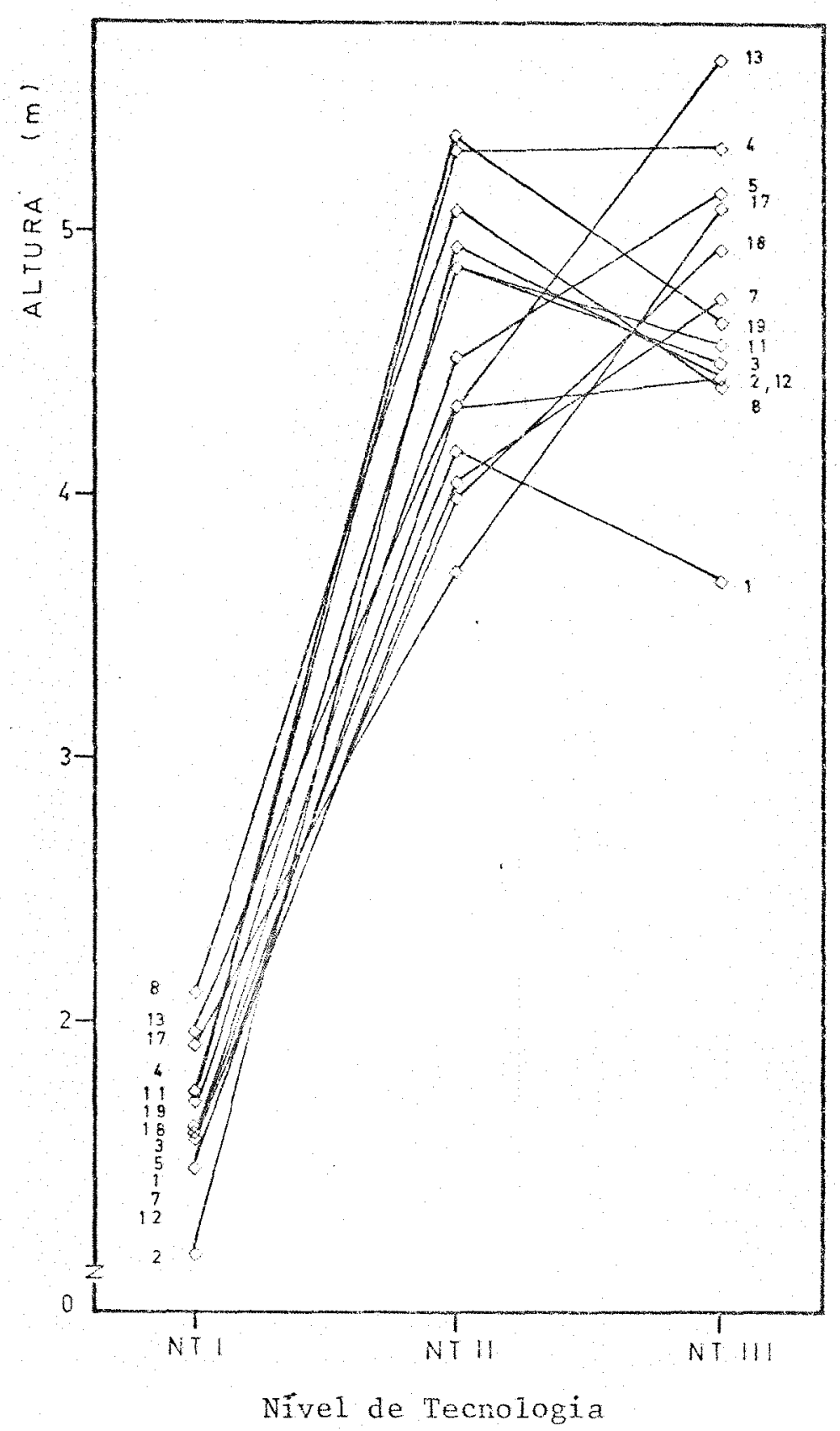

Figura 10. Crescimento em altura de progenies de $E$. grandis nos três níveis de tecnologia (WT) de implantaço florestal, aos 12 meses de idade 
4.2.1.3. Avaliaçäo de progênies de Er. grandis aos 18 meses de idade

os resultados aos 18 meses de idade para altura de plantas, DAP, volume cilindrico, porcentagem de falhas, das anälises de variancia individuais e conjuntas para os três nîveis de tecnologia de implantação florestal, são apresentados na labela 11.

Nas anälises de variância para altura de plantas em cada nive1 de tecnologia permaneceu a mesma tendência verificada nas idades anteriores, com a alta significância para o efejto de progênies somente para o nivel de tecnologia I. Os coeficientes de variação experimentais, por sua vez, foram muito semeihantes nesta idade.

A variação genëtica encre progênies para o DAp e volume ci Iindrico seguiu a mesma tendéncia observada para altura de plantas, con: alta significância para o primeiro nível de tecnologia. os coeficientes de variação experimental para o volume cilindrico foram, aproximadamente, duas vezes maiores do que os para o DAP que, por sua vez, foram maiores do que os para altura de plantas, Comportamento similar foi verificado ao nivel de espécies.

Os resultados das anālises de variância individuais para a porcentagem de falhas tiveram a mesma tendência das avaliações anteriores, com não significancia para os efeitos de progênies. 
Tabela 11. Resultados das anälises de variância individuais e conjuntas pa ra altura de plantas, DAP, volume cilindrico (VC) e porcentagem de falhas de progênies (P) de É grandis em três niveis de tecnologia (NT) de implantação florestal, aos 18 meses de idade

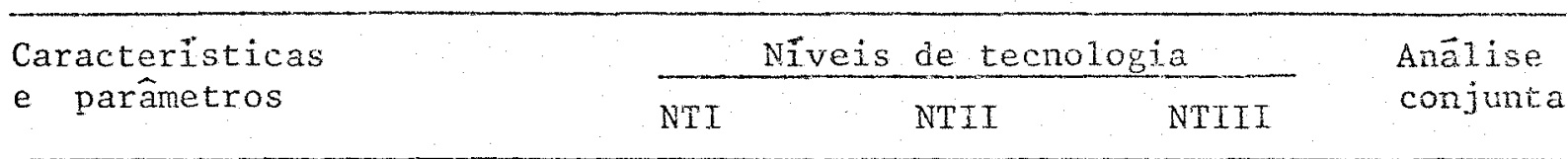

\section{Altura (m)}

Média geral

Amplitude de variação

$\mathrm{F}(\mathrm{P})$

$\mathrm{F}(\mathrm{NT})$

$\mathrm{F}(\mathrm{P} \times \mathrm{NT})$

$\mathrm{CV}$ experimental (\%)
(2)

(3)

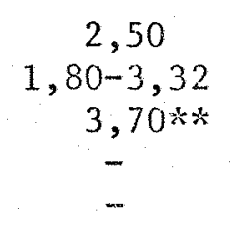

13,88

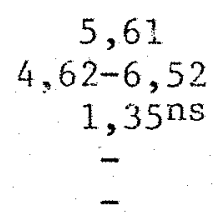

15,17

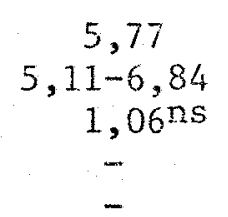

14,57
4,63

$1,32 \mathrm{~ns}$

$15,04 * *$

$1,43 \mathrm{~ns}$

15,54

DAP $(\mathrm{cm})$

Mëdia geral

Amplitude de variação

$\mathrm{F}(\mathrm{P})$

$\mathrm{F}(\mathrm{NT})$

$\mathrm{F}\left(\mathrm{P} \times \mathrm{NT}^{\mathrm{T}}\right)$

$\mathrm{CV}$ experimental (\%)

$\begin{array}{cccc}1,74 & 4,22 & 4,53 & 3,50 \\ 0,73-2,60 & 3,40-4,97 & 3,37-5,33 & - \\ 3,97 * * & 1,21 \mathrm{~ns} & 0,97 \mathrm{~ns} & 1,37 \mathrm{~ns} \\ - & - & - & 14,56 \% * \\ - & - & - & 1,36 \mathrm{~ns} \\ 22,34 & .18,29 & 19,47 & 20,38\end{array}$

VC $\left(10^{-2} \mathrm{x} \mathrm{m}^{3}\right.$ /ärvore)

Mëdia geral

Amplitude de variação

$\mathrm{F}(\mathrm{P})$

$\mathrm{F}$ (NT)

$\mathrm{F}(\mathrm{P} \times \mathrm{NT})$

CV experimental (\%)

$\begin{array}{cccc}0,11 & 1,15 & 1,22 & 0,83 \\ 0,01-0,23 & 0,69-1,80 & 0,59-1,79 & - \\ 3,15 * * & 1,35^{\mathrm{ns}} & 1,25^{\mathrm{ns}} & 1,05 \mathrm{~ns} \\ - & - & - & 5,21^{*} \\ - & - & - & 1,45^{\mathrm{ns}} \\ 47,46 & 42,73 & 38,14 & 47,31\end{array}$

Falhas (\%)

Média geral

Amplitude de variação

$\mathrm{F}(\mathrm{P})$

$\mathrm{T}$ (NT)

$F(P \times N T)$

CV experimental (\%)

$\begin{array}{cccc}29,47 & 8,98 & 18,22 & 18,89 \\ 11,05-58,50 & 0,00-32,1.2 & 5,39-32,12 & - \\ 1,33^{\mathrm{ns}} & 1,78^{\mathrm{ns}} & 1,09^{\mathrm{ns}} & 2,47 * * \\ - & - & - & 6,12 * \\ - & - & - & 0,86 \mathrm{~ns} \\ 12,90 & 9,57 & 10,95 & 11,22\end{array}$

NTI: sem preparo do solo e sem adubação mineral;

NTII: preparo do solo sem adubaçäo mineral;

NTIII: preparo do solo e adubação mineral;

(1), (2) e (3): teste $F$ para as progeñies, nîveis de tecnologia e interação de progenies $x$ nilveis de tecnologia;

(4): coeficiente de variação experimental en porcentagem;

ns: não significativo;

* : significativo ao nivel de $5 \%$;

**: significativo ao nível de $1 \%$. 
Nas anälises conjuntas para as características de crescimento (altura, DAP e volume cilindrico), detectou-se significancia sonente para os efeitos dos niveis de tecnologia, não sendo sigrificativos os efeitos de progênies e da interação destas com os níveis de tecnologia. Pa ra a porcentagem de falhas, os efeitos de progênies e niveis de tecrologia foram significativos.

A julgar pelos valores de $\mathrm{F}$ obtidos nas anālises conjuntas, para as quatro características estudadas nesta idade, o efeito do nível de tecnologia foi mais expressivo, na ordem decrescente, para altura de plantas, DAP, porcentagem de falhas e volume cilindrico. Da mesma forma o efeito da interação de progênies $x$ níveis de tecnologia foi maior para o volume cilindrico, altura, DAP e porcentagen de fathas.

As Figuras 11,12 e 13 mostram o comportamento das progénies, respectivamente, em altura de plantas, DAP e volume cilíndrico, nos diferentes niveis de tecnologia de implantação florestal. Observe-se que tanto o DAP quanto o volume cilíndrico apresentam, à semelhança da altura de plantas, uma clara tendência para interação complexa entre as progênies e os niveis de tecnologia II e III. 


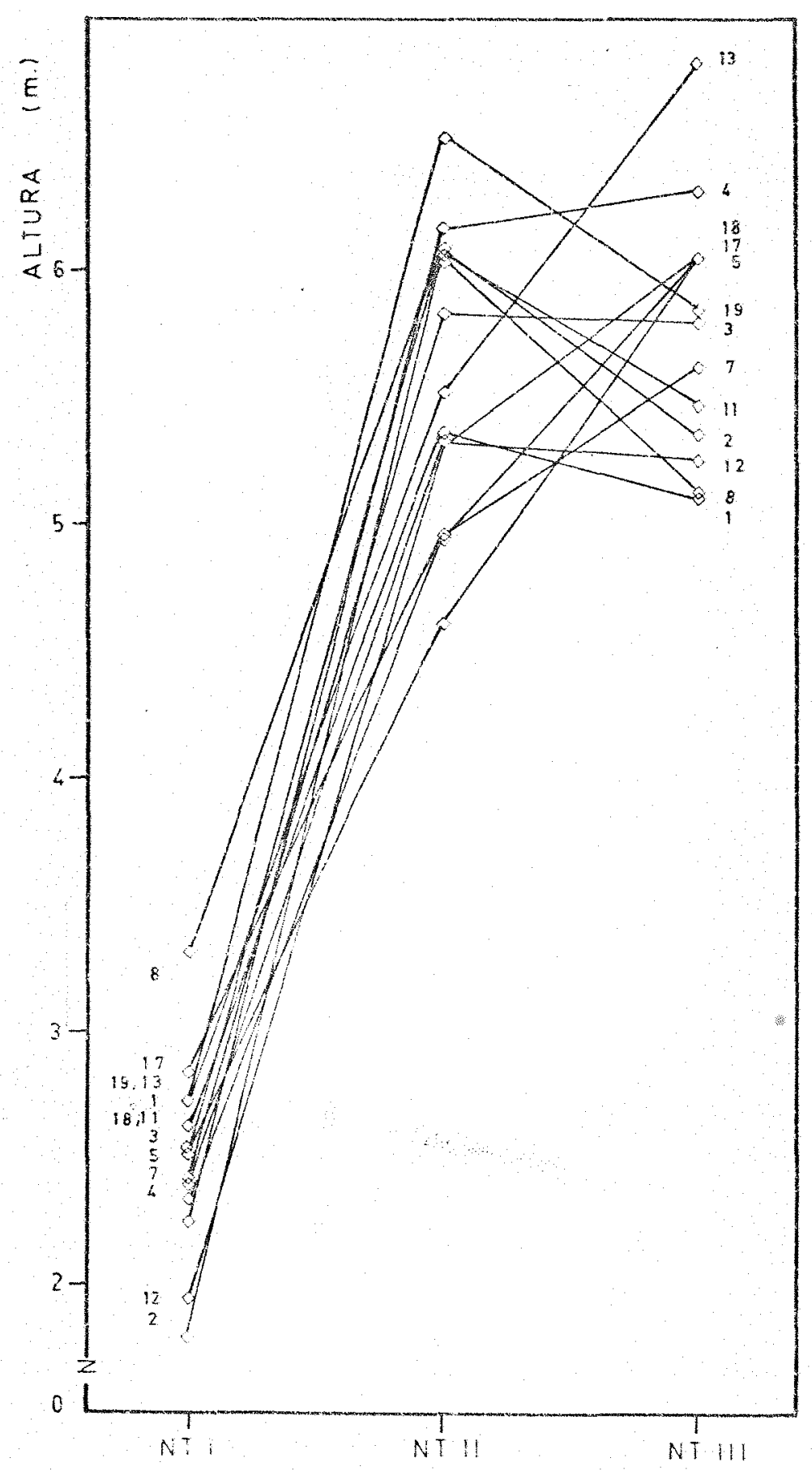

Nivel de Tecnologia

Figura 11. Crescimento em altura de progênies de $E_{2}$ grandis nos três ni-veis de tecnologia (NT) de implantaçäo florestal, aos 18 meses de idade 


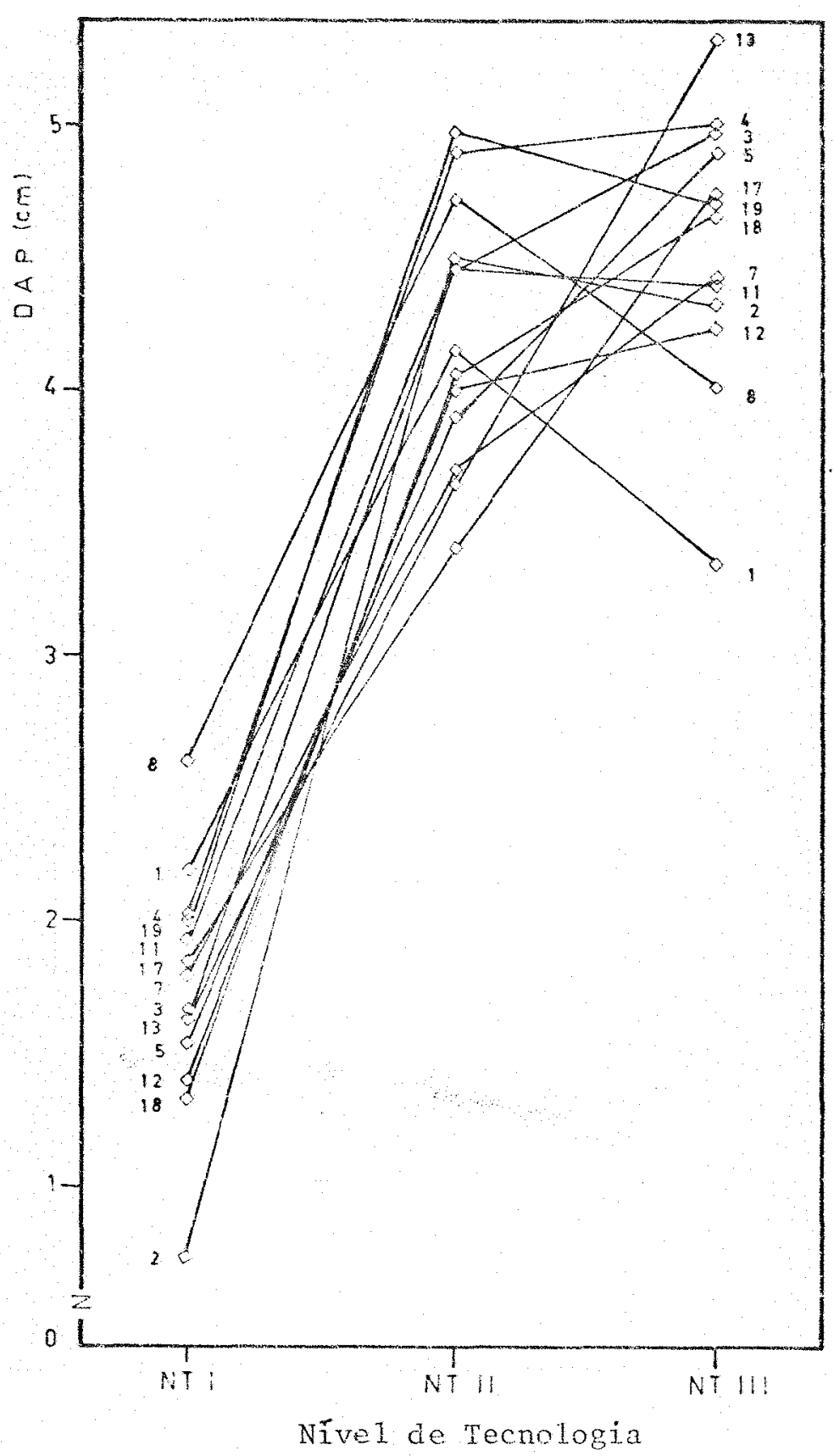

Figura 12. Crescimento em DAP de progênies de $F$. grandis em três niveis de tecnologia (NT) de implantação florestal, aos 18 meses de idade 


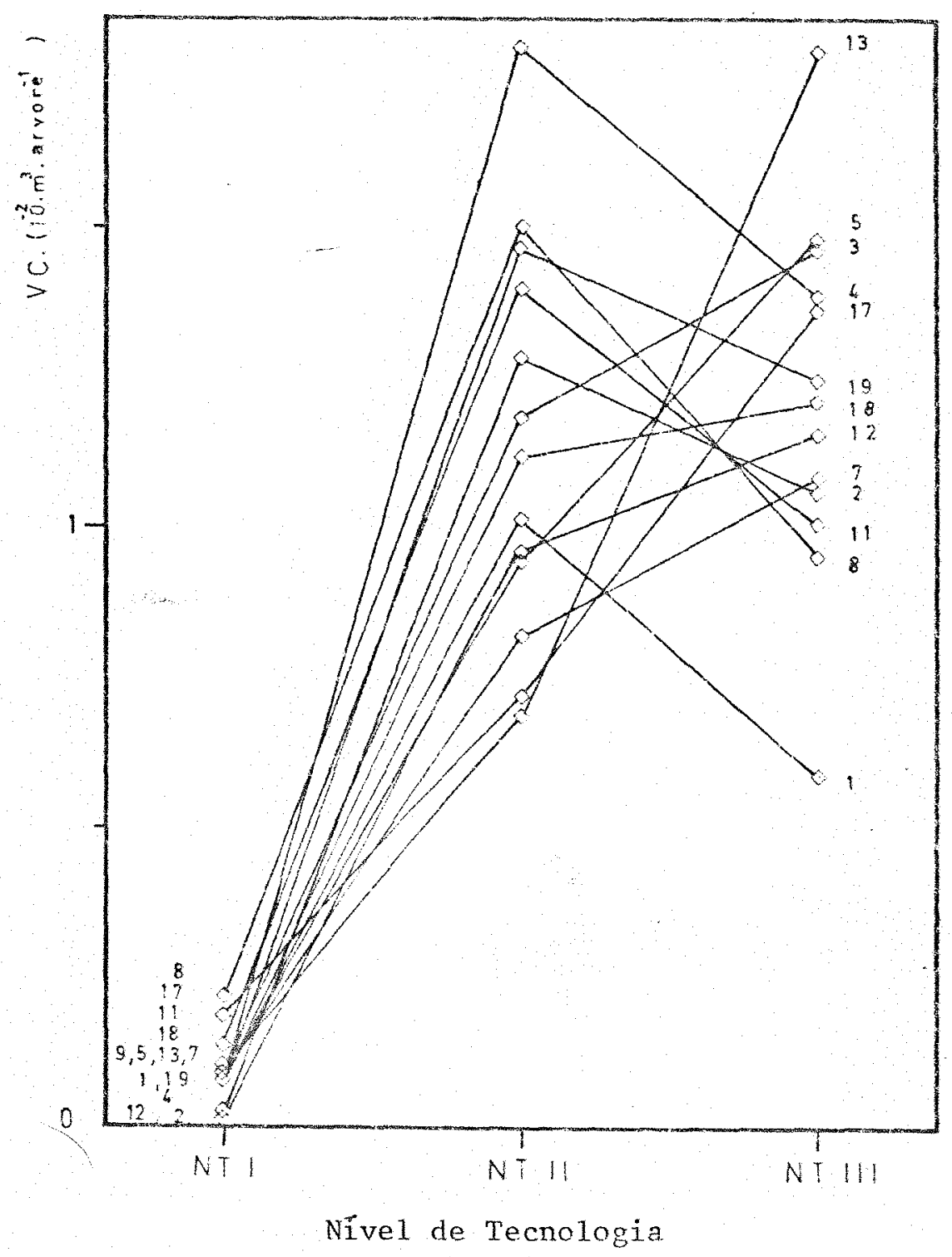

Figura 13. Crescimento em volume cilindrico (VC) de progênies de E.granais nos três niveis de techologia (NI) de implantação florestal aos 18 meses de idade 
4.2.1.4. Avaliaçäo de progênies de E. grandìs aos 24 meses de ídade

Os resultados aos 24 meses de idade de crescimento em altura de plantas, DAP, volune cilindrico, porcentagen de falhas, das anälises de variancia individuais e conjumtas para os três niveis de tecrolo gia de implantação florestal, são apresentados na Tabela 12.

os dados médios para as características de crescimento de progênies de $E$. grandis na avaliação final revelaram un crescimento expressivo de plantas nos níveis de tecnologia II e III em relação ao nível de tecnologia I. Observa-se que, em geral, a resposta ac preparo do solo em relação à testemunha foi maior do que a resposta ao preparo do solo mais fertilização mineval, em relação somente ao preparo do solo. Idêntico resultado foi verificado por ICFR $(1985)$ em $E$. grandis con 19 meses de idade.

A porcentagem de falhas a esta idade não mostrou diferen.ças flagrantes en relação aos 12 meses, sugerindo que a maior parte de falhas existentes são resultantes de fatores presentes durante a implantação e no primeiro ano de crescimento.

Considerando-se que os ensajos foram estabelecidos no final da estação de chuvas e que o Er. grandio ten se revelado muito sensivel a condicoes de déficit nidrico prolongado (PTES et ath, 1986), a deficiência hídrica no solo associada a competição con a vegetação natural durante o período de estabelecimento das mudas podem ter contribuído para a mortalidade de plantas, principalmente no nivel de tecnologia I, já que o ano de 1986 teve un periodo seco bastante pronunciado. 
Tabela 12. Resultados das anâlises de variancia individuais e conjuntas pa ra altura de rlantas, DAP, volume cilindrico (VC) e porcentagem de falhas de progênies (P) de tre grandis em três niveis de tecnologia (NI) de implantaçäo florestal, aos 24 meses de idade

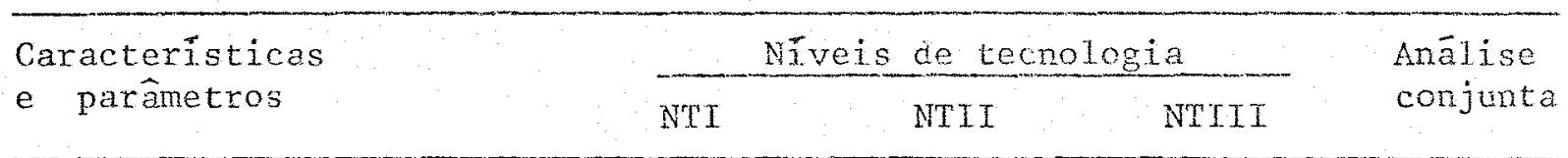

\section{Altura (m)}

Média geral

Amplitude de variação

$\mathrm{F}(\mathrm{P})$

$\mathrm{F}(\mathrm{NT})$

$\mathrm{F}(\mathrm{P} \times \mathrm{NT})$

$\mathrm{CV}$ experimental $(\%)$
(1)

(2)

(3)

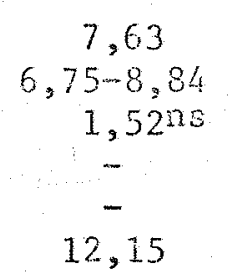
7,86
$6,71-8,66$
0,79 ns
$-$
$-$
14,86

6,62

$-$

$1,08 \mathrm{~ns}$

$8,49 \%$

$1,26 \mathrm{~ns}$

13,82

DAP (cm)

Média geral

Amplitude de variação

\section{$\mathrm{F}(\mathrm{P})$}

$\mathrm{F}(\mathrm{NT})$

$\mathrm{F}(\mathrm{P} \times \mathrm{NT})$

CV experimental

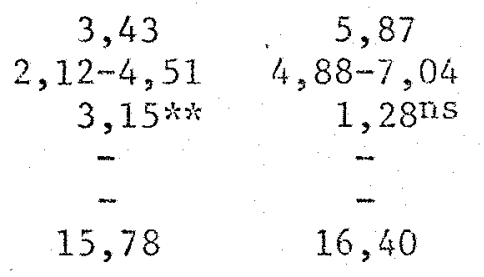

6,44
$5,16-7,30$
$0,79 \mathrm{~ns}$
-
19,09

5,25

$-$

$0,74 \pi 5$

$5,96 \%$

$1,41 \mathrm{~ns}$

18,28

VC $\left(10^{-2} \mathrm{xm}^{3} /\right.$ arvore $)$

Média geral

Amplitude de variação

$F(P)$

$\mathrm{F}(\mathrm{NT})$

$\mathrm{F}(\mathrm{P} \times \mathrm{NT})$

CV experimental (\%)
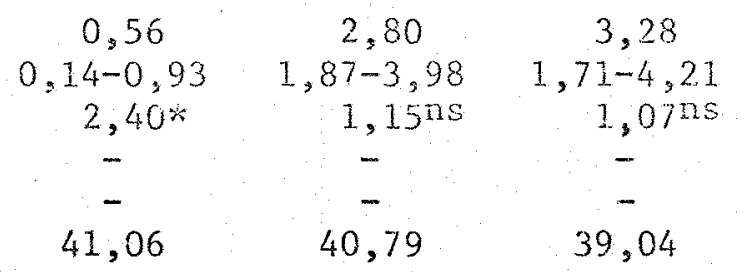

2,21

$-$

1, $08 \mathrm{~ns}$

$2,76 \mathrm{~ns}$

$1,15 \mathrm{~ns}$

45,29

Falhas (\%)

Média geral

Amplitude de variação

$\mathrm{F}(\mathrm{P})$

$\mathrm{F}(\mathrm{NT})$

$\mathrm{F}(\mathrm{P} \times \mathrm{NT})$

$\mathrm{CV}$ experimental (\%)

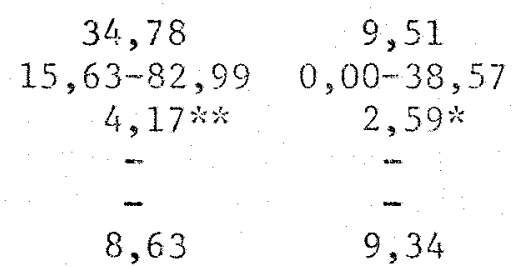

19,42
$5,39-32,12$
$0,84 \mathrm{~ns}$
-
-

21,24

-

$3,36 \%$

$9,91 *$

$1,96 \%$

9,43

Nrt: sem preparo do solo e sen adubacáa mineral:

NTII: preparo do solo sem adubacão mineral;

NTIII: preparo do solo e adubaçäo mineral;

(1), (2) e (3): teste $F$ para as progenies, niveis de tecnologia e interação de progenies $x$ níveis de tecnologia;

(4): coeficiente de variação experimental em porcentagem;

ns: não significativo;

$z$ : significativo ao nivel de $5 \%$;

$*$ : significativo ao nivel de $1 \%$ 
As anälises de variância para altura de plantas, DAP e volume cilíndrico apresentaram resultados senelhantes aos 18 meses de ida de. A tendência de significância para o efeito de progênies no primeiro nível de tecnologia permaneceu, porêm, com significância scmente para o DAP e o volume cilindrico. Os coeficientes de variação experimentais apresentaram tambèn um comportamento similar ao da avaliaçāo anterior.

Nas anälises de variância individuais, para a porcentagem de falhas, observa-se uma mudança nos resultados. O efeito de progênies foi altamente significativo nos niveis de tecrologia I e II, com tendència para a diminuição com o aumento do nivel de tecnologia. Ao que tudo indica, a essa idade, hâ uma diferenciação entre as progeñes quando não se usa o preparo do solo elou a fertilizaçăo mineral.

Na anālise conjunta para as caracteristicas de crescimento permanece, em geral, o resultado observado aos 18 meses de idade. 0 efeito dos niveis de tecnologia continua significativo para altura de plan tas e DAP, muito embora com una queda acentuada nos valores de F.

Este resultado reflete, provave1mente, a diminuição do efeito do preparo do solo e da fertilização mineral com a idade do povoamento, conforme tambërn relatado por DONALD \& SCHUTZ (1977) e SCHÖNAU (1983), dentre outros.

Para a porcentagem de falhas houve significãncia para todos os efeitos testados. 
As Figuras 14,15 e 16 confiman a tendencia de interação complexa relatadas nas idades inictais. A troca de posições relativas de progênies entre os nîveis de tecnologia II e III é bastante flagrante. No geral, as progenies com maior resposta ao preparo do solo (nível de tecnologia IT) tiveram um comportamento inferior com o preparo do solo mais a fertilização mineral e vice-versa. Semelhante comportamento foi constatado por PATTÑo-VALERA (1986) en progenies de E. saligna sob dois espaçamentos; a interaçäo de progênies $x$ espaçamento não se revelou signi ficativa, contudo foi possivel identificar as progênies mais produtivas em cada um dos espaçamentos.

Se se considerar esses resultados cono youadeiros, a sem leção de progênies no nivel de tecnologia II e no nivel de tecrologia III premiaria materiais genéticos completamente distintos, o que teria implicaçöes importantes num programa de melhoramento genético. De acordo com ALLARD \& BRADSHAN (1964) \& seria desejävel estabelecer programas de nelhoramento genético específicos para atender a cada nivel de cecnologia silvicultural.

Analisando-se as progenies de $E$. grandis quanto a padrões de comportamento em altura de plantas, aos 24 meses de idade e nos três niveis de temologia de implantaçäo florestal, pode-se visualizar os seguintes tipos de progenies:

a) aquelas com comportamento superior nos niveis de tecrologia I e II e inferiores no nive1 de tecnologia IIT, tal cono a progenie s; 
b) aquelas com comportamento superior no nivel de tecnologia $I$ e inferior nos niveis de tecnologia II e III, tal como a progênie 1:

c) aquelas con comportamento inferior nos niveis de tecnologia I e II e médios no nĩvel de tecnologia. III, tal como a progênie 12;

d) aquelas con comportamento superior no nivel de tecnolom gia $I$, inferior no nivel de tecnologia II e médio no nivel de tecnologia III, tal como a progênic 17.

Deve-se observar que não houve constataçăo de progênies com comportamento superior ou inferion, simulaneamente ros tres aiveis de tecnologia de implantaçä́ florestal. Isso mostra que os niveis de tec nologia silvicultural utilizados foram capazes de discriminar geneticamente as progênies de E. grandis. 


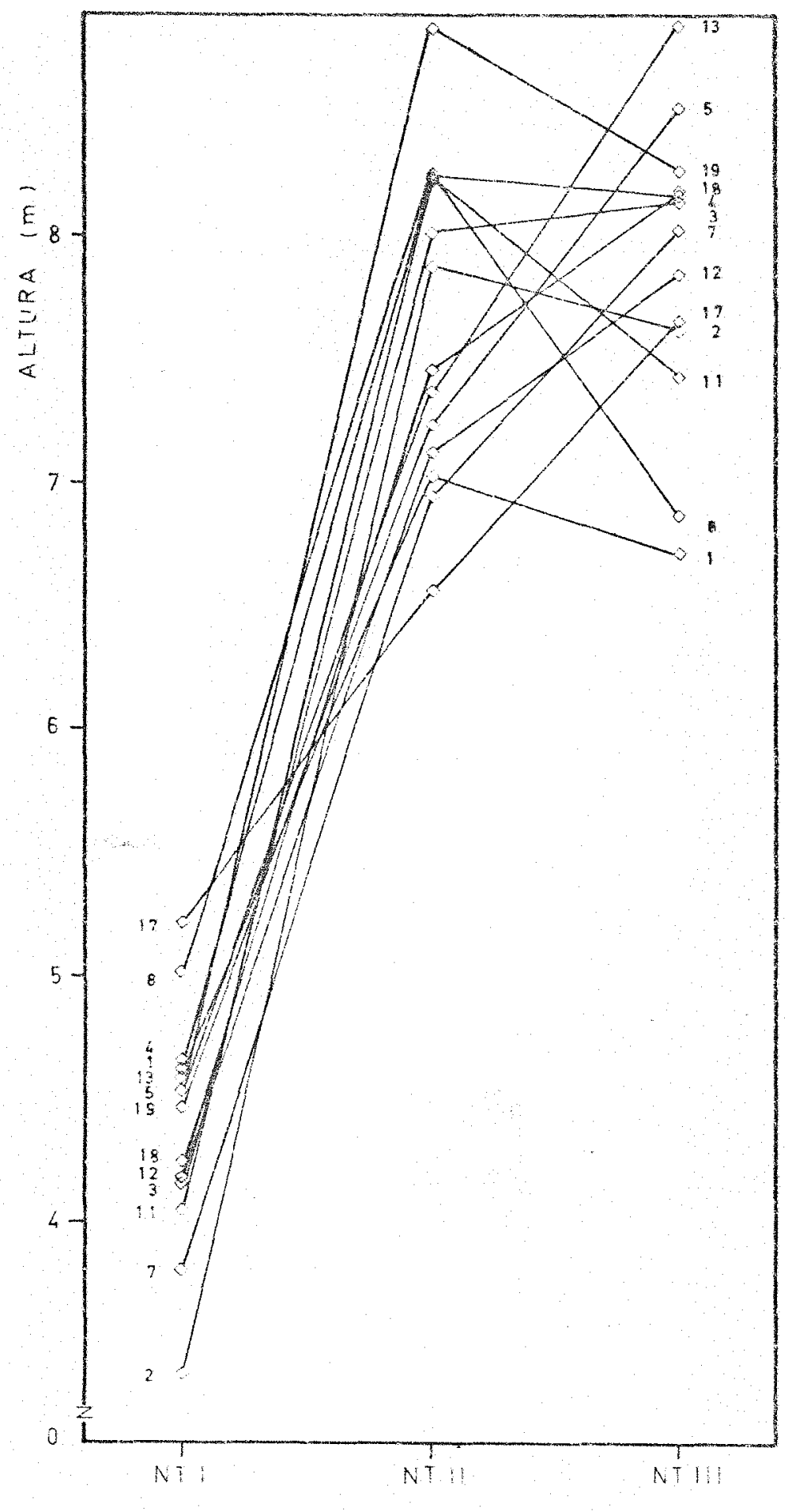

80

Nível de Tecnologia

Figura 14. Crescimento em altura de progênies de E. grochäis nos três niveis de tecnologia (NT) de implantaçăo Elorestal, aos 24 meses de idade 


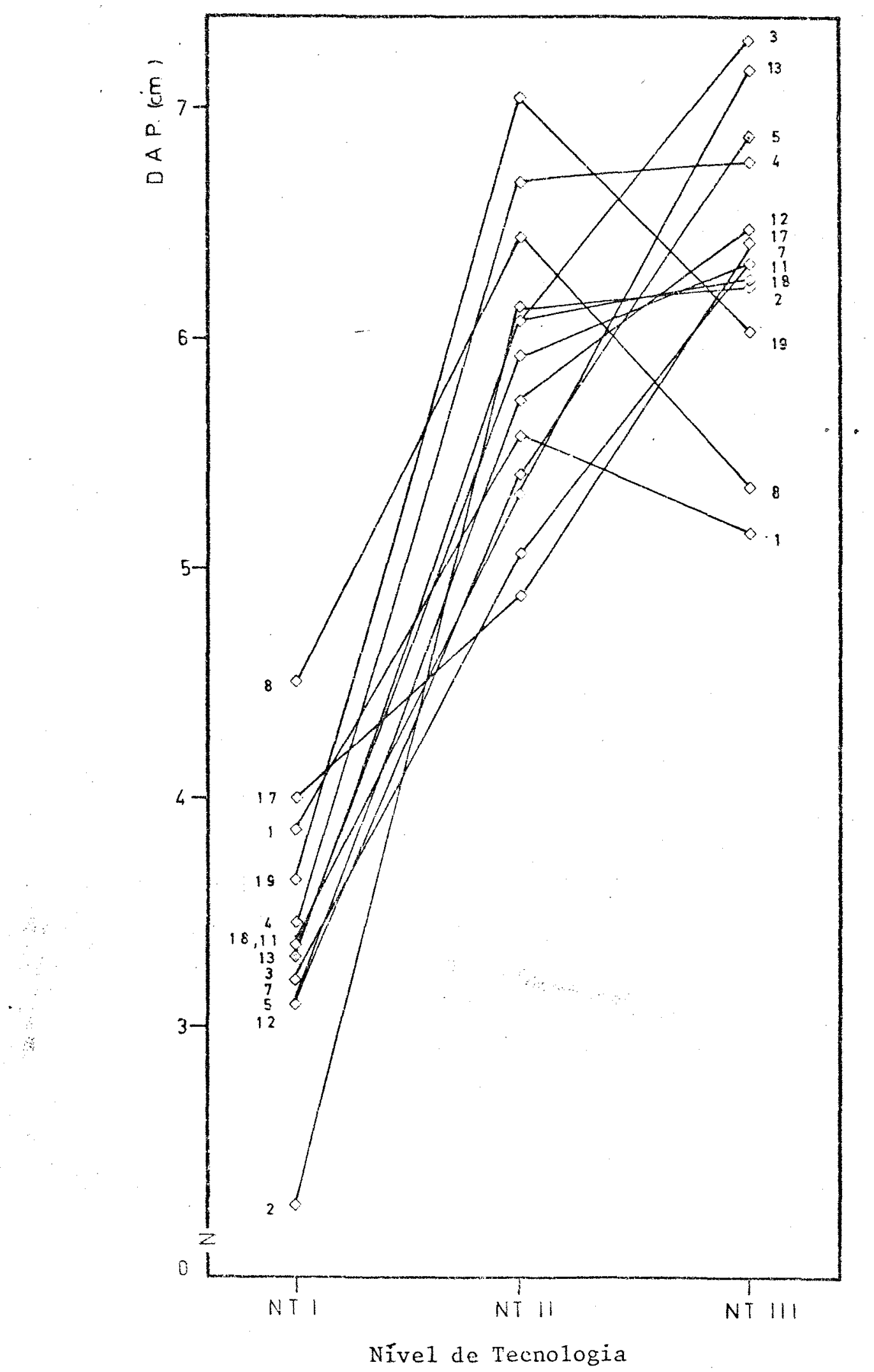

Figura 15. Crescimento em DAP de progênies de E.grandis nos três niveis de tecnologia (NT) de implantação fiorestal, aos 24 meses de idade 


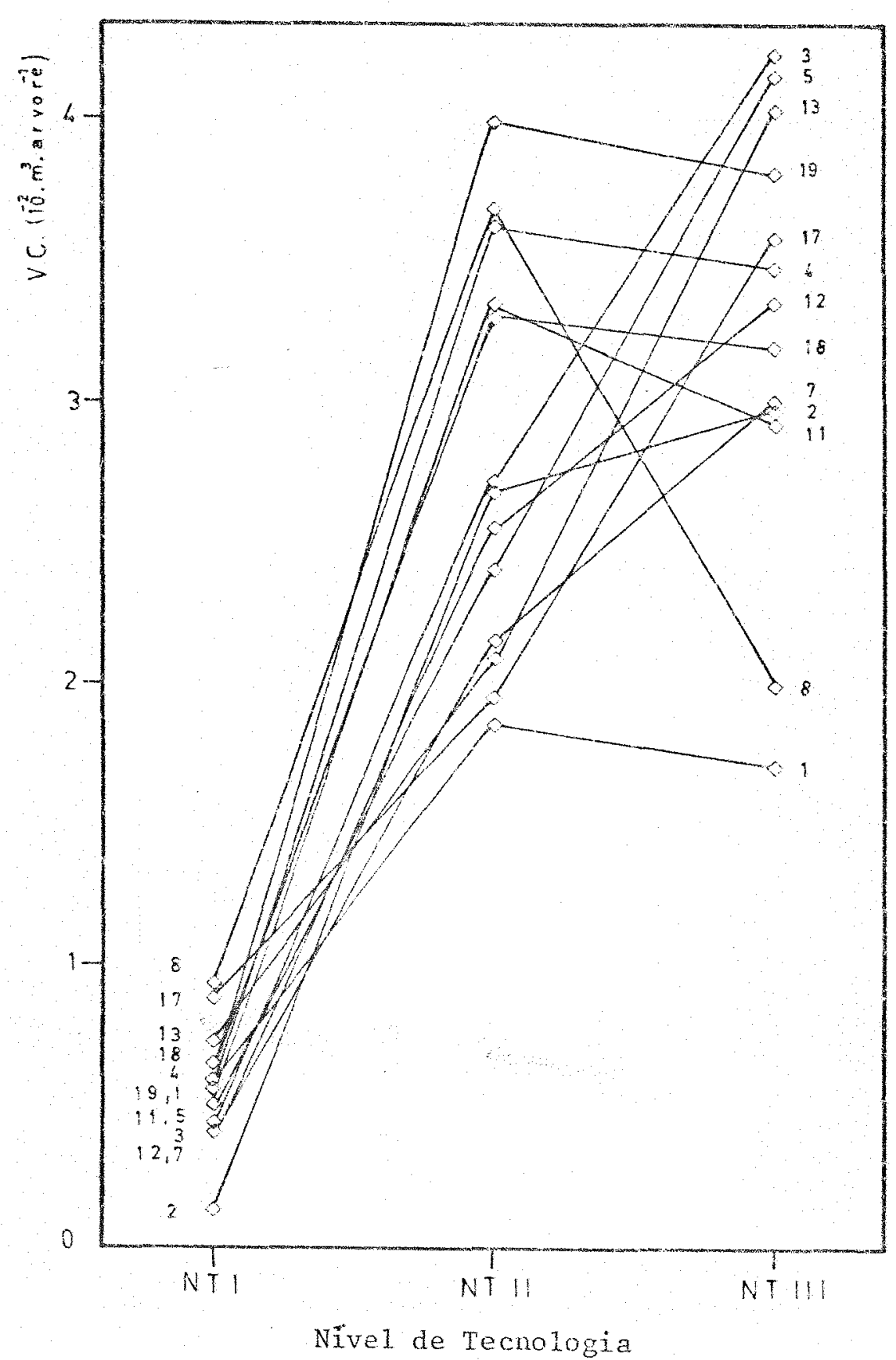

Figura 16. Crescimento em volume cilindrico (vC) de progênies de E.grandis nos três nïveis de tecnologia (NT) de implantação florestal aos 24 meses de idade 
4.2.2. Comportamento de progênies de $E$. camalduleneis

4.2.2.1. Avaliação de progênies de $E$. camaldutensis aos 7 meses de jade

Os resultados aos? meses de crescinento en altura e porcentagem de falhas, das analises de variancia individuais e conjuntas para os três nîveis de tecnologia de impiantação florestal são apresentados na Tabela 13.

As mëdias de altura de plantas de progênies de $E$. camalduZensis, nos diferentes niveis de tecnologia de implantação florestal, seguem a mesma tendência geral observada para progênies de $\mathbb{Z}$. grandis: as progênies cono um todo responderam ao preparo do solo (nível de tecnologia II) e apresentaram variaços quanto a resposta ao preparo do solo as sociado à fertilização mineral.

A porcentagem de falhas, como indicam as mëdias e as respectivas amplitudes de variação, soi reduzida ou nula para a naioria das progênies, mostrando uma boa sobrevivência para a espécie.

Nesta idade inicial, as variações genéticas entre progênies não se revelaram significativas para altura de plantas e porcentagem de falhas, a julgar pelos valores de $F$ obtidos nas anälises de variância para cada nivel de tecnologia silvicultural.

Nas anälises conjuntas, foran detectadas variações genëticas significativas somente para altura de plantas. O efeito dos niveis de tecnologia foi também notavel para esta caracteristica, sendo significati vo ao nivel de $1 \%$ 
Tabela 13. Resultados das anälises de variância individuais e conjuntas pa ra altura de plantas e porcentagen de calhas de progênies de E. comatauzensis em três niveis de tecnologia (Nr) de implantação florestal, aos 7 meses de idade

\begin{tabular}{|c|c|c|c|c|}
\hline \multirow{2}{*}{$\begin{array}{l}\text { Caracteristicas } \\
\text { e parametros }\end{array}$} & \multicolumn{3}{|c|}{ Niveis de tecnologia } & \multirow{2}{*}{$\begin{array}{l}\text { Anālise } \\
\text { conjunta }\end{array}$} \\
\hline & NTI & NTII & NIIII & \\
\hline
\end{tabular}

Altura (m)

Média geral

1,11

1,80

1,87

1,59

Amplitude de variação

$0,87-1,25$

$1,49-2,00$

$1,57-2,17$

-

$\mathrm{F}(\mathrm{P})$

(1)

1,75 ins

$1,75^{\mathrm{ns}}$

$0,82^{\text {ns }}$

$1,88 \%$

$\mathrm{F}(\mathrm{NT})$

(2)

$\mathrm{F}(\mathrm{P} \times \mathrm{NT})$

(3)

$-$

$-$

$14,47 \%$

CV experimental (\%)

(4)

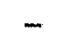

-

$0,75^{\mathrm{ns}}$

9,96

16,70

13,75

Falhas (\%)

Média geral

Amplitude de variação

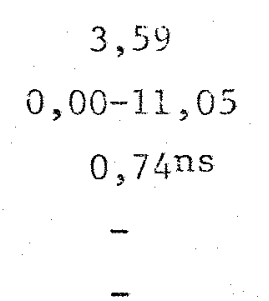

7,53
0,49
$0,00-5,39$

$0,93 n s$

-

$-$

2,76
0,49

$0,00-5,39$

0,93 ns

$-$

$-$

2,76
1,52

$-$

$0,52^{\mathrm{ns}}$

$2,36^{\mathrm{ns}}$

$0,76^{\mathrm{ns}}$

$5,30^{\mathrm{ns}}$

NTI: sem preparo do solo e sem adubação mineral;

NTIX: preparo do solo sen adubação mineral;

NTIII: preparo do solo e adubação mineral;

(1), (2) e (3): teste $F$ para as progênies, niveis de tecnologia e interaçăo de progenies $x$ utiveis de tecnologia;

(4): coeficiente de variaça experimental cm porcentagem:

ns: não significativo;

* : significativo ao njuvel de $5 \%$

$* *$ : simificativo a nivel de $1 \%$ 
A interação de progenies $x$ nïveis de cecnologia não se mos trou significativa para as duas caracteristicas. Entretanto, como iustra a Figura 17 , à semelhança de progênies de $E_{\text {. }}$ grandis, obsexva-se uma tendência de interaçăo complexa entre as progênies e os niveis de tecnologia I, II e III, porém menos nĭtido do que a verificada para o E. grandìs.

4.2.2.2. Avaliação de progênies de E. comaldulensis aos 12 meses de idade

Os resultados aos 12 meses de crescimento em altura de plantas, porcentagem de falhas, das anälises de variancia individuais e conjuntas para os três niveis de tecnologia de implantaçäo florestal, säo apresentados na Tabela 14.

Em geral os resultados das anälises de variancia individuais e conjuntas, tanto para altura de plantas como para a porcentagem de falhas, são semelhantes aos da avaliação anterior. As variações genéticas entre progênies continuaram não significativas para ambas as características, considerando-se os valores de $F$ obtidos nas anälises individuais.

Os valores de $F$ das anälises individuais para altura de plantas e porcentagem de falkas sofreram una reduçäo com a idade, e continuaram sem nostram una tendencia definida. 


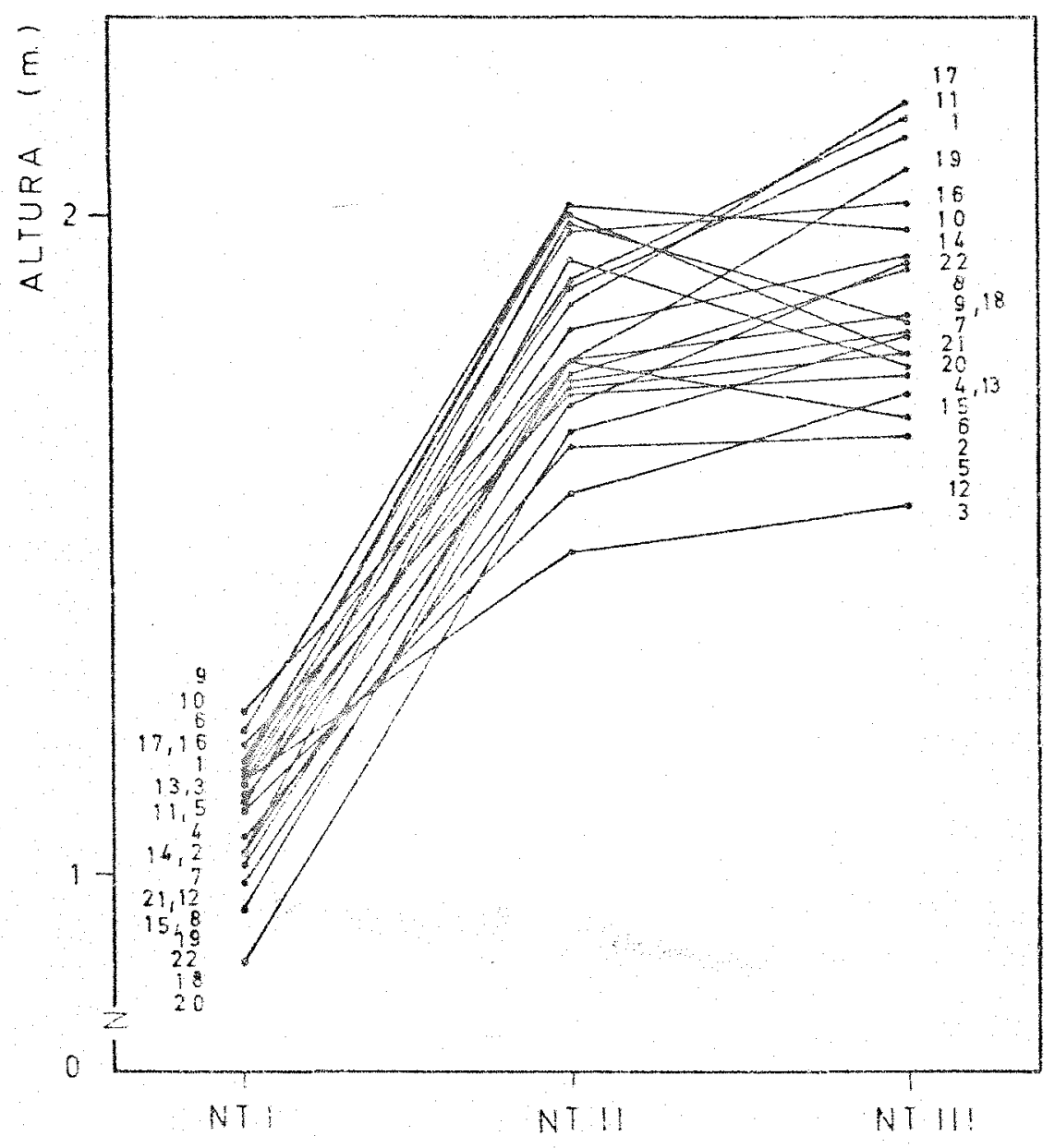

Nivel de Tecnologia

Figura 17. Crescimento em altura de progênies de E. camaldulensis nos três nîveis de tecnologia (NT) de implantação florestai aos 7 meses de idade 
Tabela 14. Resultados das anälises de variancia individuais e conjuntas pa ra altura de plantas e porcentagem de falhas de progênies de $E$. camaldubensis em três niveis de tecnologia (NT) de implan tação florestal, aos 12 meses de idade

Características

e parâmetros

Niveis de tecnologia

NI'I

NTII

Anälise

conjunta

\section{Altura (m)}

Média geral

2,08

3,71

4,07

3,29

Amplitude de variação

$\mathrm{F}(\mathrm{P})$

(1)

$1,74-2,38$

$3,12-4,24$

$3,43-4,67$

$-$

$\mathrm{F}(\mathrm{NT})$

(2)

$\mathrm{F}(\mathrm{P} \times \mathrm{NT})$

(3)

$1,38^{\mathrm{ns}}$

$1,37^{\mathrm{ns}}$

$0,70^{\mathrm{ns}}$

$1,57 \mathrm{~ns}$

$\mathrm{CV}$ experimental

(\%)

(4)

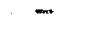

$-$

11,75
$-$

$-$

13,89
$28,85 \%$ \%

$0,83^{\mathrm{ns}}$

13,45

Falhas (\%)

Média geral

Amplitude de varíação

$\mathrm{F}(\mathrm{P})$

$\mathrm{F}(\mathrm{NT})$

$\mathrm{F}(\mathrm{P} \times \mathrm{NT})$

$\mathrm{CV}$ experimental

$\begin{array}{cccc}5,50 & 0,98 & 0,73 & 2,40 \\ 0,00-20,87 & 0,00-5,39 & 0,00-5,39 & - \\ 0,95 \mathrm{~ns} & 0,88^{\mathrm{ns}} & 0,86 \mathrm{~ns} & 0,66^{\mathrm{ns}} \\ - & - & - & 2,11 \mathrm{~ns} \\ - & - & - & 1,06 \mathrm{~ns} \\ 8,58 & 3,77 & 3,41 & 5,86\end{array}$

NTI: sem preparo do solo e sem adubação minexal;

NIII: preparo do solo sem adubaçăo mineral;

NTIII: preparo do solo e adubação mineral;

(1), (2) e (3): teste $F$ para as progênies, níveis de tecnologia e interação de progêries $x$ niveis de tecrologia;

(4): coeficiente de veriagäo experimental em porcentagem:

ns: não significativo;

* : significativo ao njuel de $5 \%$;

$* *$ : significativo ao nivel de $1 \%$ 
Os coeficientes de variação experimentais para altura de plantas foram semelhantes nos três níveis de tecnologia, aunentando Ieve mente com a melhoria do nivel de tecnologia silvicultural. Os referentes a porcentagem de falhas foram menores que os de altura de plantas e diminuiram com a elevaçäo do nive1 de tecnologia.

Nas anëlises conjuntas para os três niveis de tecnologia houve significancia somente para o efeito dos niveis de tecnologia na altura de plantas. A variaçäo genética entre progênies näo se revelou significativa para altura de plantas, mudando assim a tendência obsexvada aos 7 meses de idade.

A variação da altura de plantas devido ao efeito dos níveis de tecnologia aumentou expressivamente em relação a avaliaçäo anterior, a julgar pelos valores de F obtidos para esse efeito aos 7 e 12 meses de idade. Este resultado ë diferente do observado para progenies de E. grandis, que jä aos 12 meses de idade tiveram uma diminuição do efeito do nivel de tecnologia no crescimento em altura.

o efeito da interação continua não significativo. A Figura 18 mostra a tendência de interação complexa relatada aos 7 meses de idade. 


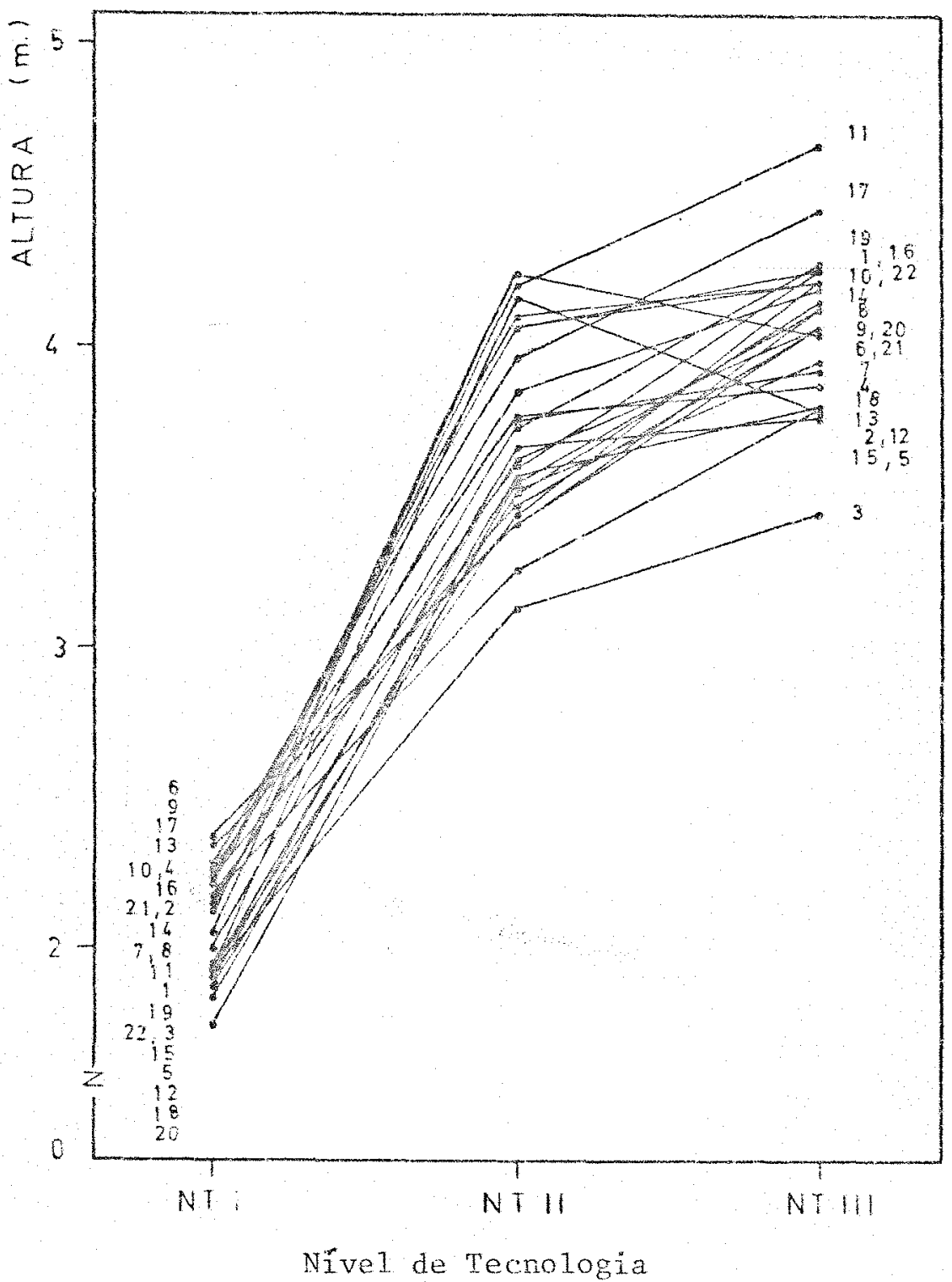

Figura 18. Crescimento em altura de progênies de E. camaldulensis em três niveis de tecnologia (NT) de implantação florestal, aos 12 me ses de idade 
4.2.2.3. Avaliação de progênies de tr. comatdutensis aos 18 meses de idade

Os resultados de crescimento em altura de plantas, DAP, volume cilindrico, porcentagem de falhas, das anālises de variancia individuais e conjuntas para os três niveis de tecnologia de implantação florestal, para progênies de E. camaläulensis aos 18 meses de idade, são apresentados na Tabela 15.

Os resultados das anälises individuais revelam a tendência geral, jä constatada em avaliações de progênies de ț. grandis, de diminuição do efeito de progênie e aumento do coeficiente de variação expe. rimental com a melhoria do nivel de tecnologia.

As variaçöes genêticas entre progênies foran significativas no primeiro nível de tecnologia para o DAP e volume cilindrico, näo o sondo para altura de plantas.

A porcentagem de falhas apresentou um comportamento inverso ao das caracteristicas de crescimento, aumentando o efeito de proge-m nies e diminuindo o coeficiente de variação com a elevação do nĩvel de tecnologia. Como em avaliaçöes anteriores, o efeito de progênies não se mostrou signíficativo para esta cracterística en lodas as anälises de variância realizadas. 
Tabela 15. Resultados das anälises de variância individuais e conjuntas pa ra altura de plantas, DAP, volune cilindrico (VC) e porcentagem

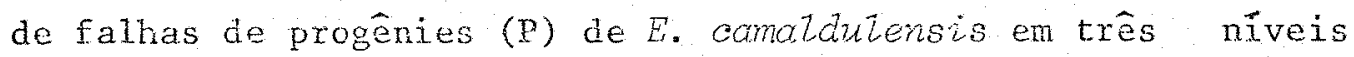
de tecnología (NT) de implantação florestal, aos 18 meses de idade

\begin{tabular}{|c|c|c|c|c|}
\hline \multirow{2}{*}{$\begin{array}{l}\text { Caracteristicas } \\
\text { e parametros }\end{array}$} & \multicolumn{3}{|c|}{ Niveis de tecnolozia } & \multirow{2}{*}{$\begin{array}{l}\text { Anālise } \\
\text { conjunta }\end{array}$} \\
\hline & NTI & NTTI & NTTII & \\
\hline
\end{tabular}

Altura (m)

Média geral

Amplitude de variação

$\mathrm{F}(\mathrm{P})$

$\mathrm{F}(\mathrm{NT})$

$\mathrm{F}(\mathrm{P} \times \mathrm{NT})$

$\mathrm{CV}$ experimenta1
(1)

(2)

(3)

$(\%)$

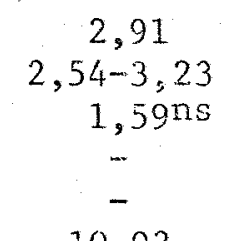

(4) 10,03

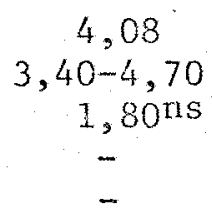

11,21

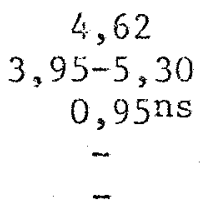

12,57
3,87

$-$

$2,28 * \%$

$17,36 \% *$

$0,84 \mathrm{~ns}$

11,85

DAP (cm)

Média geral

Amplitude de variação

$\mathrm{F}(\mathrm{P})$

$\mathrm{F}(\mathrm{NT})$

$\mathrm{F}(\mathrm{P} \times \mathrm{NT})$

CV experimental (\%)

$$
1,97
$$

$1,50-2,43$

$2,30 *$

3,11

3,71

$2,97-4,27$

$1,00^{\text {ns }}$

2,93

$2,57-3,67$
$1,01 \mathrm{~ns}$

$-$

$-$

$-$

13,68

-

$-$

16,60

$1,54 \mathrm{~ns}$

$14,66 * 2$

1,21 ns

16,47

VC $\left(10^{-2} \mathrm{x} \mathrm{m}^{3} /\right.$ ärvore $)$

Média gera1

Amplitude de variação

$F(P)$

$\mathrm{F}(\mathrm{NT})$

$F(P \times N T)$

CV experimental (\%)

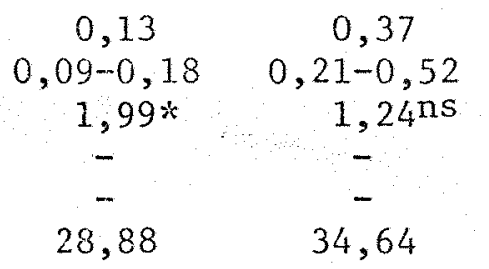
0,62
$0,40 \cdots 0,83$
1,08 ns
$-$

0,37

$-$

$1,57^{\mathrm{ns}}$

$14,03 * *$

$0,93^{\text {ns }}$

38,68

Falhas (\%)

Mëdia geral

Amplitude de variação

$F(P)$

$\mathrm{F}(\mathrm{NT})$

$\mathrm{E}(\mathrm{P} \times \mathrm{NT})$

CV experimental (\%)

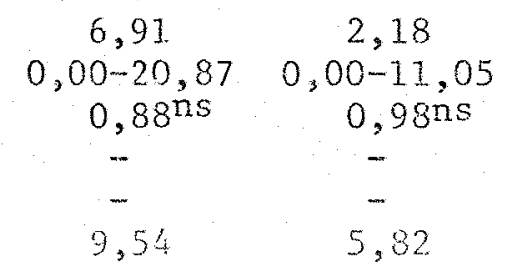

1,45

3,51

$0,00-11,05$

$1,25 \mathrm{~ns}$

$0,83^{\mathrm{ns}}$

$2,02 \mathrm{~ns}$

$1,01 \mathrm{~ns}$

7,14

NTI: sem preparo do solo e sem adubação mineral;

NTII: preparo do solo sem adubaçäo mineral;

NTIII: preparo do solo e adubacáo mineral:

(1), (2) e (3): teste $F$ para as progênies, niveis de tecnologia e interação de progenies $x$ niveis de tecnologia;

(4): coeficiente de variação experimental em porcentagem;

ns : não significativo:

$*$ : significativo ao nuvel de $5 \%$;

$* *$ : significativo ao nivel de $1 \%$ 
As variaçōes genēticas para as quatro caracteristicas, in dicadas pelos respectivos valores de $F$, bem como os coeficientes de varia ção experimentais, para a maioria das anälises individuáăs, continuaran menores do que os observados para o $E$. grandis, seguindo a tendência relatada aos 12 meses de idade.

o efeito dos niveis de cecnologia foi altamente signjitcativo para as características de crescimento, não o sendo para a porcentagem de falhas como na idade anterior. Variaçöes genëticas significativas para os três níveis de tecnologia foram detectadas sonente para aitura de plantas. A interação de progênies $x$ niveis de tecnologia continuou não significativa. As Figuras 19,20 e 21 mostram o crescimento cm altura, DAP e volume cilindrico das diferentes progêries, nos três niveis de tecnologia de implantação florestal.

Contrastando con os resultados das anälises individuais, os efeitos de progênies e níveis de tecnologia, nas anälises conjuntas para as caracteristicas de crescimento, foram mais expressivos no $E_{\text {. ca- }}$ maldulensis do que no $E$. grandis. Observe-se que, como nas anälises de variancia individuais, os coeficientes de variaçäo experimentais foram sempre maiores para o E. grandis. 


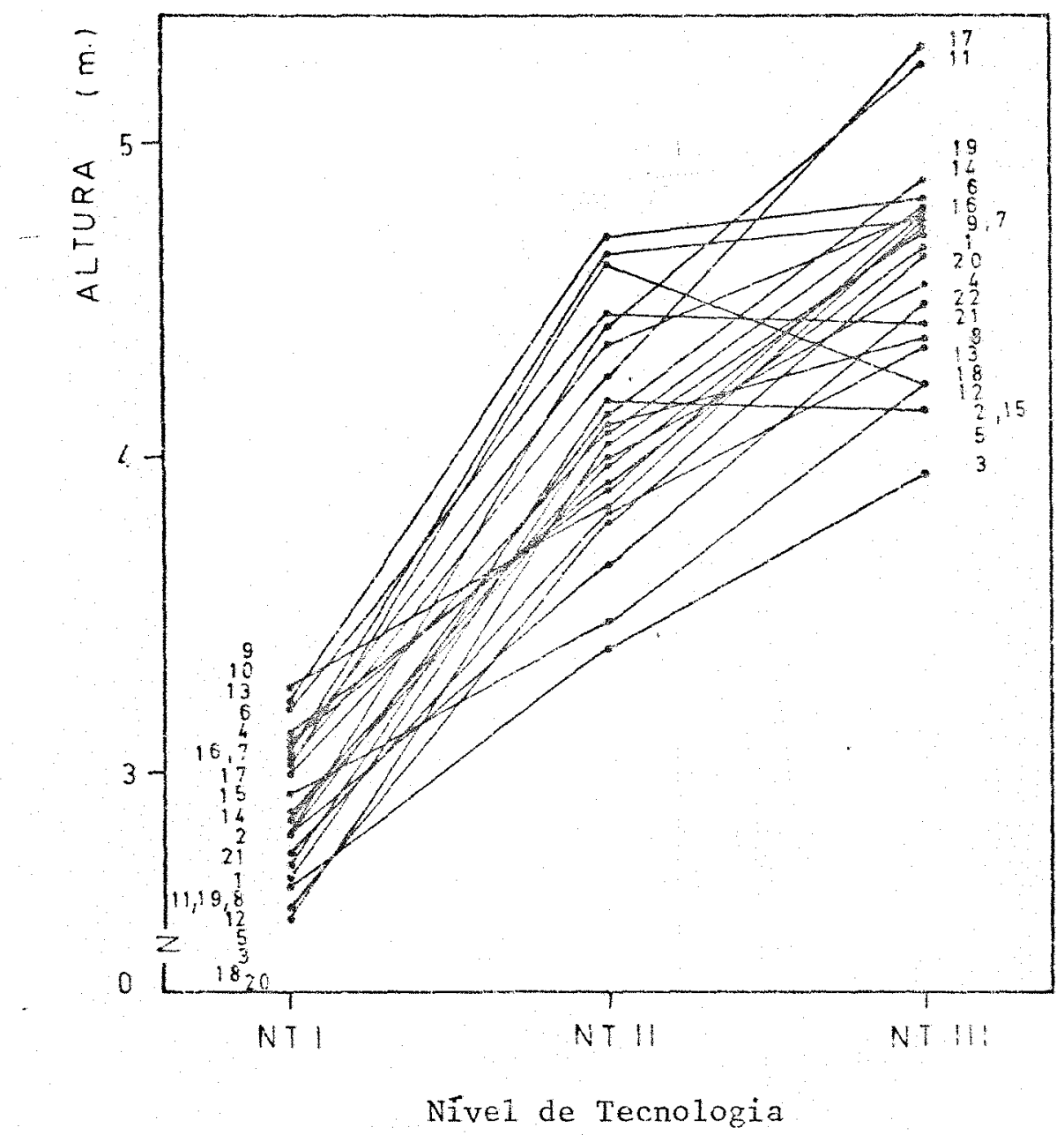

Figura 19. Crescimento en altura de progentes de $E$. camatäuzensis nos três niveis de tecnologia (IT) de implantaçäo florestal, aos 18 meses de iaade 


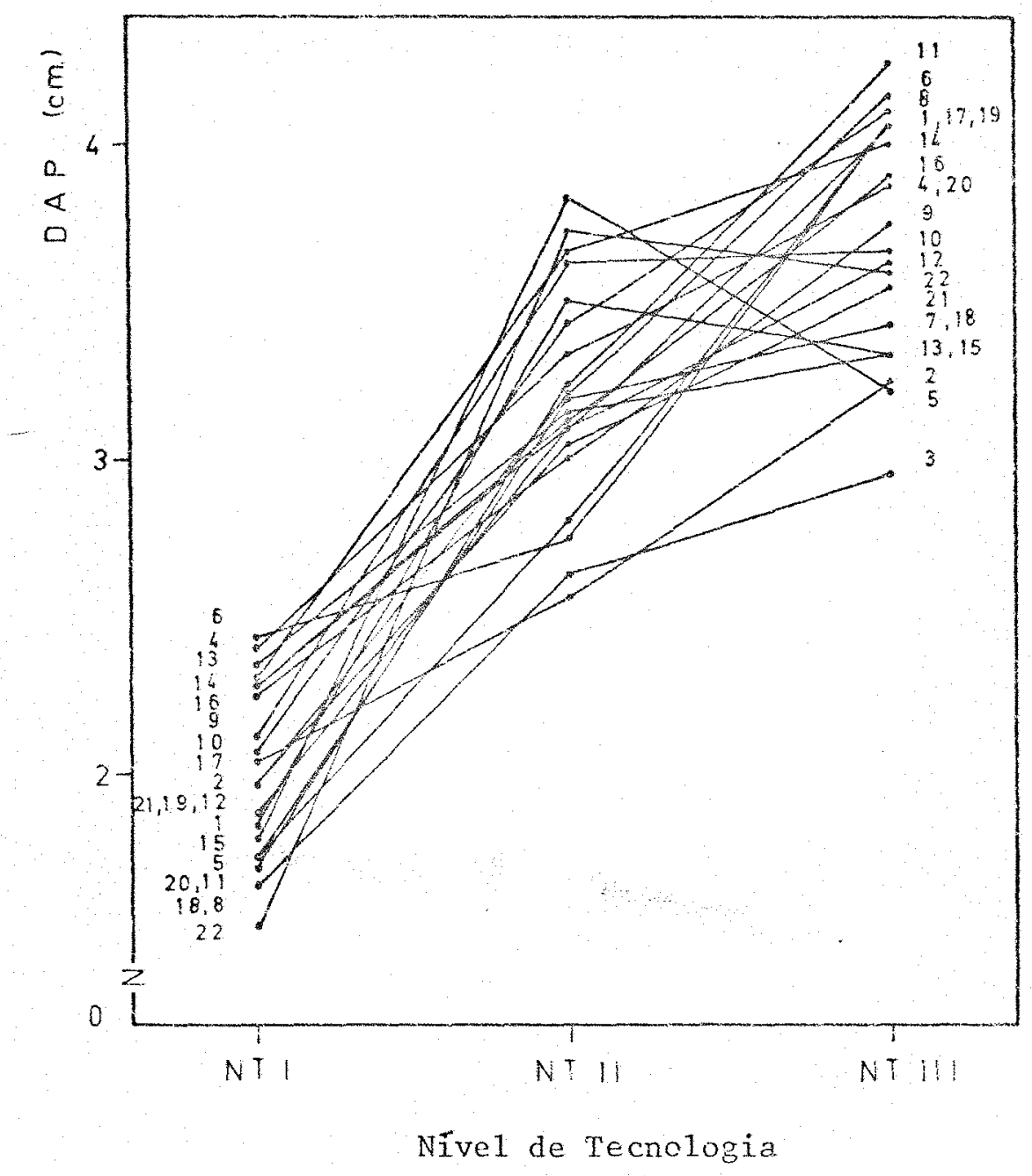

Figura 20. Crescimento en DAP de progênies de E. comaldulensis nos três niveis de tecnologia (MI) de implantaçäo filorestal, aos 18 meses de idade 


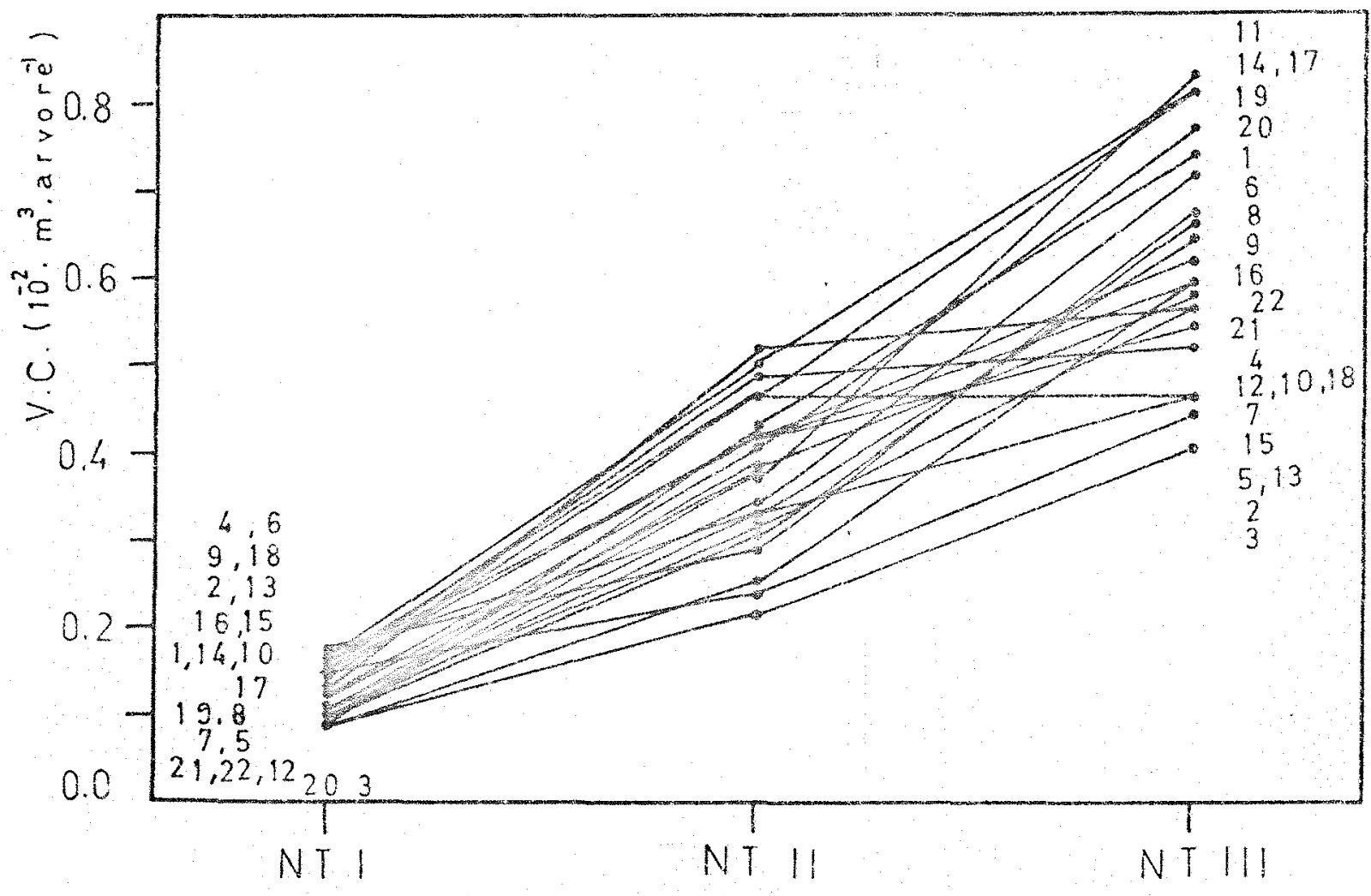

Nivel de Tecnologia

Figura 21. Crescimento en volume cilindrico (vC) de progentes de $E$. camaldutenstas nos três niveis de tecnologia (NT) de implantação florestal, aos 18 meses de idade 
4.2.2.4. Avaliação de progênies de $E$. camaldulensis aos 24 meses de idade

Os resultados de crescimento en altura de píntas, DAP, vo lume cilîndrico, porcentagem de falhas, das anälises de variância individuais e conjuntas para os três nǐveis de tecnologia de implantação flores ta1, são apresentados na Tabela 16.

os dados médios de altura de plantas obtidos aos 24 meses confirmam a tendência observada nas idades iniciais, quanto à resposta às técnicas de implantação florestal, especialmente ao preparo do solo, para a maioria das progênies de $E$. camalduZensis.

A porcentagem de falhas continuou baixa nos três riveis de tecnologia. Nas parceìas que não receberan o preparo do solo nem a fertilização mineral (nível de tecnologia I), onde registrou-se a maior mortalidade de plantas en progênies de $E$. grandis, a sobrevivência de plantas foi elevada para a maioria das progênies de E. camalduzensis, comprovando a boa adaptação da espécie a condições rüsticas. Resultados semeThantes foram obtidos por DELWAULLE (1979) e PIRES et ali i (1983), respectivamente, em pesquisas de resposta de $E$. camaldulensis à niveis de pre paro do solo e en ensaios de competiçäo de espëcies de Eucalyptus em condiçöes semi-äridas. 
Tabela 16. Resultados das anälises de variancia individuais e conjuntas pa ra altura de plantas, DAP, volume cilindrico (VC) e porcentagem de falhas de progênies (P) de E. camaldulensis em três níveis de tecnologia (NT) de implantação florestal, aos 24 meses de idade

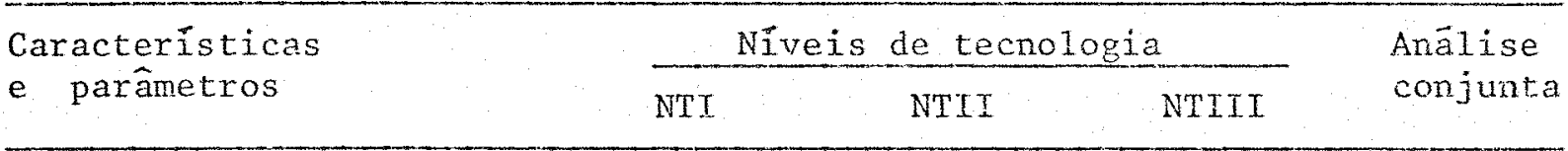

Altura (m)

Média geral

Amplitude de variação

$\mathrm{F}(\mathrm{P})$

$\mathrm{F}(\mathrm{NT})$

$\mathrm{F}(\mathrm{P} \times \mathrm{NT})$

$\mathrm{CV}$ experimental
(1)

(2)

(3)

4,42
$3,85-4,95$
1,7705
-
-
9,17

5,61
$4,72-6,33$
$1,07 n s$
-
12,34

6,28
$5,47-7,03$
$1,25 n s$
-
-
-

5,44

$2,17 * \%$

$12,23 * *$

$0,82 \mathrm{~ns}$

11,00

DAP $(\mathrm{cm})$

Média geral

Amplitude de variação

$\mathrm{F}(\mathrm{P})$

$\mathrm{F}(\mathrm{NT})$

$\mathrm{F}(\mathrm{P} \times \mathrm{NT})$

CV experimental (\%)

VC $\left(10^{-2} \times \mathrm{m}^{3} /\right.$ arvore $)$

Média geral

Amplitude de variaçăo

$\mathrm{F}(\mathrm{P})$

$\mathrm{F}$ (NT)

$F(P \times N T)$

$\mathrm{CV}$ experimental (\%)

$\begin{array}{cccc}3,35 & 4,16 & 5,23 & 4,25 \\ 2,74-3,97 & 3,19-4,94 & 4,18-5,97 & - \\ 2,64 * * & 1,34 \mathrm{~ns} & 1,15 \mathrm{~ns} & 2,38 * * \\ - & - & - & 8,39 * \\ - & - & - & 0,94 \mathrm{~ns} \\ 12,48 & 17,09 & 15,14 & 15,62\end{array}$

$\begin{array}{cccc}0,52 & 0,95 & 1,65 & 1,04 \\ 0,33-0,71 & 0,45-1,35 & 1,09-2,27 & \\ 2,20 * & 1,51 \mathrm{~ns} & 1,14 \mathrm{~ns} & 2,08 * \mathrm{*} \\ - & - & - & 8,96 \% \\ - & - & - & 0,95 \mathrm{~ns} \\ 27,86 & 37,23 & 32,96 & 36,98\end{array}$

Falhas (\%)

Mëdia geral

Amplitude de variação

$\mathrm{F}(\mathrm{P})$

$F(N T)$

$\mathrm{F}(\mathrm{P} \times \mathrm{NT})$

CV experimental (\%)

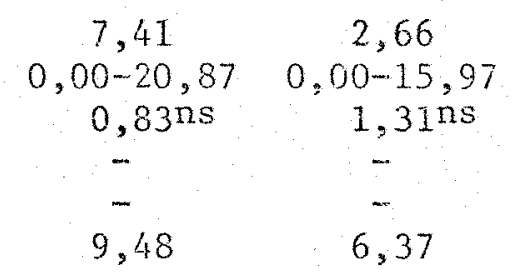
1,45
$0,00-10,07$
$0,85^{\mathrm{ns}}$

3,84

$0,90^{\mathrm{ns}}$

$2,32 n \varepsilon$

$0,93 \mathrm{~ns}$

7,27

NTI: sem preparo do solo e sem adubaçäo mineral;

NTII: preparo do solo sem adubação mineral;

NTIII: preparo do solo e adubaçáo mineral;

(1), (2) e (3): teste $\mathrm{F}$ para as progênies, níveis de tecnologia e interação de progenies $x$ niveis de tecrologia;

(4): coeficiente de variação experimental em porcentagem;

ns : não significativo:

* : significativo ao nivel de $5 \%$;

$* *$ : significativo go nivel de $1 \%$. 
LADRACí (1983a), por sua vez, constatou, em ensaios de competição de espëcies e procedências de Eucalyptus em vários locais, uma tendência para oE. camaldulensis superar O E. grandis en condições de baixo potencial florestal, ou seja, de menor precipitação anual e em solos de baixa fertilidade.

Os resultados das anālises de variância individuais foram semelhantes aos obtidos na avaliação anterior, confirmando, na avaliaçäo final, a tendência para a diminuição da variação entre progênies com o aumento do nivel de tecnologia.

Por outro lado, ICFR (1985) comenta que o preparo do solo e a fertilização mineral, alēm do incremento que proporcionan nas características de crescimento, aumentam a uniformidade dentro dos povoamentos. Relatam ainda que, em geral, o coeficiente de variação da população tem se revelado menor em parcelas que receberam o preparo do solo e adubação mineral do que naquelas que não tiveram melhorias no ambiente. Assim, provavelmente, o preparo do solo e a aplicação de fertilizantes minerais tenderam a reduzir as variações entre as progênies nos niveis de tecnologia II e III.

Comparancio-se os resultados das anälises de variância individuais de $E$. grandis e E. camalduzensis, aos 24 meses, verifica-se a mesma tencencia de điminuição do efeito de progeñies con a melhoriá do nivel de tecnologia silvicultural, para as caracteristicas de crescimento. os coeficientes de variação experimentajs correspondentes a essas anälises mostraram-se semelhantes nas duas espëcies, com valores no geral, menores para E. camatäritensis para as três caracteristicas. 
No caso da porcentagem de falhas, as especies tiveram tendências bastante distintas. Enquanto ro E. grandis houve uma tendencia de diminuiçäo do efeito de progênies com o aumento do nivel de tecnologia, no $E$. camaldulensis isso não se verificou, não se registrando diferenças entre progênies nas três tecrologias conforme foi enfatizado.

Nas anāilises conjuntas os efeitos de progênies e de niveís de tecnologia foram significativos para as três caracteristicas de crescimento. Por outro lado a interação de progênies $x$ níveis de tecnologia não se mostrou significativa para essas caracteristicas, Para porcentagem de falhas, nenhum dos efeitos foi significativo.

Muito embora não tenha sido detectada interação significativa de progènies com niveis de tecnologia, $\vec{e}$ interessante observar a ten dência de comportamento diferencial de algumas progênies quando se muda 0 nivel de tecnologia. Esse comportamento se verifica entre os três niveis de tecnologia silvicultural, diferinto do E. grandis onde isso se dava somente entre os níveis de tecnologia II $\in$ III, conforme pode ser visualizado nas Figuras 22,23 e 24.

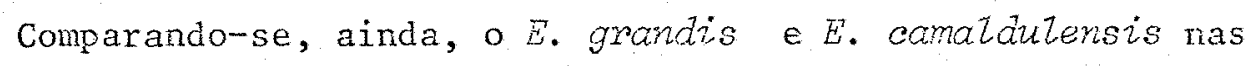
análises conjuntas, verifica-se que os efeitos de progênies e níveis de tecnologia foram mais expressivos para $\circ E$. camazdizensis. Da mesma forma, os coeficientes de variação experimentais foram sempre maiores em $E_{\text {. }}$ grandis. 


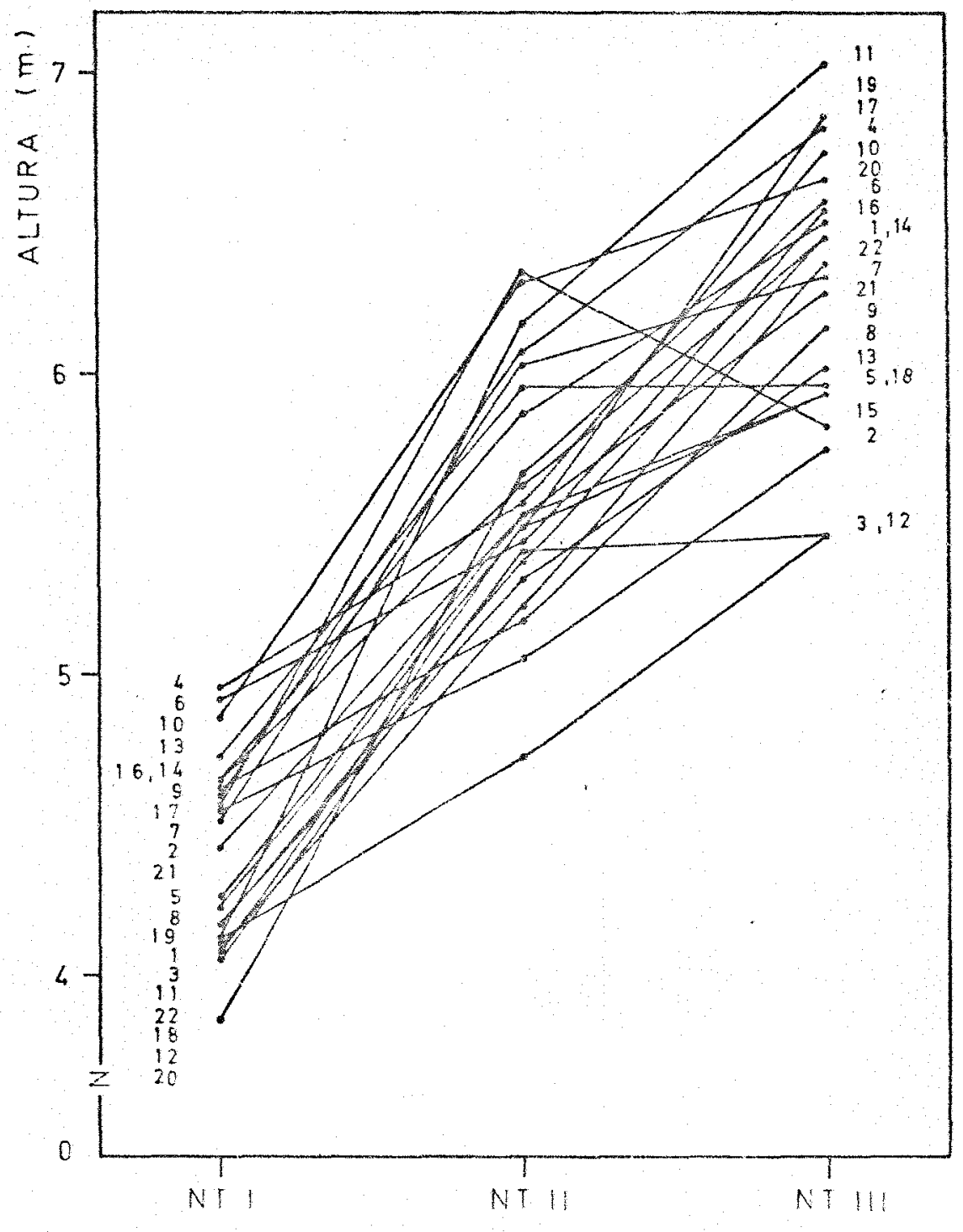

Nivel de Tecnologia

Figura 22. Altura mëdia de progênies de $E$. camaldulensis nos três níveis de tecnologia (NT) de implantação florestal, aos 24 meses de idade 


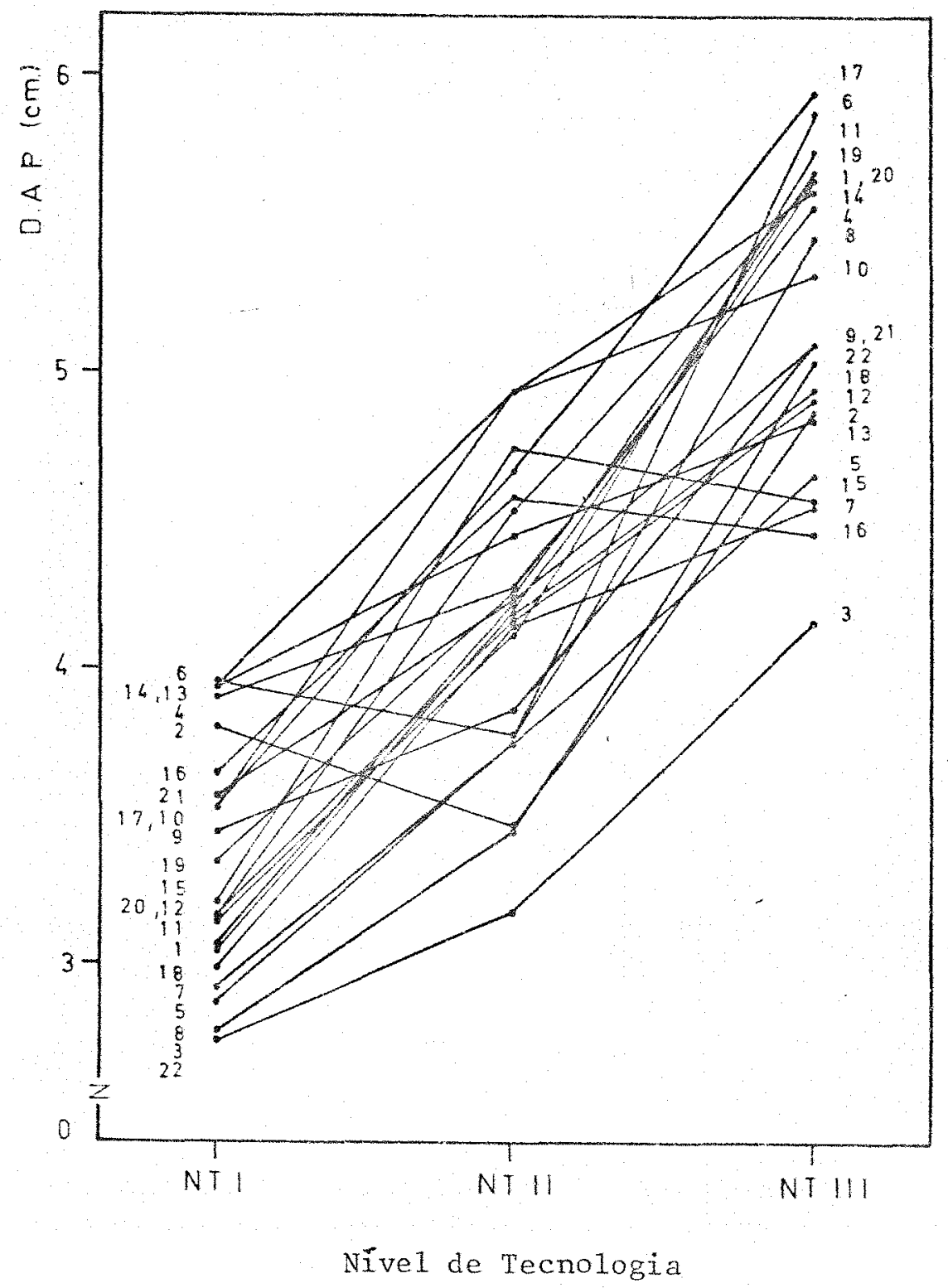

Figura 23. Crescimento em DAP de progênies de E. camaldutensis nos três nỉveis de tecnologia (NT) de implantação florestal aos 24 meses de idade 


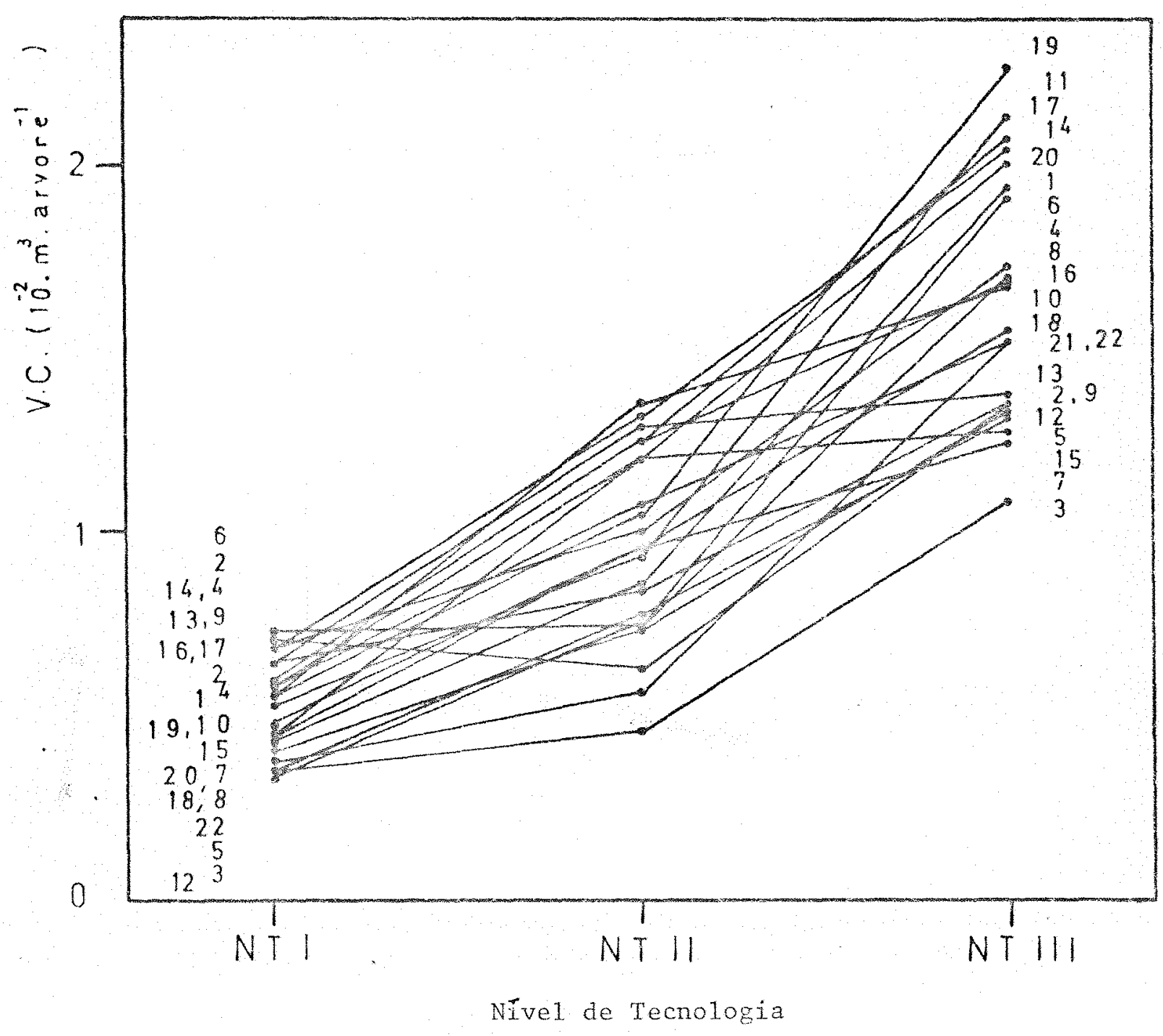

Figura 24. Crescimento em volume cilfundrico (Vo) de progentes de E. Camalutuensis nos três niveis de tecnologia (NT) de implantação florestal, aos 24 meses de idade 
4.2.3. Comportamento de progênies de E. citriodora

4.2.3.1. Avaliação de progênies de E.citriodora aos 7 meses de idade

Os resultados aos 7 meses de crescimento em altura, porcentagem de falhas, das análises de variância individuais e conjuntas pa ra os três nỉveis de tecnologia de implantação florestal, são apresentados na Tabela 17.

O. E. citriodora como relatado nas anälises efetuadas ao nível de espécies, apresentou um comportamento diferente ao do E. grandis e $E$. camaldutensis aos 7 meses de idade: respondeu ao preparo do solo e não reagiu ao preparo de solo mais a fertilização mineral. Esse conportamento geral, ao nivel de progênies, pode ser visualizado na Figura 25, na qual se observa que para a maioria das progênies o melhor desenvolvimento em altura de plantas foi verificado em parcelas que receberam somente o preparo do solo (nivel de tecnologia II).

As anälises de variäncia individuais revelaram variações genéticas significativas para altura de plantas somente no segundo nível de tecnologia e não significativas para a porcentagem de falhas.

O resultado encontrado para altura de plantas foi diferente do obtido para o $E$. grandis e E. camaldulensis, que tiveram uma tendên cia para a significância da variação genética para esta característica no nivel de tecnologia $I$. 
Tabela 17. Resultados das anälises de variância individuais e conjuntas pa ra altura de plantas e porcentagem de falhas de progênies de E. citriodora em três níveis de tecnologia (NT) de implantação florestal, aos 7 meses de idade

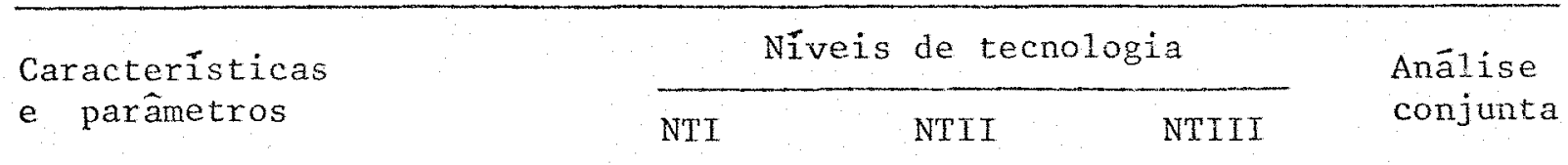

Altura (m)

Média geral

0,99

1,34

1,22

1,18

Amplitude de variação

$0,82-1,17$

$1,11-1,54$

$1,03-1,38$

$-$

$\mathrm{F}(\mathrm{P})$

(1)

$2,02^{\mathrm{ns}}$

$3,23 * *$

$0,84^{\mathrm{ns}}$

$2,41 * *$

$\mathrm{F}(\mathrm{NT})$

(2)

$-$

$-$

$-$

$4,54^{\mathrm{ns}}$

$\mathrm{F}(\mathrm{P} \times \mathrm{NT})$

(3)

$-$

$-$

$-$

$1,04^{\text {ns }}$

CV experimental

(\%)

(4) 12,27

8,95

17,95

13,50

Falhas (\%)

Mëdia geral

$$
10,56 \quad 0,38
$$

6,73

5,89

Amplitude de variação

$0,00-21,14$

$0,00-5,39$

$0,00-15,97$

-

$\mathrm{F}(\mathrm{P})$

$0,70^{\text {ns }}$

1,00 ns

$0,84 \mathrm{~ns}$

$0,49 n$

$F(N T)$

$\mathrm{F}(\mathrm{P} \times \mathrm{NT})$

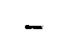

$-$

$9,74 *$

$\mathrm{CV}$ experimental (\%)

12,26

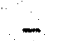

$-$

$0,65 \mathrm{~ns}$

NTI: sem preparo do solo e sem adubação mineral;

NTII: preparo do solo sem adubação mineral;

NTIII: preparo do solo e adubação mineral;

(1), (2) e (3): teste $F$ para as progênies, niveis de tecnologia e interação de progenies $x$ niveis de tecnologia;

(4): coeficiente de variaçäo experimental om porcentagen;

ns : não significativo;

* : significativo ao nível de $5 \%$;

$*$ : significativo ao nivel de $1 \%$ 


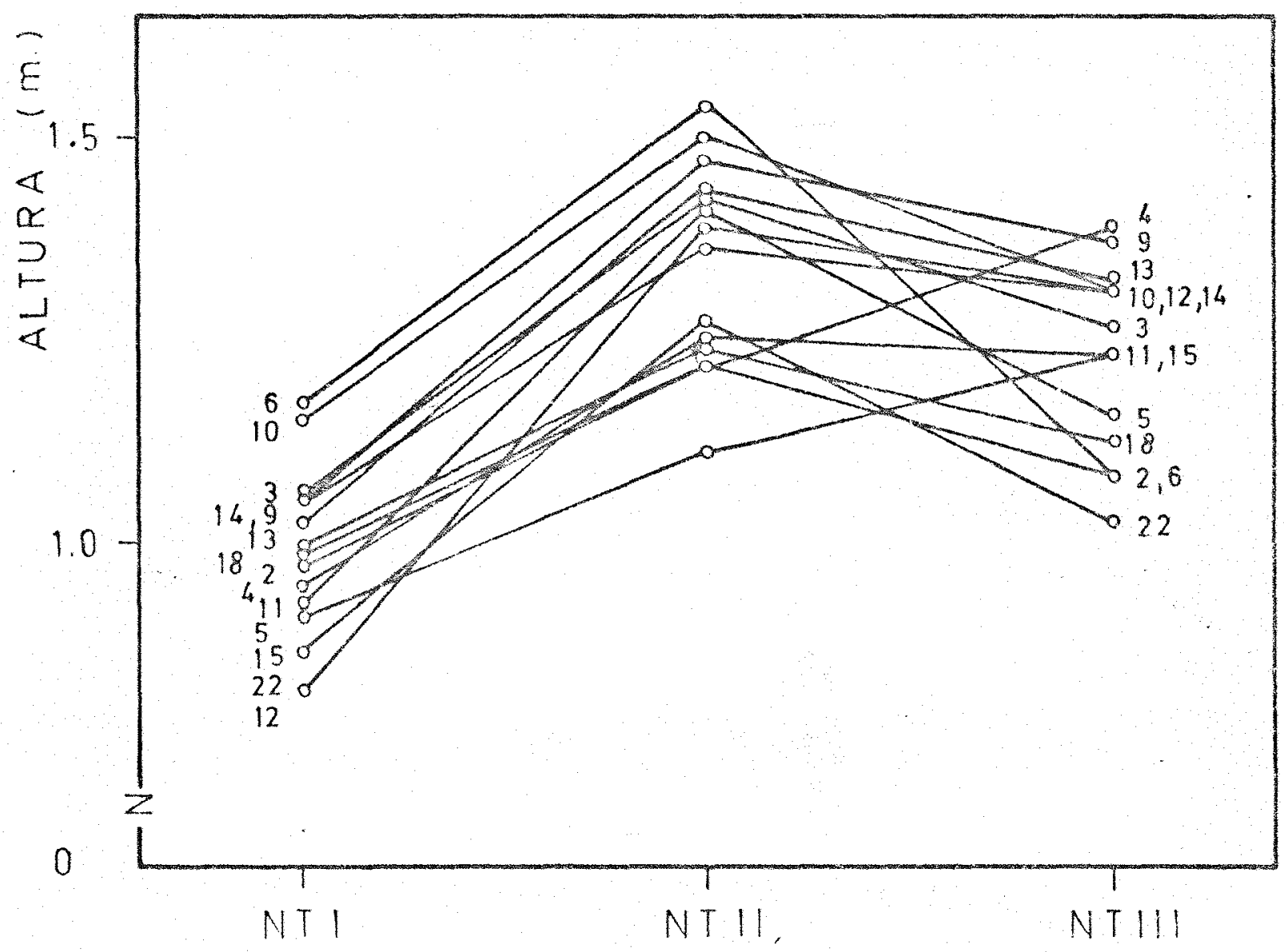

Nivel de Tecnologia

Figura 25. Crescimento em altura de progênies de E, citmiodona nos três niveis de tecnologia (NT) de implantação florestal, aos 7 meses de idade 
os resultados das anälises conjuntas para os três niveis de tecnologia foram tambën diferentes aos obtidos para o E. grandis e E. camalduzensis.

Na Figura 25 pode-se observar o comportamento das progênies de E. citmiodora nos três níveis de tecnologia e a tendência de interação complexa entre progênies de níveis de tecnologia, com menor nitidez do que o verificado para as progenies de E. grandis e mais semelhante às de $E$. camaldulensis.

4.2.3.2. Avaliação de progênies de E. citriodora aos 12 meses de idade

Os resultados aos 12 meses de crescimento em altura, porcentagem de falhas, das anälises de variância individuais e conjuntas para os três níveis de tecnologia de implantação floresta1, para progênies de E. citriodora, são apresentados na Tabela 18.

As progênies de E. citriodora, para altura de plantas, tiveram um comportamento diferente ao verificado na idade de sete meses e semelhante ao verificado para as outras duas especies, considerando-se a mesma idade. 
Tabela 18. Resultados das anälises de variancia individuais e conjuntas pa ra altura de plantas e porcentagem de falhas de progênies de $E$. citriodor em três niveis de tecnologia (NT) de implantação florestal, aos 12 meses de idade

\begin{tabular}{|c|c|c|c|c|}
\hline \multirow{2}{*}{$\begin{array}{l}\text { Caracteristicas } \\
\text { e parâmetros }\end{array}$} & \multicolumn{3}{|c|}{ Níveis de tecnologia } & \multirow{2}{*}{$\begin{array}{l}\text { Anälise } \\
\text { conjunta }\end{array}$} \\
\hline & NTI & NTII & NTIII & \\
\hline
\end{tabular}

Altura (m)

Média geral

2,09

2,87

2,91

2,62

Amplitude de variação

$$
1,51-2,42
$$

$2,52-3,23$

$2,51-3,24$

$-$

$F(P)$

(1)

$2,36 *$

$1,36^{\mathrm{ns}}$

$0,93^{\text {ns }}$

$1,50^{\text {ns }}$

$\mathrm{F}(\mathrm{NT})$

(2)

-

$-$

$-$

$2,62^{\text {ns }}$

$\mathrm{F}(\mathrm{P} \times \mathrm{NT})$

(3)

-

$-$

$1,06^{\text {ns }}$

$\mathrm{CV}$ experimental

(\%)

(4)

11,63

10,17

15,47

12,99

Falhas (\%)

Mëdia geral

12,93

- 0,38

7,51

6,94

Amplitude de variação

$0,00-22,14$

$0,00-5,39$

$0,00-21,07$

$-$

$\mathrm{F}(\mathrm{P})$

$0,72^{\text {ns }}$

1,00 ns

$0,78 \mathrm{ris}$

$0,67^{\text {ns }}$

$\mathrm{F}(\mathrm{NT})$

$\mathrm{F}(\mathrm{P} \times \mathrm{NT})$

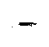

-

$14,30 \%$

$\mathrm{CV}$ experimental

$(\%)$

$-$

$-$

$-$

$0,78^{\text {ns }}$

NTI: sem preparo do solo e sem adubação mineral;

NTII: preparo do solo sem adubação mineral;

NTIII: preparo do solo e adubação mineral;

(1), (2) e (3): teste $F$ para as progênies, niveis de tecnologia e interação de progenies $x$ niveis de tecnologia;

(4): coeficiente de variação experimental en porcentagen;

ns : não significativo;

* : significativo ao nível de $5 \%$;

$* *$ : significativo ao nivel de $1 \%$. 
Os resultados das anälises individuais seguiram a mesma tendência geral observada en progênies das duas primeiras espécies, de diminuição do efeito de progênies com o aumento do nível de tecnologia, revelando-se significativo somence para altura de plantas no primeiro nível de tecnologia. Para a porcentagem de falhas essa tendência não se verificou, porèm, o efeito de progênies não se revelou significativo, como em outras duas espēcies.

Os coeficientes de variação experimentais para altura de plantas foram menores que os para $E$. grandis e semelhantes ao $E$. camaZdulensis. Os correspondentes a porcentagem de falhas foram variäveis en tre os níveis de tecnologia e intermediärios aos coeficientes de varia-

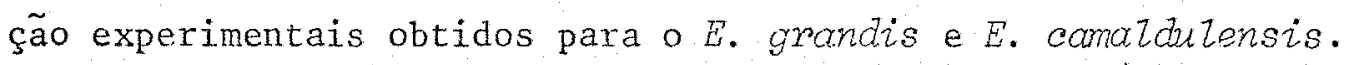

os resultados das anälises conjuntas para os três níveis de tecnologia foram diferentes aos resultados obtidos para o $E$. grandis e E. camaldulensis. Enquanto para estas duas espécies o efeito de níveis de tecnologia foi expressivo, para o E. citriodora esse efeito não foi significativo, mostrando a insensibilidade das progênies desta espécie tanto ao preparo de solo como à fertilização. Resultado semelhante foi obtido por MACEDO (1987) en ensaio de fertilização mineral envolvendo $E$. citriodora, E. urophyzla e E. cloeziana, aos 67 meses de idade. 0 E. citriodora, ao contrário das outras duas espêcies, não respondeu a niveis de fertilização mineral e, emi alguns tratamentos, o efeito da adubação foi negativo para o crescimento de plantas desta espécie.

A Figura 26 mostra ocrescimento das progênies em função dos nîveis de tecnologia de implantação florestal e a tendência de interação com plexa entre progênies e os difexentes niveis de tecnologia silvicultural. 


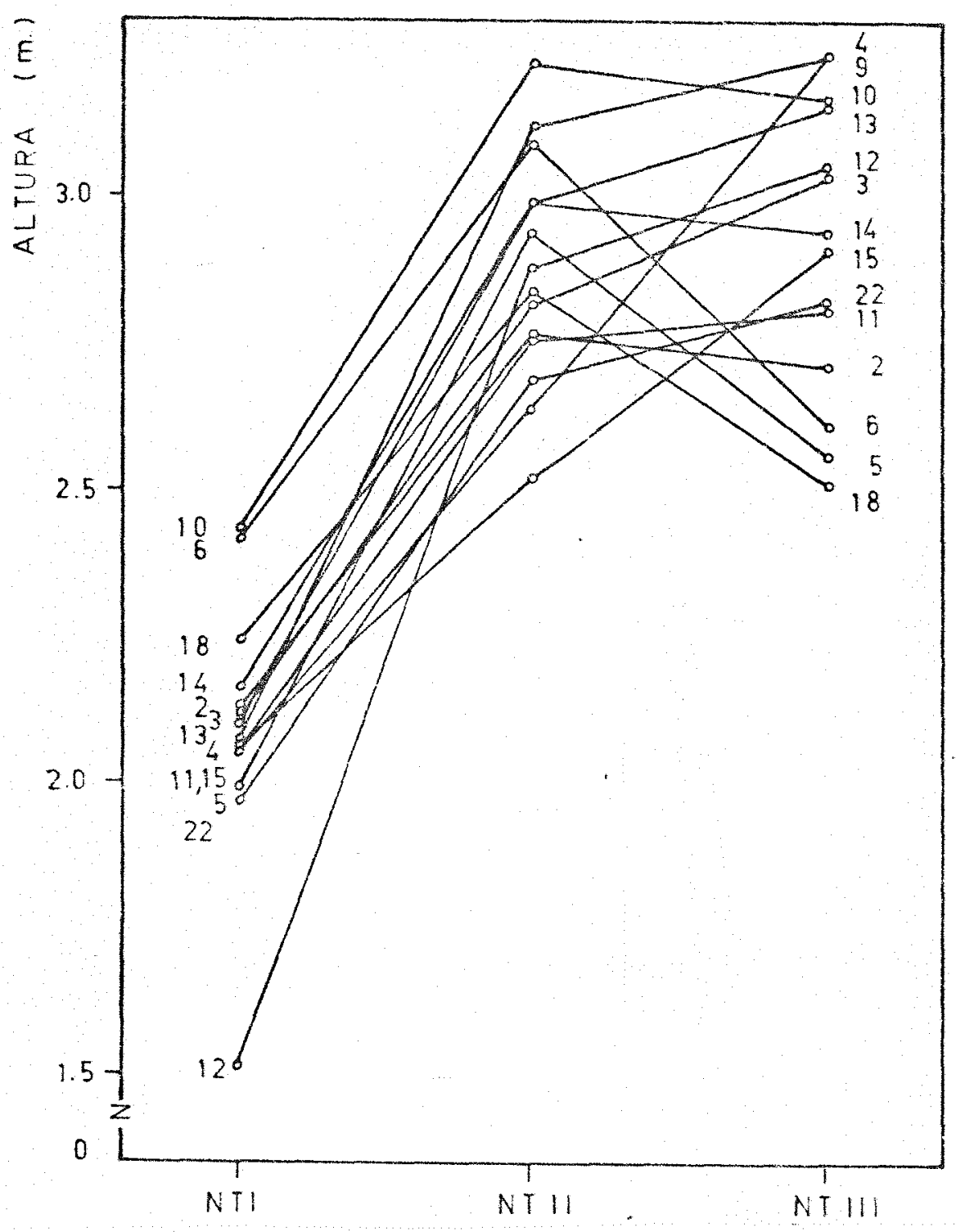

Nivel de Tecnologia

Figura 26. Crescimento en altura de progênies de E. citriodora nos três níveis de tecnologia (NT) de implantação florestal, aos 12 me ses de idade 
4.2.3.3. Avaliação de progênies de E. citriodora aos 18 meses de idade

Os resultados aos 18 meses de crescimento em altura de plantas, DAP, volume cilindrico e porcentagem de falhas, das anälises de variância individuais e conjuntas para os três niveis de tecnologia de implantação florestal, são apresentados na Tabela 19.

As médias de altura de plantas de progênies de. E. Citriodora seguiram a mesma tendência observada aos 12 meses de idade. A porcentagem de falhas foi semelhante a verificada na avaliação anterior, sendo que o acréscimo na mortalidade foi insignificante nos três níveis de tecnologia, conforme indicam os dados das Tabelas 18 e 19.

De um modo geral, os dados do DAP e volume cilindrico seguiram a mesma tendência verificada para a altura de plantas, porëm com menos expressão para o efeito de progênies.

Os valores de $F$ e os coeficientes de variação experimentais obtidos nas anälises de variância individuais, para as caracteristicas de crescimento, apresentaram a mesma tendência geral relatada para altura de plantas aos 12 meses de idade.

Foram detectadas variações genéticas significativas entre progentes para altura de plantas nos nîveis de tecnologia I e II e para - DAP no nível de tecnologia II. Não foi constatada a variação genética entre progênies para o volume cilindrico, segundo os valores de F obtidos nas análises de variância. 
Tabela 19. Resultados das anälises de variância individuais e conjuntas pa ra altura de plantas, DAP, volume cilindrico (VC) e porcentagem de falhas de progênies (P) de E. citriodora en três niveis de tecnologia (NT) de implantação florestal, aos 18 meses de idade

\begin{tabular}{lcccc}
\hline Características & \multicolumn{3}{c}{ Níveis de tecnologia } & Anälise \\
\cline { 2 - 5 } & NTI & NTII & NTIII & conjunta \\
\hline
\end{tabular}

Altura (m)

Média geral

Amplitude de variação

$\mathrm{F}(\mathrm{P})$

$\mathrm{F}(\mathrm{NT})$

$\mathrm{F}(\mathrm{P} \times \mathrm{NT})$

$\mathrm{CV}$ experimental
(1)

(\%) (4)

2,64
$2,05-3,06$
$4,46 * *$
-
-
8,05

3,11
$2,72-3,70$
$2,39 *$
-
10,07

3,11
$2,67-8,48$
0,80
-
-
15,00

2,95

$-$

$2,24 *$

$0,54 \mathrm{~ns}$

$1,42 \mathrm{~ns}$

11,74

DAP $(\mathrm{cm})$

Média geral

Amplitude de variação

$F(P)$

$\mathrm{F}(\mathrm{NT})$

$\mathrm{F}(\mathrm{P} \times \mathrm{NT})$

CV experimental (\%)

$\begin{array}{cccc}1,65 & 2,22 & 2,38 & 2,08 \\ 1,33-2,20 & 1,53-2,77 & 1,93-3,07 & - \\ 1,88^{\mathrm{ns}} & 2,16^{*} & 1,14 \mathrm{~ns} & 2,11^{*} \\ - & - & - & 0,96 \mathrm{~ns} \\ - & - & - & 1,27 \mathrm{~ns} \\ 18,34 & 16,20 & 22,48 & 19,75\end{array}$

VC $\left(10^{-2} \mathrm{xm}^{3}\right.$ /ärvore)

Mêdia geral

Amplitude de variação

$\mathrm{F}(\mathrm{P})$

$\mathrm{F}$ (NT)

$\mathrm{F}(\mathrm{P} \times \mathrm{NT})$

CV experimental (\%)

$\begin{array}{cccc}0,12 & 0,15 & 0,20 & 0,16 \\ 0,06-0,19 & 0,07-0,25 & 0,10 m 0,31 & - \\ 1,44 \mathrm{~ns} & 1,33^{\mathrm{ns}} & 1,15 \mathrm{~ns} & 1,90 * \\ - & - & - & 0,52 \mathrm{~ns} \\ - & - & - & 0,93 \mathrm{~ns} \\ 42,07 & 42,23 & 45,39 & 44,95\end{array}$

Falhas (\%)

Média geral

Amplitude de variação

$F(P)$

$\mathrm{F}(\mathrm{NT})$

$F(P \times N T)$

CV experimental (\%)

$\begin{array}{cccc}13,28 & 1,15 & 8,62 & 7,68 \\ 0,00-22,14 & 0,00-5,39 & 0,00-21,07 & - \\ 0,69 \mathrm{~ns} & 0,84 \mathrm{~ns} & 0,67 & 0,57^{\mathrm{ns}} \\ - & - & - & 9,78 * \\ - & - & - & 0,74 \mathrm{~ns} \\ 12,90 & 4,16 & 11,56 & 10,55\end{array}$

NTI: sem preparo do solo e sen adubaça mineral;

NTII: preparo do solo sem adubação mineraI;

NTIII: preparo do solo e adubação mineral;

(1), (2) e (3): teste $F$ para as progênies, niveis de tecnologia e interação de progênies $x$ niveis de tecnologia;

(4): coeficiente de variaçăo experimental em porcentagem;

ns : não significativo;

* : significativo ao nivel de $5 \%$;

$* *$ : significativo ao nivel de $1 \%$. 
o valor de $F$ para a porcentagem de falhas não mostrou nenhuma tendência e, como na avaliação anterior, não se revelou significativo para os três níveis de tecnologia.

Considerando-se os valores de $F$ das anälises conjuntas para os três nîveis de tecnologia, a variação genética entre progênies mostrou-se significativa para as três características de crescimento, o que não se constatou em relação à sobrevivência de plantas. O efeito dos níveis de tecnologia, ao conträrio, foi expressivo e significativo para a porcentagem de falhas e não para as características de crescimento. A interação de progênies $x$ nivveis de tecnologia não foi significativa para to das as características estudadas. Contudo, verifica-se ainda a tendência de interação complexa para as características de crescimento, como ilustram as Figuras 27 e 28.

Comparando-se os resultados das anälises conjuntas das três espécies aos 18 meses, para as características de crescimento, observa-se as seguintes tendências gerais:

- maior variação genética relativa entre progênies de E. citriodora, vindo a seguir o $E$. comaldulensis e por ültimo o E. grandis;

- maior efeito do nível de tecnologia em E. camaldulensis e menor en $E$. chtmodora, sendo o efeito intermediário em $E$. grandis; 
- maior efeito da interação em E. grandis, seguindo o E. citriodora e finalmente o $E$. camalduiensis;

- maior coeficiente de variação experimental para $\circ E$. grandis, intermediärio para o $E$. citriodora e menor pa ra o E. camaldutensis.

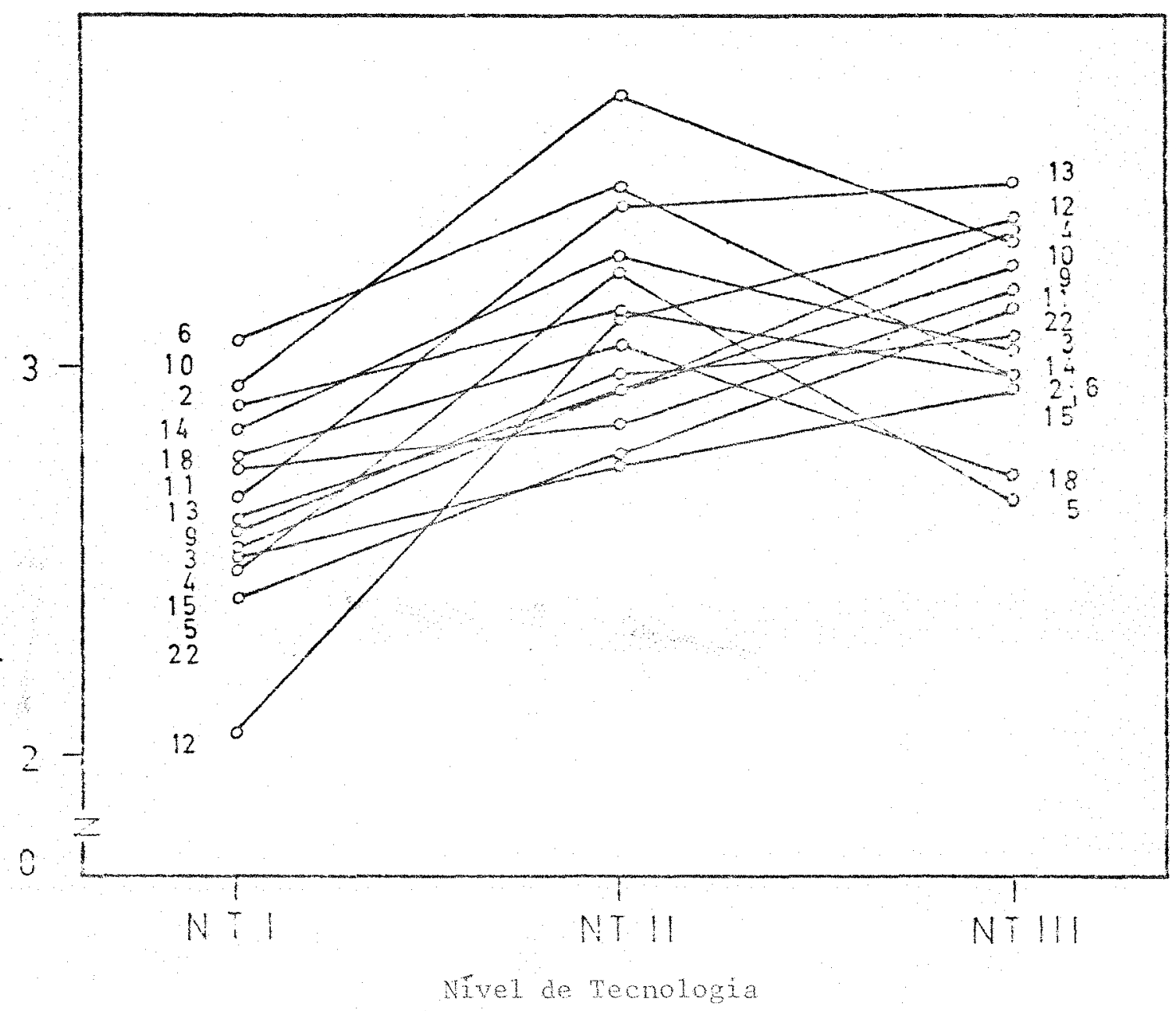

Figura 27. Crescimento em altura de progênies de $E$. citriodora nos três niveis de tecnologia (NT) de implentação florestal, aos 18 meses de idade 

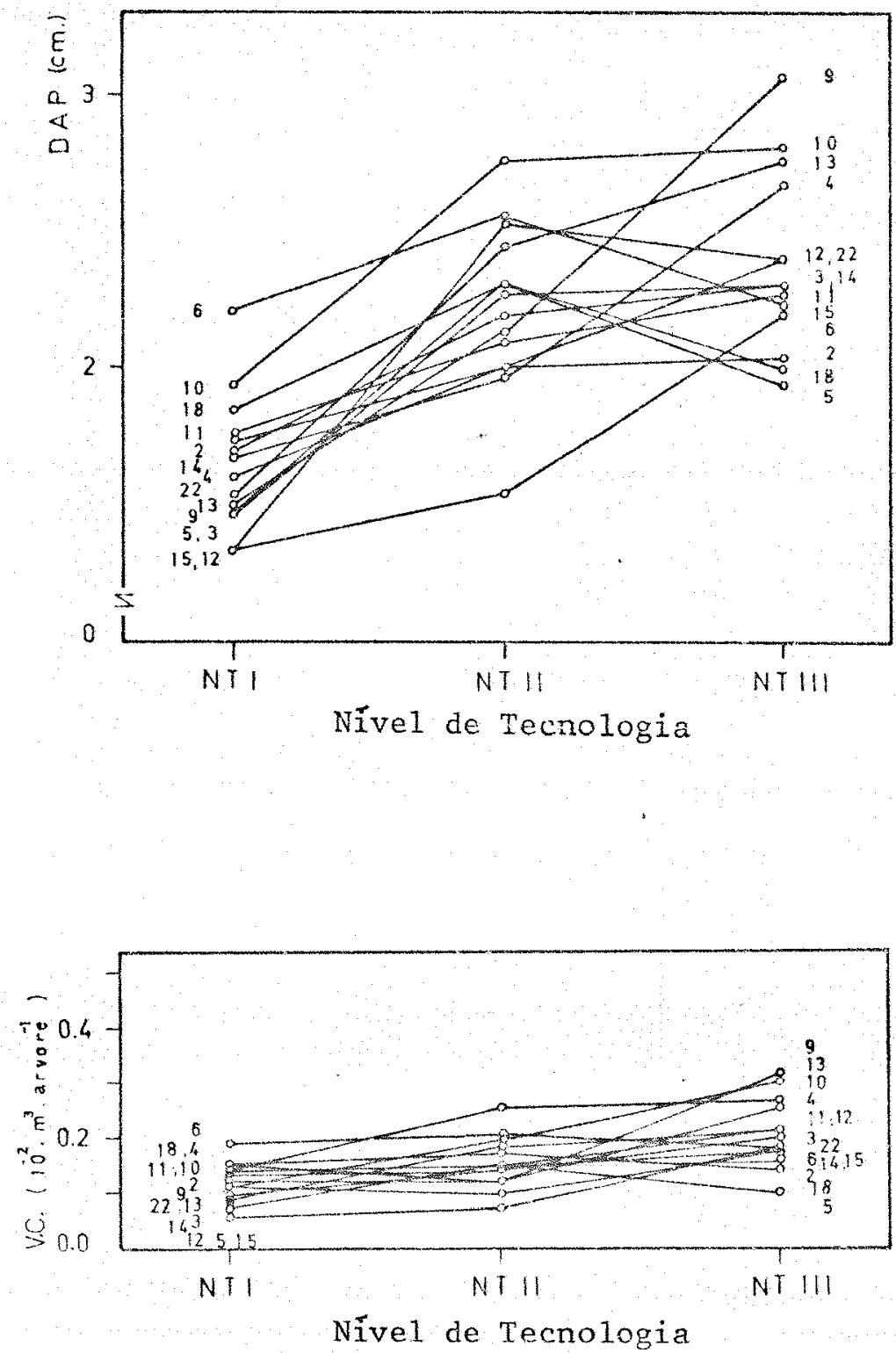

Figura 28. Crescimento em DAP e volume cilíndrico (VC) de progênies de E. citriodona nos três núveis de tecnologia (NT) de implantaça florestal aos 18 meses de idade 
4.2.3.4. Avaliação de progênies de E. citriodora aos 24 me ses de idade

Os resultados aos 24 meses de crescimento em altura, DAP, volume cilindrico, porcentagem de falhas, das anälises de variancia individuais e conjuntas para os três níveis de tecnologia de implantação flom restal são apresentados na Tabeia 20 .

Os resultados obtidos aos 24 meses confirman as tendências verificadas em avaliações anteriores. O valor de F para as características de crescimento diminuiram com a elevação do nível de tecnologia; os coeficientes de variação experimentais tiveran um comportanento inverso, a não ser para volume cilindrico, onde esses valores foram muito similares. Os valores de F para a porcentagem de falhas apresentaram nesta idade a mesma tendência observada para as caracteristicas de crescimento. o coeficiente de variação experimental continuou variāvel sem nenhuma tendência definida.

Variações genéticas significativas foram detectadas no nivel de tecnologia I para altura de plantas e DAP. As mesmas foram expres sivas para o volume cilíndrico, porēn não se revelando significativas.

Os resultados das anäises conjuntas foran semelhantes aos obtidos na avaliação anterior. O efeito de progênies aumentou com a idade, sendo significativo para as trés características de crescimento; o efeito dos niveis de tecnologia foi significativo somente para a porcentagem de falhas. Esses resultados confirmam a pouca influencia das têni cas de implantação florestal no crescimento imicial do R. citriodora. 
Tabela 20. Resultados das anälises de variancia individuais e conjuntas pa ra altuxa de plantas, DAP, volume cilindrico (VC) e porcentagem de falhas de progênies (P) de E. citmodona en três niveis de tecrologia (NT) de implantação florestal, aos 24 meses de idade

\begin{tabular}{llll}
\hline Caracteristicas & Niveis de tecnologia & Anälise \\
e parâmetros & NTI & NIII & NTIII
\end{tabular}

\section{Altura (m)}

Média geral

Amplitude de variação

$F(\mathrm{P})$

$\mathrm{F}(\mathrm{NT})$

$\mathrm{F}(\mathrm{P} \times \mathrm{NT})$

$\mathrm{CV}$ experimentaI
(1)

(2)

(3)

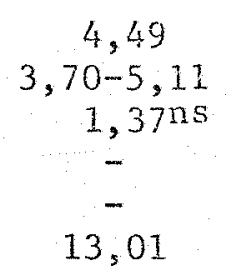
4,47
$-$
$1,86 \%$
$0,41^{\text {ns }}$
1,19 ns
12,06

\section{DAP (cm)}

Média geral

Amplitude de variação

$\mathrm{F}(\mathrm{P})$

$\mathrm{F}(\mathrm{NT})$

$\mathrm{F}(\mathrm{P} \times \mathrm{NT})$

CV experimenta1 (\%)

$\begin{array}{cccc}2,96 & 3,33 & 3,76 & 3,35 \\ 2,25-3,69 & 2,65-3,97 & 3,15-4,41 & - \\ 4,09 * * & 1,51 \mathrm{~ns} & 1,21 \mathrm{~ns} & 2,60 \% \\ - & - & - & 0,52^{\mathrm{ns}} \\ - & - & - & 1,50 \mathrm{~ns} \\ 11,94 & 14,04 & 15,38 & 14,20\end{array}$

VC $\left(10^{-2} \mathrm{xm}^{3} /\right.$ arvore $)$

Média geral

Amplitude de variação

$F(P)$

$\mathrm{F}(\mathrm{NT})$

$\mathrm{F}(\mathrm{P} \times \mathrm{NT})$

$\mathrm{CV}$ experimental (\%)

$\begin{array}{cccc}0,50 & 0,48 & 0,70 & 0,56 \\ 0,29-0,85 & 0,29-0,69 & 0,39-0,94 & - \\ 1,86 \mathrm{~ns} & 1,25 \mathrm{~ns} & 1,31 \mathrm{~ns} & 2,43^{* \%} \\ - & - & - & 0,30 \mathrm{~ns} \\ - & - & - & 0,92 \mathrm{~ns} \\ 35,59 & 36,26 & 35,33 & 36,17\end{array}$

Falhas (\%)

Média geral

Amplitude de variaçáo

$\mathrm{F}(\mathrm{P})$

$\mathrm{F}(\mathrm{NT})$

$\mathrm{F}(\mathrm{P} \times \mathrm{NT})$

$\mathrm{CV}$ experimental (\%)

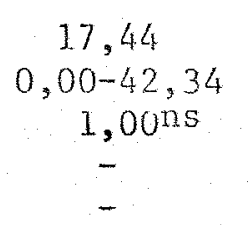

13,99

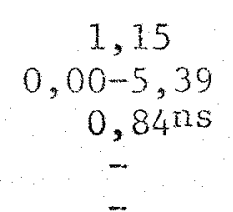

$-$

4,16

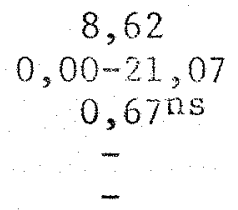

11,55
9,07

$-$

$0,77 \mathrm{~ns}$

$14,90 * \%$

$0,92 \mathrm{~ns}$

11,13

NIT: sem preparo do solo e sen adubaçà mineral;

NTII: preparo do solo sem adubaçăo mineral;

NTIII: preparo do solo e adubação mineral;

(1), (2) e (3): teste $F$ para as progênies, niveis de tecnologia e interaçäo de progentes $x$ riveis de tecnologia;

(4): coeficiente de variaçăo experimental em porcentagem;

ns : não significativo;

* : significativo ao nivel de $5 \%$;

** : significativo ao nivel de $1 \%$. 
De acordo com KREJCI et alii (1986), esta espécie, contrastando com o E. grandis não responde à tecnologia silvicultural por possuir um sistema radicular fortemente pivotante, com maior desenvolvimento da raiz pivotante e poucas raízes laterais, o que não permitiria à espëcie o aproveitamento do preparo do solo e da fertilização mineral.

Os valoxes de $\mathrm{F}$ e os coeficientes de variação experimentais obtidos nas anälises conjuntas para cada uma das espëcies confirmam as tendências verificadas aos 18 meses de idade. A maiox variação genēti ca para as caracteristicas de crescimento foi verificada em E. citriodora e E. camaldulensis; o maior efeito dos niveis de tecnologia observoumse en E. comaldutensis e E. grandis; o maior efeito da interação de progênies $x$ niveis de tecnologia, muito embora estatisticmente não significativo, foi observado em E. grandis.

As Figuras 29 e 30 ilustran o conportamento de progênies de $E$. citriodora em altura de plantas, DAP e volume cilindrico, aos 24 meses, em função dos níveis de tecnologia de implantação florestal, mostrando novamente a tendência de algumas progênies mostraren um comportamento diferencial com a mudança do nivel tecnologia silvicultural. Esse comportamento geral, como enfatiza QUIJADA (1980), obriga a seleção de distintos genötipos para cada nivel de tecnologia silvicultural, a fim de se obter o major ganho na produtividade. 


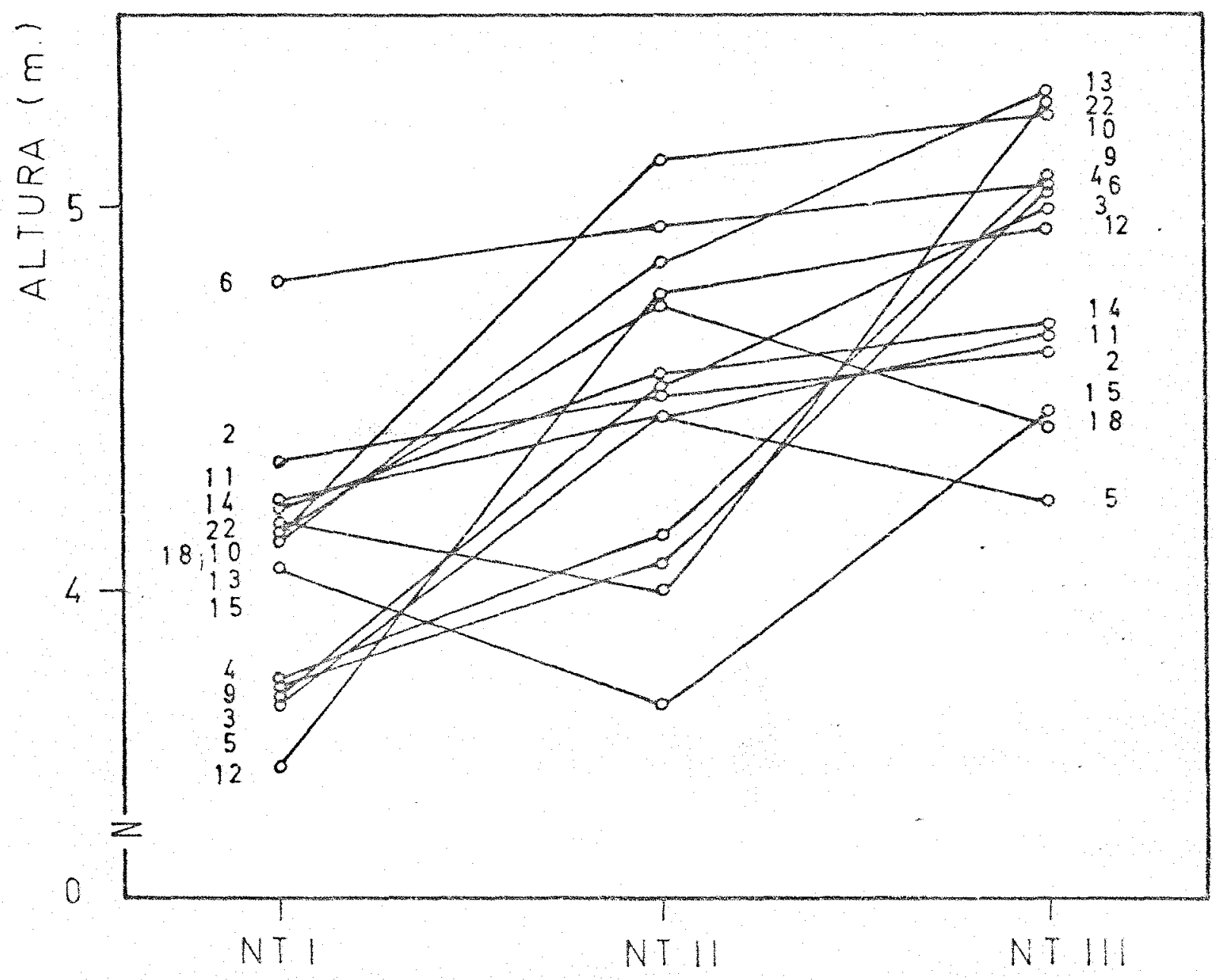

Nível de Tecnologia

Figura 29. Crescimento em altura de progênies de E. citriodora nos três niveis de tecnologia (NT) de implantação florestal, aos 24 me ses de idade 

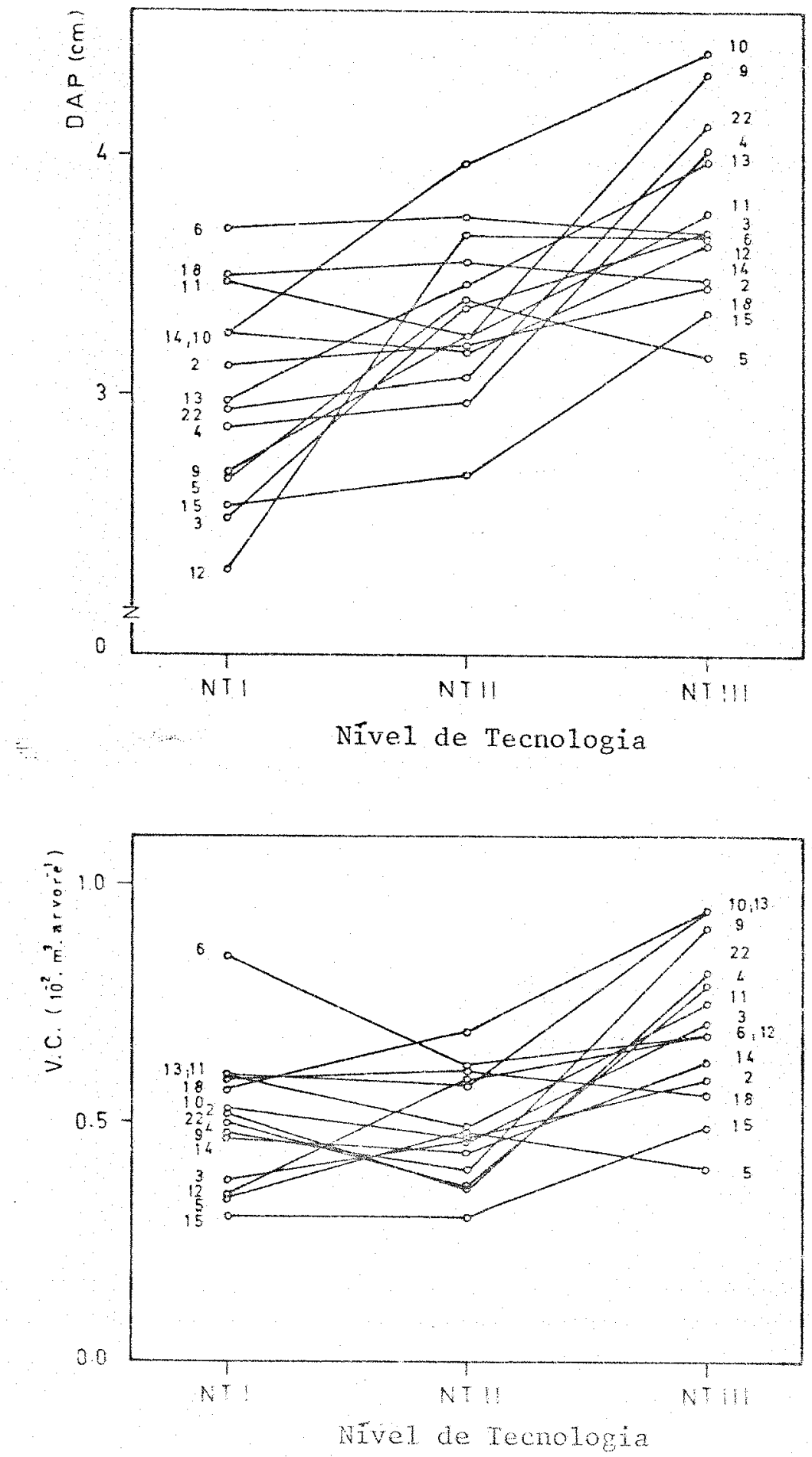

Figura 30. Crescimento em DAP e volume cilindrico (VC) de progênies de E. citriodora nos três níveis de tecnologia (NT) de implantação florestal aos 24 meses de idade 
Muito embora a interação de progênies com niveis de tecnologia não temha sido significativa, de acordo com vencovsky citado por KAGEYAMA (1980), a constatação da variação genética num nỉvel de tecnologia e não em outro jä indicaria, por si, a ocorrência de interação de progênies x niveis de tecnologia. Esse fato, que ocorreu na maioria das anälises realizadas para as três espécies, anälise de variância conjunta não conseguiu detectar.

ZOBEL \& TALBERT (1984) relatam, por sua vez, que a falta de controle da interação em florestas pode acarretar prejǘzos consideräveis no reflorestamento e no melhoramento genético. o prejuizo pode resultar da morte de plantas ou da diminuição na produtividade dos povoamentos. MORI et aliz (1986) mostraram, por exemplo, que a transferência de materiais selecionados, de um ambiente para o outro, pode reduzir expressivamente a produtividade desses materiais.

En casos de interação de genötipos x tecnologia silvicultural espera-se idêntico comportamento: materiais genéticos selecionados em condições de alta tecnologia, provavelmente, não se comportaram bem en condições de baixa tecnologia.

Ao se atentar mais para a Figura 30, observa-se um fato de alta importância e com implicações relevantes para programas de melhoramento genetico com o E. atmodora. o comportamento da progenie 6 no nivel de tecnologia I tem un volume cilindrico superior ao de todas as progênies do nivel de tecnologia II e pouco inferior às progênies mais produtivas do nivel de tecnologia III. Isso significa que è possivel a seleção de progênies con boa produtividade mesmo em baixo nível de 
tecnologia. o teste de um grande nümero de progênies certamente possibilitaria a obtenção de material genético apropriado para o uso em condições de ausência de preparo do solo e de fertilização mineral, situação comum em vários reflorestamentos.

Os resultados obtidos de comportamento das espécies e progênies dentro de espécies, nos três niveis de tecnologia de implantação florestal, permitem uma reflexão importante sobre a necessidade de ensaios cuidadosos, com adequado número de repetições, na definição de materiais genéticos indicados para cada nîvel de tecnologia.

Finalmente, enfatiza-se que uma análise de custos e benefícios deve ser considerada, complementando os aspectos genéticos e tecno lógicos, na escolha da melhor tecnologia silvicultural para cada material genético. 
5. CONCLUSÕES

Os resultados dos ensaios ao nível de espécies e de progênies dentro de espécies nos diferentes niveis de tecnologia de implantação florestal permitem as seguintes conclusões:

a) os niveis de tecnologia silvicultural estudados permitiram a diferenciação de espëcies mais aptas (E. gronn$d i s$ ) intermediärias (E. camaldulensis) e menos apta ( $E$. citriodora) a resposta ao preparo do solo e fertilização mineral;

b) o aumento gradativo do nível de tecnologia silvicultural mostrou-se diretamente correlacionado à capacidade dos testes de detectarem as variaçôes genéticas relativas entre espécies; 
c) a interação de espécies com núveis de tecnologia verificala para características de crescimento foi do tipo simples, com aumento da amplitude entre espécies com a melhoria do nivel de tecnologia de implantação florestal;

d) o nivel mais baixo de tecnologia de implantação florestal permitiu separar flagrantemente as espëcies com alta capacidade de sobrevivência em baixo nivel de tecnologia ( $E$. camaldulensis e E. citriodora) e com baixa ca pacidade de sobrevivência a essa condição ( $E$. grandis);

e) a produção de matéria seca por unidade de área, considerando-se a densidade bäsica da madeira das espécies estudadas, mostra que no nivel de tecnologia mais baixo o E. camaldulensis e o E. citmodora se tornam mais produtivos do que o E. grandis;

f) a maior eficiencia estatística dos ensaios ao nivel de espëcies foi conseguida com o aunento do nivel de tecno logia silvicultural;

g) as progênies das três espëcies estudadas mostraran um decrescimo na sua vaxiaço genetca relativa com o aumento do nivel de tecnologia silvicultural, contrariamente ao observado ao nivel de especie; 
h) para a sobrevivência de plantas somente as progênies de E. Grandis mostraram variação genéticanos niveis de tec nologia mais baixos de tecnologia; para esta espëcie foi significativo o efeito do interação de progênies com ní veis de tecnologia;

i) na anāise conjunta, no geral, as progênies de E. grandis responderam somente ao nivel de tecnologia silvicultural; as do E. camaldulensis responderam aos niveis de tecnologia silvicultural e em termos de variação genëtica; as progênies de E. citriodora só responderam ao nível de variação genética;

j) nas idades avaliadas houve um decrescimo no efejto dos níveis de tecnologia sobre as progênies, principalnente para progenies de E. grandis e E. comazdulensis;

1) muito embora näo tenha havido significância para a interação de progênies com níveis de tecnologia, observou-se uma clara tendencia de interação complexa, principalmente para o E. grandis es niveis de tecnologia II e III;

m) os resultados obtidos, tanto do nivel de espécies cono de prosenies dentro de especies, mostran que adequaça de material genêtico, a correta tecnologia silvicultural, permite a utilização racional dos recursos tanto geneticos como ambientais e tecnológicos. 


\section{BIBLIOGRAFIA}

ALBINo, J.C. Caracteristicas de crescimento e variação da densidade bãsica da madeira em 12 especies de Eucalyptus em três regioes do Estado de Minas Gerais. Piracicaba, 1983. 90p. (Mestrado-Fsola Supericr de Agricultura "Luiz de Queiroz"/usp).

ALLARD, R.W. \& BRADSHAW, A.D. Implications environment inceractions in applied plant breeding. Crop Science, Madison, 4:503-7, 1964.

AYAlA, F.J. Mechanisms of evolution, In: A Scientific American. San Francisco, Fredman \& Company, 1978. p.14-27.

BALLONI, E.A. \& SIMÕES, J.W. Influências do espaçamento de plantio na produtividade das florestas de Eucalyptus. Seme Témica IPEF, Piracicaba, 1(3):1-16, Set. 1980 . 
BARNES, R.D.; BURLEY, J.; GIBSON, G.L. \& GARCLA DE LEON, J.P. GenotypeEnvironment interactions in tropical pines and their effects on the structure in breeding populations. Sitvae Genetica, Frankfurt, $33(6)$ $186-98,1984$

BARNES, R.D. Genorype-environment interactions in the genetic improvement of fast-growing plantationes three. In: IUFRO SYMPOSIUM ON SITE AND PRODUCTIVITY OF FAST GROWING PLANTATIONS, Pretoria, 1984. Froceedings. Pretoria, South African Forest Research Institute, 1984. p, 197-214.

BARROS, N.F.de Adubação mineral de plantios florestais. In: SEMINÄRTO REFLORESTAMENTO NO NORDESTE SEMI-ARRDO, Petrolina, 1982: Petrolina, EMBRAPA/IBDK, 1982, p. 55-72.

BERTOLOTI, G. Comportamento de clones de Eucaluptus grandis W. Hill ex Maiden en solo podzólico vemetho escuro e areja quartzosa älica en Lençöis Paulista, SP. Piracicaba, 1986. 80p. (Mestrado-Escola Superior de Agricultura "Luiz de Queiroz"/USP).

BRASIL, M.A.M. Variação da densidade bäsice da madeira entre e dentro de procedencias de Eucalyptus urophylza St. Blake. Botucatu, 1983. 86p. (Livre-Docência-Universidade Estadual de São Paulo-UNESP).

BROWN, A. \& HALL, N. Growtrg trees on Austratian fams. Canbera, Forestry Conmission of NSW, $1968.2 \mathrm{p}$. 
BURLEY, J. \& KEMP, R.H. Internationl tropical provenance trials and $G \mathrm{X} E$ (Genotype $x$ Environment) interactions. In: TUFRO GENETIC SABRAO JOINT SIMPOSIA, Tokio, 1972. Proceeáings. Tokio, IURRO-SABRAO, 1972. B-2(1): $5-19$.

COSTA, L.M.da \& CARMO, D.N. Aspectos de Manejo de Solo em áreas de Reflorestamento no Brasil. In: STMPÓSIO FLORESTAS PLANIADAS NOS NEOTRÖPICOS COMO FONTE DE ENERGIA, Viçosa, 1983. Anais. Viçosa, UFV, 1983. p. $118-32$.

CROMER, R.W. Site amelioxation for fast growing plantation. IUERO SYMPOSIUM ON SITE AND PRODUCTIVITY OF FAST GRONING PLANTATIONS. Pretória, 1984. Proceedings. Pretöria, South African Forest Research Insm titute, 1984 . p.181-95.

DELWAULLE, J.C. Plantations forestieres en Afrique tropicaux seche; Technique à utiliser. Bois et forets des Tropiques, Paris, 183:3-17, Jan/Fev. 1979.

DONALD, D.G.M. \& SHUTZ, C.J. The Response of Eucalyptus to Fertilizer Application at planting: The Louw's Creek Trial. South Africon Erosestry Joumal, Johannesburg (102):23-9, Set. 1977.

ELDRTDGE, K.D. An amotated bibtiogrophy of genetie variation in Eucatyptus camaldutensis. Cambera, CIF/CSTRO, 1975. 59p.

FAo. Actividades forestales en el desarrotito de commidades $20 c a i s$. Rona, FAO, 1978. 136p. 
FERREIRA, M. \& ARAUJO, A.J. Procedimentos e Recomendagöes para testes de procedências. Curitiba, EMBRAPA-IBDF-PNPF, 1981.28p.

FERREIRA, M. Interação genötipo x ambiente e sua importância na seleção de espëcies procedências. In: REUNIÃO SOBRE INTERAÇÃO DO GENÖTIPO COM CLIMA E SOLO. Piracicaba, 1986. IPEF. Piracicaba, 1986. p.16-7.

FONSECA, S.M.da Preparo do Solo para Implantação Florestal. Piracicaba. Departamento de Silvicultura-ESALQ. 1978, 20p. (mimeografado).

FONSECA, S.M.da Estimação e interpretação dos componentes de variação to tal em experimentos de melhoramento florestal. In: CURSO PRÄTTCAS EXPERIMENTAIS EM SILVICULTURA. Piracicaba, 1979. Piracicaba, IPEL, 1979. $\mathrm{p} \cdot \mathrm{H} 1-\mathrm{H} 2 \mathrm{O}$.

FRANCIS, P.J. The role of cultivation in plantation establishment in sub tropical eastern Australia. In: IUFRO SYMPOSIUM ON SITE AND PRODUCTIVITY OF FAST GROWING PLANTATIONS. Pretöria, 1984. Proceedings, Pretöria, South African Forest Research Institute, 1984. p.579-96.

HAAG, H.P.; SIMÕES, J.W.; OLIVEIRA, G.D.de; SARRUGE, J.R. \& POGGIANI, F. Distūrbios nutricionais em Eucalyptus citriodora. IPER, Piracicaba, (14):59-68, ju1.1977.

HAAG, H.P. Nutrição Mineral de Eucalyptus, Pinus, Araucaria e Gmetina no Brasiz. Campinas, Fundação Cargi11, 1983, 210p. 
HERBERT, M.A. Fertilizing out planting. In, TNSTTUTE FOR COMERCTAL FORESTRY RESEARCH. Annual Repont 1985. Pietermaritzburg, 1985, p.125-9.

INSTITUTE FOR COMERCIAL FORESTRY RESEARCH. Silviculture. Annual report. 1985. Pietermaritzburg, 1985. p.34-68.

IPEF. Curso de Aperfeicoamento: Anälise de experimentos em genëtica flores. tal. Piracicaba, Departamento de Ciências Forestais/TpeF, 1986. $45 \mathrm{p}$.

KAGEYAMA, P.Y. Variação genētica em uma população de Eucalyptus granáis (Hi11) Maiden. Piracicaba, 1980. 125p. (Doutorado-Escola Superior de Agricultura "Luiz de Queiroz"USP).

KAGEYAMA, P.Y. Report on technical-scientific visit made to the vinh phat putp and paper mitz project in nopthem Vietnan. Piracicaba, 1984. 62p.

KAGEYAMA, p.Y. Interação de genötipo por amoiente. In: REUNIÃo sobre INTERAÇÃO DO GENOTIPO COM CLIMA E SOLO. Piracicaba, 1986. IPEF. Piracicaba, $1986 . \mathrm{p} \cdot 18-20$.

KAGEYAlA, P.Y.; BILA, A.D.; IIJIMA, J. Criterios de escotha de espécies para utitizacão em pequenas areas de reflorestamento. São Paulo, IBDF. 1987. 25p. (no prelo).

KHLISON, R.C. Cultural pratices for optimizing productivity of Eucalyptus for fiber and energy. Sizviaultura, são Paulo, 8(31):593-5. ju1/ago. 1983. 
KREJCI, K.C.; MARGINS, L.G.C.; LOURENCO, P.Y. DEsenvolvimento do sistema radicular de Ëucalyptus spp. sob diferentes condicões de solo. Salvador, COPENER, 1986. 24p.

LANDRACH, W.E. Two years results of a Eucalyptus species and provenance test on six sites in Colombia. Silvicultura, São Paulo, 8(31):45558, jul/ago. 1983a.

LANDRACH, W.E. Preparacion fisica y quimica de una pendiente en potreropa ra la reflorestacion con Eucatyptus grandis, Cupressus Iusitanica. y Pinus oocarpa: Resultados despues de dos anos. Cali, Carton de Co1ombia S.A., 1983b, 8p.

MACEDO, P.R. Comportamento de três espēcies de Eucatyptus frente a diferentes nỉveis de adubação mineral. In: Cia. Agricola Floresta1 Santa Bärbara, Relatório Bianul de Pesquisa Florestal 1985-86. Belo Horizonte, 1987, Tomo II, p.61/123-62/124.

MAGALHÃES, J.G.R. \& RESENDE, C.C.de. Técnicas de plantio e condução de florestas para produção de energia em Mines Gerais. In: SIMPÖSIO FLORESTAS PLANTADAS NOS NEOTRÖPICOS COMO FONTE DE ENERGIA, ViçOSa, 1983. Anais. Viçosa, UFV, 1983. p.97-117.

Malvos, C. Primeiros resultados de ensaios de adubação em plantação de Euco typtus em Madagascar. Silviouttuma, Säo Paulo, 8(32):625-8, set/out. 1983.

MELLO, H.A. \& RODRIGUES, N.S. Efeito do preparo do solo de cerrado no desenvolvimento de Eucalyptus aranais. Revista de Agricultura, Piracicaba, 41(4):163-78, Mar. 1966. 
MORA, A.L. Interação con espaçamentos e locais em clones de Eucatyptus spp. no norte do Estado da Bahia. Piracicaba, 1986. 98p. (MestradoEscola Superior de Agricultura "Luiz de Queiroz"/Usp).

MORI, E.S.; LELLO, L.R.B.; KAGEYAMA, P.Y. Efeitos da interação genötipo x ambiente em progênies de Eucalyptus saligna Smith. IDEF, piraciaba, (33):19-25, Ago. 1986.

NAMKOONG, G.; BARNES, R.D.; BURLEY, J. A phylosophy of breeding strategy for tropical forest tree. Oxford, Commealth Forestry Institute, 1980.67p.

NATIONAL ACADEMY OF SCTENCE. Fire wood crops: Shmb and tree species for energy production. Washington, DC, $1980.237 \mathrm{p}$.

OLIVEIRA, J.B. \& PARDO, H.do. Levantamento pedolögico semidetalhado do Esta do de São Paulo. São Paulo, Secretaria de Estado da Agricuitura. 1983. (Mapa).

PATIÑO-VALERA, F. Variação genética em progênies de Eucalyptus saligna Smith. Piracicaba, 1986. 164p. Mestrado-Escola Superior de Agricultura "Luiz de Queiroz"/USP).

PINTo Jr., J.E. Variação genética en progênies de uma população de Éucatyptus urophyttaS.T. Blake da Tha Flores-indonesia. Piracicaba, 1984. 164p. (Mestrado-mscola Superior de Agricultura "indz de Queiroz"/usp).

PIRES, I.E.; SOUSA, M.S.de; DRUMMOND, M.A.; SILVA, H.D.da; LIMA, P.C.F.; RIBASKI, J. Teste de procedencia de Eucalyptus camaiduzensts Dehn, na região do Nordeste Semi-Ärido Brasileiro. Sizviouttura, São Paulo, $8(31): 493-7$, ju1/ago. 1980 . 
QUIJADA, R.M. Interaccion genötipo-ambiente. In: FAO/DANDDA. Mejora genética de arboles fonestales. Mérida, FAO, 1980. p.231-5.

RIBEIRo, M.A. Competição de espëcies de eucalipto. Comunicado técnico. IPEAL, Cruz das Almas, n. 30, 1971. 3p.

ROCHA, D.; MAGALHÄES, J.G.R.; NASCIMENTO FO, M.B.do; FERNANDES, J.C. efeito dos sistemas de preparo do solo no crescimento de Eucalyptus grandis na Região de Capelinha-MG. Sitvicultura, são Paulo, $\quad 8(28): 464-6$, $\mathrm{jan} / \mathrm{fev} \cdot 1983$.

RODRIGUES, L.C.; JUNIOR, B.V.; SILVA, A.P. Manejo e melhoramento de florestas de Eucatyptus em areias quartzosas na Região Nordeste do Estado de São Paulo. Sizvicuztura, São Paulo, 11(41):104-10. 1986.

SCHÖNAU, A.P.G. Sone controversial issues in silviculture. South African Forestry Joumal, Johannesburg, (100):27-31, Mar. 1977.

SCHÖNAU, A.P.G.; VERLOREN, V.T.R; BODEN, D.I. The importance of complet site preparation and fertilising in the establishment of Eucalyptus grandis. South African Forestry Joumat, Johannesburg, (116):1-10, Mar. 1981.

SCHÖNAU, A.P.G. Fertilization in South African Forestry. South Afyican. Forestry Joumal, Johannesburg, (125):1-19, jun. 1983.

SCHÖNAU, A.P.G. Basic Silviculcure for Establishment of Eucalypt plantations with special reference to Eucatuptus grandis. South African Forestmy Joumal, Johannesburg, (134):4-9. set. 1985. 
SCHUTz, C.J. Fertilization of fast-growsing Finus and Eucalyptus in South African. South African Forestry Toumal, Johannesburg, (98): $44-7$, set. 1976

SIMÕES, J.W.; BRANDI, R.M.; LEITE, N.B.; BALIONT, E.A. Formação, manejo e exploracão de florestas com espécies de rapido crescimento. Brasi1ia, IBDF, 1981. 131p.

STMÕES, J.W. \& BRANDI, R.M. Anälise dos mëtodos silviculturais para a produção de energia. In: SITPÓSIO FLORESTAS PLANTADAS NOS NEOTRÖPICOS COMO FONTE DE ENERGIA, Viçosa, 1983. Anais. Viçosa, UFV, 1983. p.78-96.

SIMÕES, J.W. \& SPINA FRANÇA, F. Produção de Madeira em Florestas Ẽnergëticas sob präticas silviculturais. In: SIMPOSIO ENERGIA DA BIOMASSA FLORESTAI, São Paulo, 1983. Relatörio kinal. SãoPau1o, CESP/IPEF, 1983. p. $1-36$

SUITER FILHO, W.; RESENDE, C.C.de: MENDES, C.J.; CASTRO, P.F.de. Efeitos de diversos métodos de preparo do solo sobre o desenvolvimento de Eucalyptus grandis plantado em solos com camada de impedimento. Circular Téonica. IPEE, Piracicaba, n. 90, 1980.9p.

TURNBULL, J.W. \& PRYOR, L.D. Choice of species and Seed sources. In: HILIS, W.E. \& BRoWN, H.G., (ed.) Eucatypts for wood produotion. Adelaide, CSIRO, 1978. p.6-65.

TURNBULt, J.W. Conserving our eucalypt genes. CSLRO infomation bervice. Melbourne, $(1-10): 1-2, j u 1.1978$. 
VENTURA, A.G.; BERENGUT, C.; VICTOR, M.A.M. Características edafo-climäticas das dependências do Serviço Florestal do Estado de São Paulo. Sit vicultura em são Poulo, São Paulo, 4/5(4):57-140, $1965 / 66$.

WAKELEY, P.C. Planting the Southern Pines. Agriculture Monograph. Washington D.C., 18:121-5. 1954.

THE WATTLE RESEARCH INSTITUTE. Handbook on Encalypt growing. Pietermaritzburg, $1972.164 \mathrm{p}$.

WATTLE RESEARCH INSTTTUTE. Silviculture. Report for 1982-83. Pietermaritzburg, 1983. p.27-62.

zOBEL, B. \& TAIBERT, J. Apptied Forest tree improvement. New York. John Wiley \& Sons, 1984. 496p.

ZOBEL, B. Aumentos y cambios en la demanda industrial de naderas. Th: Septimo Congresso Forestal Mundial, Buenos Aires, 1972. Buenos Aires, 1972. $7 \mathrm{CFM} / \mathrm{C}: \mathrm{I} / 1 \mathrm{G}, 13 \mathrm{p}$. 
135

APENNDICES 


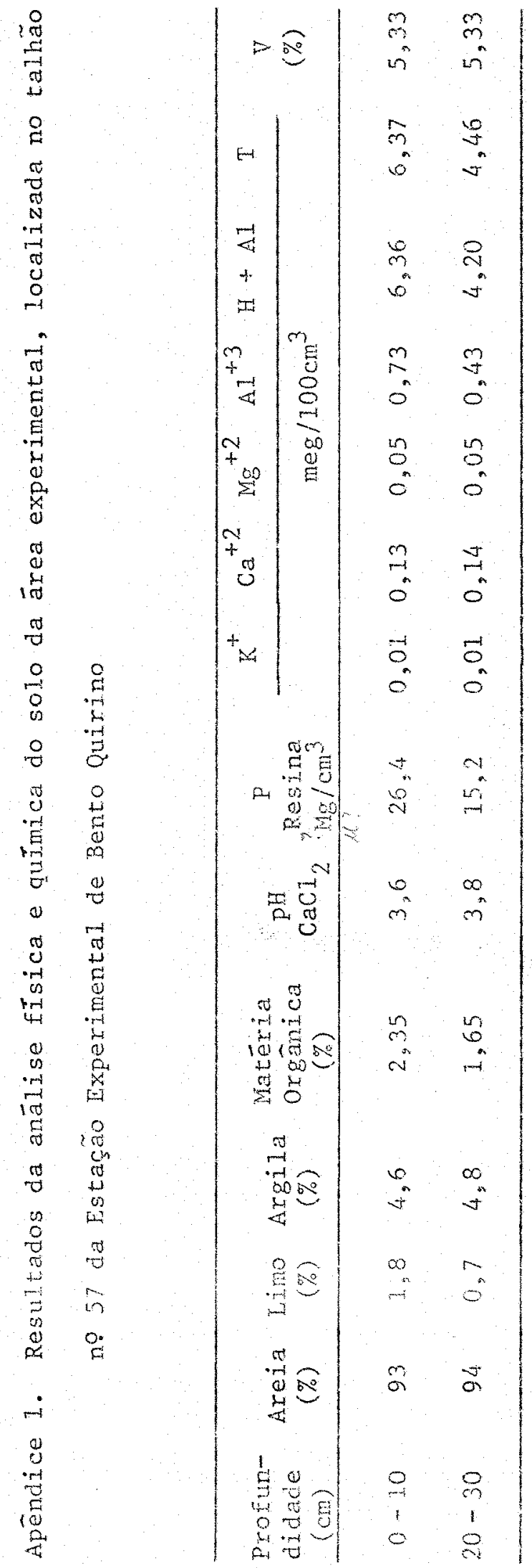




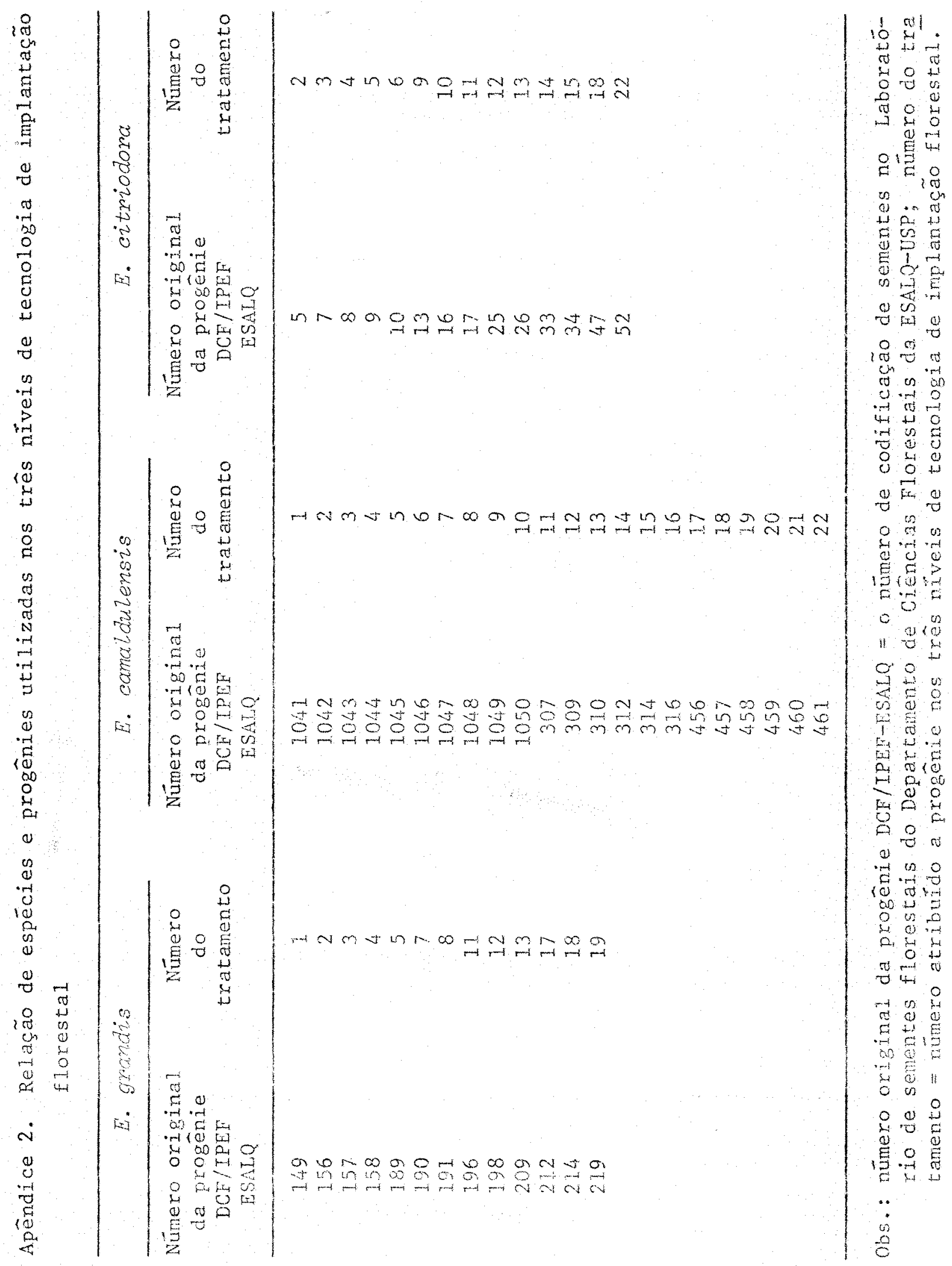


Apêndice 3. Médias de altura de plantas e porcentagen de falhas de prow gênies de $E$. grandis nos três nîveis de tecnologia (NT) de implantação florestal, aos 7 meses de idade

\begin{tabular}{|c|c|c|c|c|c|c|c|c|}
\hline \multirow{3}{*}{$\begin{array}{l}\text { Proge- } \\
\text { nies }\end{array}$} & \multicolumn{4}{|c|}{ Altura (m) } & \multicolumn{4}{|c|}{ Falhas (\%) } \\
\hline & \multicolumn{8}{|c|}{ Niveis de Tecnologia } \\
\hline & NTI & NTII & NTIII & Mëdia & NTI & NTII & NTIII & Media \\
\hline 1 & 0,73 & 1,68 & 1,28 & 1,23 & 27,26 & 5,39 & 14,76 & 15,80 \\
\hline 2 & 0,58 & 1,77 & 1,49 & 1,28 & 15,97 & 0,00 & 17,00 & 10,99 \\
\hline 3 & 0,70 & 1,66 & 1,67 & 1,34 & 32,78 & 5,39 & 25,53 & 21,23 \\
\hline 4 & 0,76 & 1,95 & 1,94 & 1,55 & 20,37 & 0,00 & 11,05 & 10,64 \\
\hline 5 & 0,74 & 1,58 & 1,78 & 1,37 & 32,78 & 0,00 & 27,47 & 19,75 \\
\hline 7 & 0,73 & 1,36 & 1,64 & 1,24 & $11,0.5$ & 0,00 & 5,39 & 5,48 \\
\hline 8 & 1,00 & 1,83 & 1,56 & 1,45 & 27,47 & 10,07 & 5,39 & 14,32 \\
\hline 11 & 0,88 & 1,86 & 1,62 & 1,45 & 21,07 & 5,39 & 22,14 & 16,20 \\
\hline 12 & 0,70 & 1,45 & 1,44 & 1,20 & 11,05 & 5,39 & 5,39 & 7,2 \\
\hline 13 & 0,72 & 1,53 & 2,02 & 1,42 & 20,87 & 10,07 & 5,39 & 12,11 \\
\hline 17 & 0,84 & 1,43 & 1,80 & 1,36 & 15,97 & 5,39 & 15,97 & 12,44 \\
\hline 18 & 0,75 & 1,50 & $1,91$. & 1,39 & 27,26 & 14,76 & 15,97 & 19,33 \\
\hline 19 & 0,91 & 2,09 & 1,68 & 1,56 & 17,00 & 5,39 & 21,07 & 14,49 \\
\hline Mēdia & 0,77 & 1,67 & 1,68 & 1,37 & 21,65 & 5,17 & 14,81 & 13,87 \\
\hline
\end{tabular}

NII: sem preparo do solo e sem adubação nineral;

NTII: preparo do solo sem adubação mineral;

NTIII: preparo do solo e adubação mineral. 
Apêndice 4. Médias de altura de plantas e porcentagen de falhas de progênies de E. grandis nos três niveis de tecnologia (NT) de implantação florestal, aos 12 meses de jidade

\begin{tabular}{|c|c|c|c|c|c|c|c|c|}
\hline \multirow{3}{*}{$\begin{array}{l}\text { Progê- } \\
\text { níes }\end{array}$} & \multicolumn{4}{|c|}{ Altura $(\mathrm{m})$} & \multicolumn{4}{|c|}{ Falhas (\%) } \\
\hline & \multicolumn{8}{|c|}{ Niveis de Tecnologia } \\
\hline & NTI & NTII & NTIII & Mëdia & $N N^{r} I$ & NiTI & NTII & Média \\
\hline 1 & 1,57 & 4,29 & 3,68 & 3,18 & 32,78 & 10,07 & 19,21 & 20,68 \\
\hline 2 & 1,21 & 4,95 & 4,47 & 3,54 & 21,07 & 0,00 & 22,14 & 14,40 \\
\hline 3 & 1,59 & 4,89 & 4,51 & 3,66 & 58,50 & 11,05 & 32,12 & 33,89 \\
\hline 4 & 1,73 & 5,31 & 5,32 & 4,12 & 20,87 & 0,00 & 11,05 & 10,64 \\
\hline 5 & 1,57 & 4,52 & 5,15 & 3,75 & 32,78 & 0,00 & 27,47 & 20,08 \\
\hline 7 & 1,43 & 4,06 & 4,77 & 3,42 & 17,00 & 0,00 & 15,97 & 10,99 \\
\hline 8 & 2,12 & 5,08 & 4,44 & 3,88 & 27,47 & 10,07 & 5,39 & 14,31 \\
\hline 11 & 1,70 & 4,89 & 4,58 & 3,72 & 21,07 & 5,39 & 22,14 & 16,20 \\
\hline 12 & 1,42 & 4,35 & 4,46 & 3,41 & 15,97 & 5,39 & 5,39 & 8,91 \\
\hline 13 & 1,97 & 4,36 & 5,66 & 4,00 & 26,16 & 20,87 & 5,39 & 17,47 \\
\hline 17 & $1,9 / 4$ & 3.71 & 5,09 & 3,58 & 21,07 & 5,39 & 15,97 & 14,14 \\
\hline 18 & 1,60 & 4,00 & 4,94 & 3,51 & 48,79 & 32,12 & 21,07 & 33,99 \\
\hline 19 & 1,69 & 5,36 & 4,66 & 3,90 & 17,00 & 5,39 & 21,07 & 14,48 \\
\hline Média & 1,66 & 4,60 & 4,75 & 3,67 & 27,73 & 8,13 & 17,26 & 17,70 \\
\hline
\end{tabular}

NTT: sem preparo do solo e sem adubação mineral;

NTII: preparo do solo sem adubação mineral;

NTIIT: preparo do solo e adubaçäo mineral. 


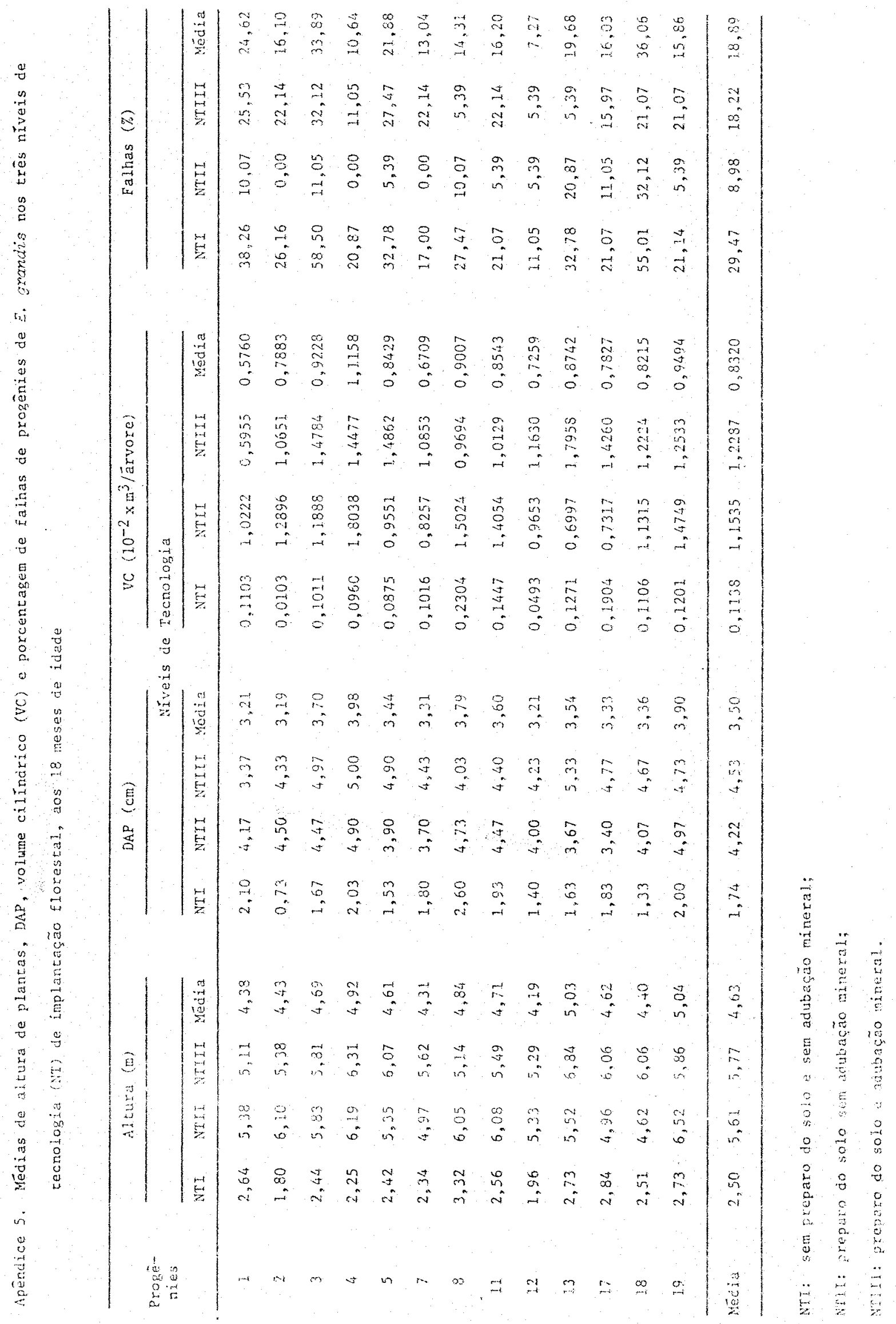




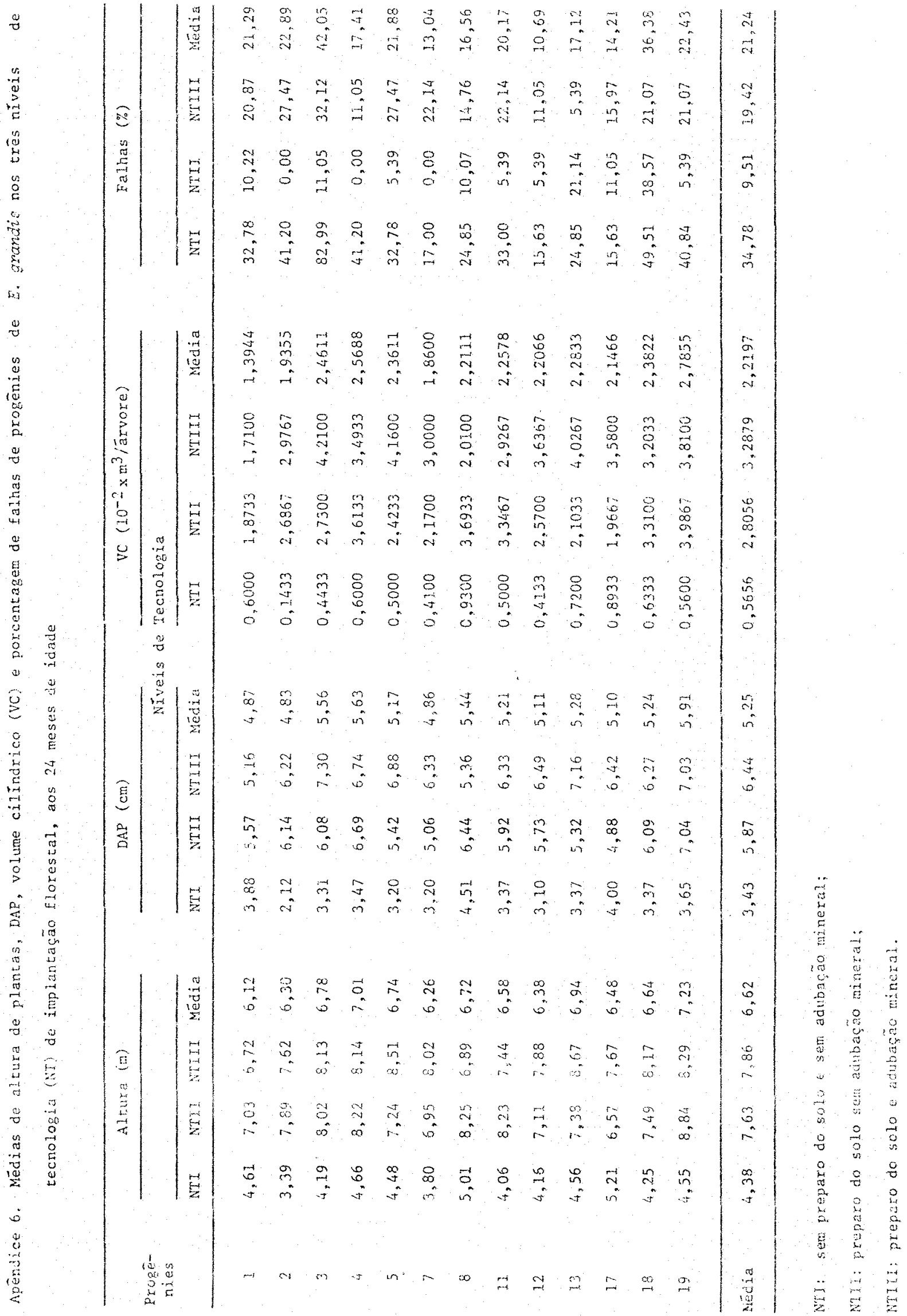


Apêndice 7. Medias de altura de plantas e porcentagen de falhas de progênies de $E$. camalduzensis nos três niveis de tecnologia (NT) de implantação florestal, aos 7 meses de idade

\begin{tabular}{|c|c|c|c|c|c|c|c|c|}
\hline \multirow{3}{*}{$\begin{array}{l}\text { Progê- } \\
\text { nies }\end{array}$} & \multicolumn{4}{|c|}{ A]tura (m) } & \multicolumn{4}{|c|}{ Falhas $(\%)$} \\
\hline & \multicolumn{8}{|c|}{ Niveis de Tecnologia } \\
\hline & NTI & NIII & NTIII & Média & NTI & $\operatorname{NTII}$ & NTIII & Média \\
\hline 1 & 1,17 & 1,89 & 2,12 & 1,73 & 0,00 & 0,00 & 0,00 & 0,00 \\
\hline 2 & 1,10 & 1,58 & 1,73 & 1,43 & 0,00 & 0,00 & 0,00 & 0,00 \\
\hline 3 & 1,15 & 1,49 & 1,56 & 1,40 & 5,39 & 0,00 & 5,39 & 3,59 \\
\hline 4 & 1,12 & 1,74 & 1,79 & 1,55 & 10,07 & 0,00 & 0,00 & 3,36 \\
\hline 5 & 1,14 & 1,78 & 1,70 & 1,54 & 0,00 & 0,00 & 0,00 & 0,00 \\
\hline 6 & 1,20 & 1,73 & 1,76 & 1,56 & 0,00 & 5,39 & 0,00 & 1,80 \\
\hline 7 & 1.11 & 1,99 & 1,84 & 1,65 & 5,39 & 0,00 & 0,00 & 1,80 \\
\hline 8 & 1,04 & 1,76 & 1,93 & 1,58 & 0,00 & 0,00 & 0,00 & 0,00 \\
\hline 9 & 1,25 & 1,78 & 1,85 & 1,63 & 0,00 & 5,39 & 0,00 & 1,80 \\
\hline 10 & 1,22 & 2,01 & 1,98 & 1,74 & 0,00 & 0,00 & 0,00 & 0,00 \\
\hline 11 & 1,14 & 1,90 & 2,15 & 1,73 & 0,00 & 0,00 & 0,00 & 0,00 \\
\hline 12 & 1,06 & 1,65 & 1,67 & 1,46 & 5,39 & 0,00 & 0,00 & 1.80 \\
\hline 13 & 1,15 & 2,00 & 1,79 & 1.65 & 10,07 & 0,00 & 0,00 & 3,36 \\
\hline 14 & 1,10 & 1,83 & 1,94 & $x, 62$ & 0,00 & 0,00 & 0,00 & 0,00 \\
\hline 15 & 1,21 & 1,94 & 1,78 & 1,64 & 5,39 & 0,00 & 0,00 & 1,80 \\
\hline 16 & 1,17 & 1,98 & 2,02 & 1,72 & 0,00 & 0,00 & 0,00 & 0,00 \\
\hline 17 & 1,17 & 1,86 & 2,17 & 1,73 & 5,39 & 0,00 & 0,00 & 1,80 \\
\hline 18 & 0,95 & 1,83 & 1,85 & 1,54 & 5,39 & 0,00 & 0,00 & 1,80 \\
\hline 19 & 1,04 & 1,78 & 2,07 & 1,63 & 0,00 & 0,00 & 5,39 & 1,80 \\
\hline 20 & 0,87 & 1,67 & 1,82 & 1,45 & 11,05 & 0,00 & 0,00 & 3,68 \\
\hline 21 & 1,06 & 1,75 & 1,83 & 1,55 & 5,39 & 0,00 & 0,00 & 1,80 \\
\hline 22 & 0,99 & 1,72 & 1,93 & 1,55 & 10,07 & 0,00 & 0,00 & 3,36 \\
\hline Média & 1,11 & 1,80 & 1,87 & 1,59 & 3,59 & 0,49 & 0,49 & 1,52 \\
\hline
\end{tabular}

NTT: sem preparo do solo e sem adubaça mineral:

NTII: preparo do solo sem adubação minezal;

NTIIT: preparo do solo e adubaçäo minexal. 
Apêndice 8. Médias de altura de plantas e porcentagem de falhas de prom gênies de $E_{\text {s }}$ camalduzensis nos três niveis de tecnologia (NT) de implantaçäo florestal, aos 12 meses de idade

\begin{tabular}{|c|c|c|c|c|c|c|c|c|}
\hline \multirow{3}{*}{$\begin{array}{l}\text { Progê- } \\
\text { nies }\end{array}$} & \multicolumn{4}{|c|}{ Altura (m) } & \multicolumn{4}{|c|}{ Falhas (\%) } \\
\hline & \multicolumn{8}{|c|}{ Niveis de Tecnologia } \\
\hline & NTI & NTTI & NTIII & Media & $\mathrm{NTI}$ & NTII & NTIII & Mëdia \\
\hline 1 & 2,00 & 3,73 & 4,29 & 3,34 & 0,00 & 0,00 & 0,00 & 0,00 \\
\hline 2 & 2,18 & 3,26 & 3,80 & 3,08 & 5,39 & 0.00 & 0,00 & 1,80 \\
\hline 3 & 1,93 & 3,13 & 3,44 & 2,83 & 5,39 & 0,00 & 5,39 & 3,59 \\
\hline 4 & 2,23 & 3,52 & 3,96 & 3,24 & 10,07 & 0,00 & 0,00 & 3,36 \\
\hline 5 & 1,91 & 3,68 & 3,78 & 3,12 & 0,00 & 0,00 & 0,00 & 0,00 \\
\hline 6 & 2,38 & 3,49 & 4,07 & 3,31 & 0,00 & 5,39 & 0,00 & 1,80 \\
\hline 7 & 2,11 & 4,24 & 4,05 & 3,47 & 11,05 & 0,00 & 0,00 & 3,68 \\
\hline 8 & 2,11 & 3,51 & 4,14 & 3,25 & 0,00 & 0,00 & 5,39 & 1,80 \\
\hline 9 & 2,37 & 3,41 & 4,15 & 3,31 & 0,00 & 5,39 & 0,00 & 1,80 \\
\hline 10 & 2,22 & 4,10 & 4,21 & 3,51 & 5,39 & 0,00 & 0,00 & 1,80 \\
\hline 11 & 2,05 & 4,20 & 4,68 & 3,64 & 0,00 & 0,00 & 0,00 & 0,00 \\
\hline 12 & 1,89 & 3,57 & 3,80 & 3,09 & 5,39 & 5,39 & 0,00 & 3,59 \\
\hline 13 & 2,24 & 3,76 & 3,89 & 3,30 & 10,07 & 5,39 & 0,00 & 5,15 \\
\hline 14 & 2,14 & 3,85 & 4,20 & 3,40 & 5,39 & 0,00 & 0,00 & 1,80 \\
\hline 15 & 1,96 & 4,17 & 3,69 & 3,27 & 5,39 & 0,00 & 0,00 & 1,80 \\
\hline 16 & 2,20 & 4,06 & 4,26 & 3,51 & 0,00 & 0,00 & 0,00 & 0,00 \\
\hline 17 & 2,17 & 3,97 & 4,46 & 3,53 & 10,07 & 0,00 & 0,00 & 3,36 \\
\hline 18 & 1,89 & 3,74 & 3,91 & 3,18 & 11,05 & 0,00 & 0,00 & 3,68 \\
\hline 19 & 1,95 & 3,60 & 4,28 & 3,28 & 0,00 & 0,00 & 5,39 & 1,80 \\
\hline 20 & 1,74 & 3,56 & 4,14 & 3,15 & 20,87 & 0,00 & 0,00 & 6,96 \\
\hline 21 & 2,13 & 3,63 & 4,07 & 3,28 & 5,39 & 0,00 & 0,00 & 1,80 \\
\hline 22 & 1,93 & 3,45 & 4,21 & 3,20 & 10,07 & 0,00 & 0,00 & 3,36 \\
\hline Média & 2,08 & 3,71 & 4,07 & 3,29 & 5,50 & 0,98 & 0,73 & 2,40 \\
\hline
\end{tabular}

NTI: sem preparo do solo e sem adubação mineral;

NTIT: preparo do solo sem adubaça mineral;

NTITT: preparo do solo e adubação mineral. 


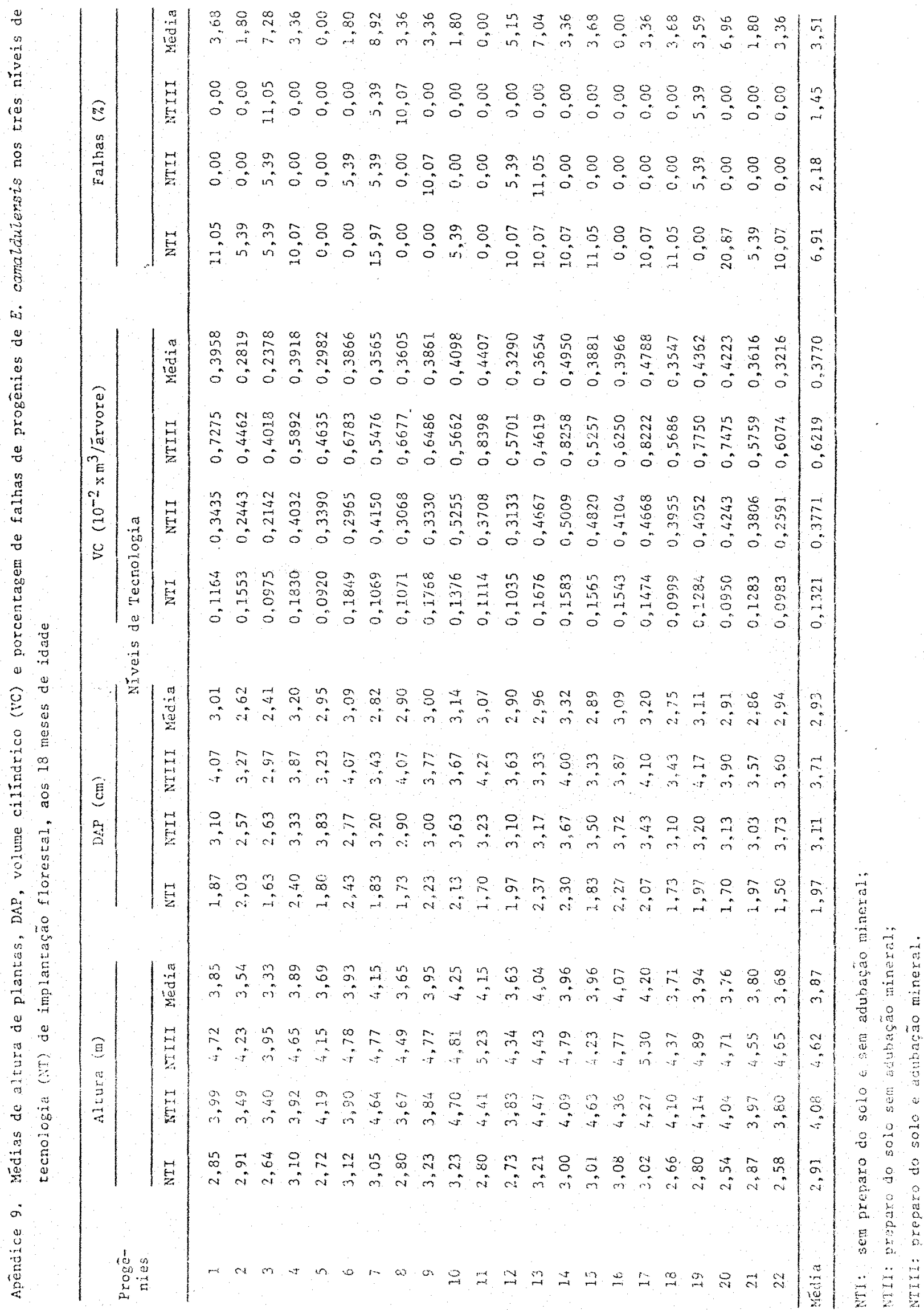




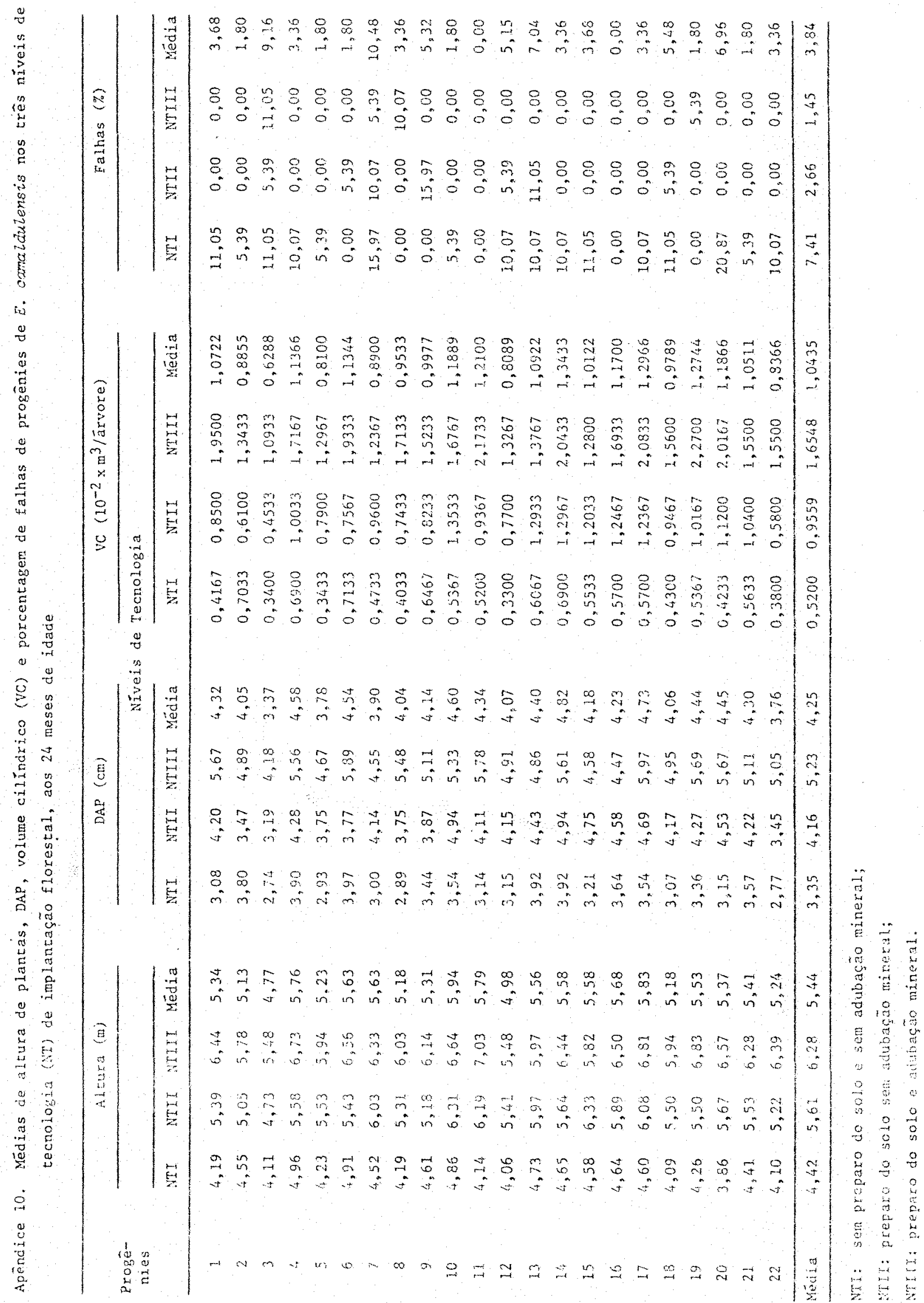


Apêndice 11. Médias de altura de plantas e porcentagen de falhas de progênies de 2 . citriodora nos três niveis de tecnologia de implantação florestal, aos 7 meses de idade

\begin{tabular}{|c|c|c|c|c|c|c|c|c|}
\hline \multirow{3}{*}{$\begin{array}{l}\text { Progê- } \\
\text { nies }\end{array}$} & \multicolumn{4}{|c|}{ Altura (m) } & \multicolumn{4}{|c|}{ Falhas (\%) } \\
\hline & \multicolumn{8}{|c|}{ Niveis de Tecnologia } \\
\hline & NTI & NTII & NTIII & Média & NTI & NTIT & NTIII & Media \\
\hline 2 & 0,98 & 1,23 & 1,08 & 1,10 & 19,21 & 0,00 & 5,39 & 8,20 \\
\hline 3 & 1,06 & 1,42 & 1,27 & 1,25 & 11,05 & 0,00 & 10,07 & 7,04 \\
\hline 4 & 0,97 & 1,23 & 1,39 & 1,20 & 0,00 & 0,00 & 11,05 & 3,68 \\
\hline 5 & 0,93 & 1,41 & 1,16 & 1,17 & 11,05 & 0,00 & 5,39 & 5,48 \\
\hline 6 & 1,17 & 1,54 & 1,08 & 1,26 & 0,00 & 0,00 & 0,00 & 0,00 \\
\hline 9 & 1,05 & 1,47 & 1,37 & 1,30 & 11,05 & 0,00 & 5,39 & 5,48 \\
\hline 10 & 1,15 & 1,50 & 1,30 & 1,32 & 0,00 & 0,00 & 15,97 & 5,32 \\
\hline 11 & 0,94 & 1,25 & 1,23 & 1,14 & 15,97 & 0,00 & 10,07 & 8,68 \\
\hline 12 & 0,82 & 1,39 & 1,30 & 1,17 & 15,97 & 5,39 & 0,00 & 7,12 \\
\hline 13 & 1,02 & 1,43 & 1,31 & 1,25 & 22,14 & 0,00 & 5,39 & 9,16 \\
\hline 14 & 1,05 & 1,36 & 1,30 & 1,24 & 5,39 & 0,00 & 0,00 & 1,80 \\
\hline 15 & 0,91 & 1,11 & 1,23 & 1,08 & 10,07 & 0,00 & 5,39 & 5,15 \\
\hline 18 & 0,99 & 1,24 & 1,13 & 1,12 & 15,97 & 0,00 & 5,39 & 7,12 \\
\hline 22 & 0,86 & 1,27 & 1,03 & 1,05 & 10,07 & 0,00 & 14,76 & 8,27 \\
\hline Média & 0,99 & 1,34 & 1,22 & 1,18 & 10,56 & 0,38 & 6,73 & 5,89 \\
\hline
\end{tabular}

NTI: sem preparo do solo e sen adubaçáo mineral;

NTII: preparo do solo sem adubaçäo mineral;

NTIII: preparo do solo e adubação mineral. 
Apêndice 12. Mëdias de altura de plantas e porcentagem de falhas de progênies de $E_{0}$ citriodora nos três niveis de tecnologia de implantação florestal, aos 12 meses de idade

\begin{tabular}{|c|c|c|c|c|c|c|c|c|}
\hline \multirow{3}{*}{$\begin{array}{l}\text { Progê- } \\
\text { nies }\end{array}$} & \multicolumn{4}{|c|}{ Altura (n) } & \multicolumn{4}{|c|}{ Fathas (\%) } \\
\hline & \multicolumn{8}{|c|}{ Niveis de Tecnologia } \\
\hline & NTI & NTII & NTIII & Média & NTI & NTII & NIIII & Media \\
\hline 2 & 2,13 & 2,77 & 2,71 & 2,54 & 19,21 & 0,00 & 5,39 & 8,20 \\
\hline 3 & 2,12 & 2,82 & 3,04 & 2,66 & 11,05 & 0,00 & 10,07 & 7,04 \\
\hline 4 & 2,05 & 2,64 & 3,24 & 2,58 & 5,39 & 0,00 & 11,05 & 5,48 \\
\hline 5 & 1,99 & 2,94 & 2,56 & 2,50 & 17,00 & 0,00 & 5,39 & 7,46 \\
\hline 6 & 2,41 & 3,09 & 2,61 & 2.70 & 0,00 & 0,00 & 0,00 & 0,00 \\
\hline 9 & 2,07 & 3,12 & 3,24 & 2,81 & 11,05 & 0,00 & 5,39 & 5,48 \\
\hline 10 & 2,42 & 3,23 & 3,17 & 2.94 & 0,00 & 0,00 & 21,07 & 7,02 \\
\hline 11 & 2,06 & 2,76 & 2,81 & 2,54 & 21,07 & 0,00 & 15,97 & 12,34 \\
\hline 12 & 1,51 & 2,88 & 3,05 & 2,48 & 15,97 & 5,39 & 0,00 & 7,12 \\
\hline 13 & 2,11 & 2,99 & 3,16 & 2,75 & 22,14 & 0,00 & 5,39 & 9,17 \\
\hline 14 & 2,16 & 2,99 & 2,94 & 2,70 & 5,39 & 0,00 & 0,00 & 1,80 \\
\hline 15 & 2,06 & 2,52 & 2,91 & 2,50 & 15,97 & 0,00 & 5,39 & 7,12 \\
\hline 18 & 2,24 & 2,84 & 2,51 & 2,53 & 20,87 & 0,00 & 5,39 & 8,75 \\
\hline 22 & 1,97 & 2,69 & 2,82 & 2,49 & 15,97 & 0,00 & 14,76 & 10,24 \\
\hline Média & 2,09 & 2,87 & 2,91 & 2,62 & 12,93 & 0,38 & 7,51 & 6,94 \\
\hline
\end{tabular}

NTT: sem preparo do solo e sem adubação mineral;

NTII: preparo do solo sem adubação mineral;

NTIII: preparo do solo e adubação nineral. 


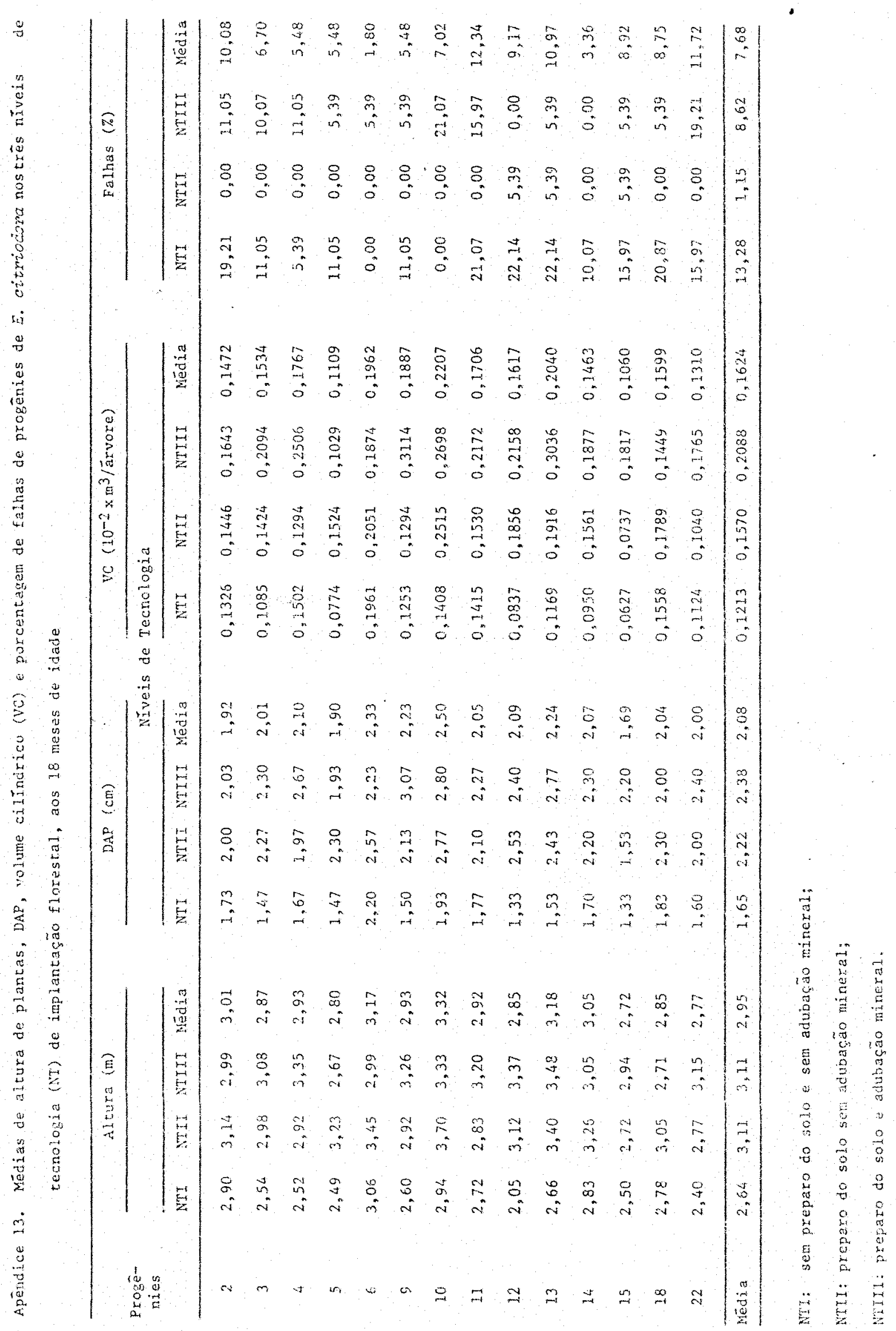




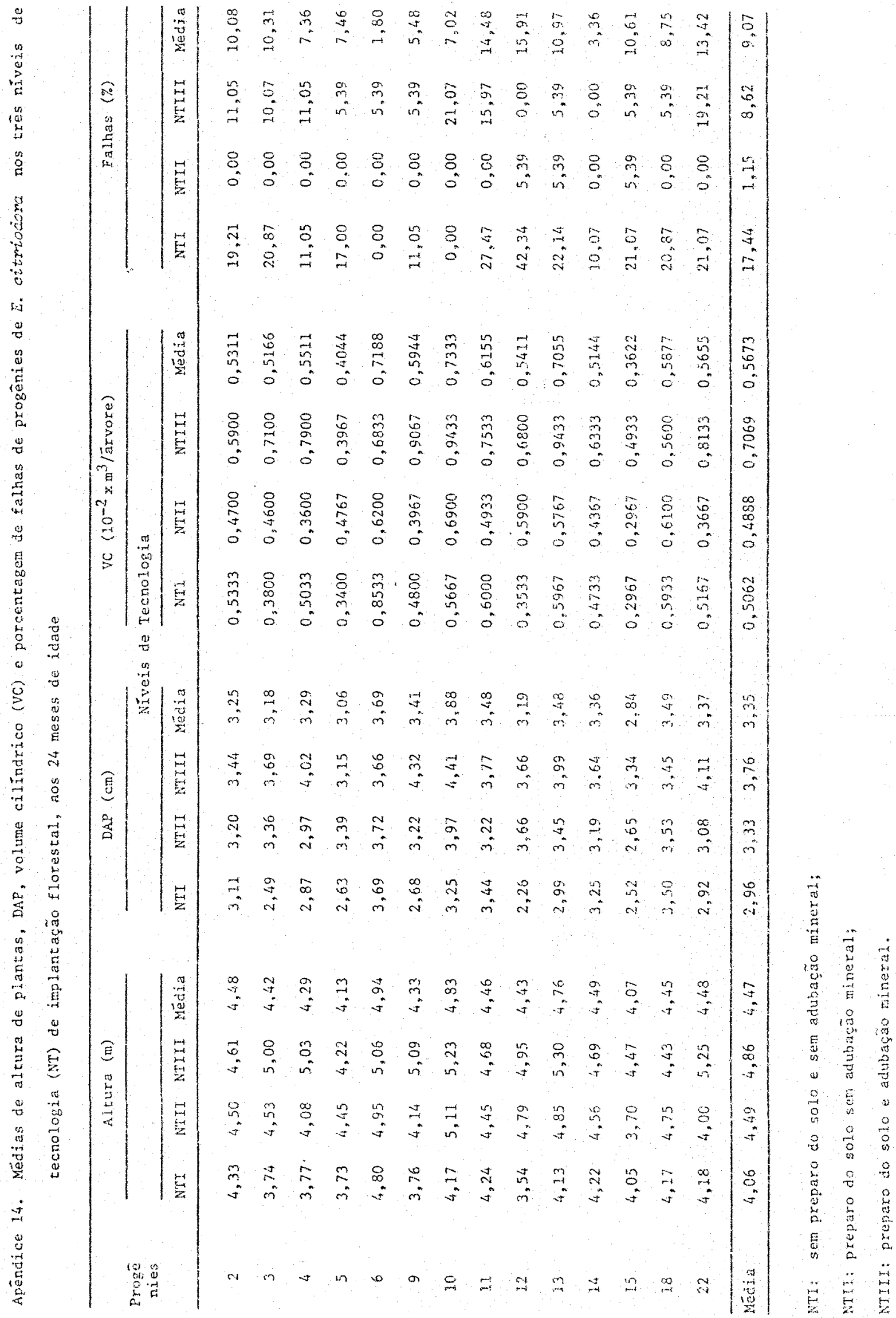

